Perceptions of self-service technology in the small, rural public library of New Zealand:

Self-issue @ Selwyn Library - a case study

by

\title{
Christine Grant
}

Submitted to the School of Information Management,

Victoria University of Wellington

in partial fulfilment of the requirements for the degree of Master of Information Studies 


\title{
VICTORIA UNIVERSITY OF WELLINGTON \\ School of Information Management
}

\author{
Master of Information Studies
}

IMPORTANT DISCLAIMER

with respect to a MIS Research Project (INFO 580)

\section{Perceptions of self-service technology in the small, rural public library of New Zealand: \\ Self-issue @ Selwyn Library - a case study}

\section{(hereafter referred to as 'The MIS Research Project')}

\author{
being undertaken by
}

\section{Christine Grant}

in partial fulfilment of the requirements of the degree of

Master of Information Studies,

School of Information Management, Victoria University of Wellington.

\section{Topic Commencement: 7 June 2013}

1. Victoria University of Wellington and its Council, its members, staff, employees, students and agents undertake no duty of care in contract, tort, or otherwise, to users (whether direct or indirect) of the MIS Research Project and make no warranties or representations of any kind whatsoever in relation to any of its contents.

2. The MIS Research Project is only made available on the basis that all users of it, whether direct or indirect, must take appropriate legal or other expert advice in relation to their own circumstances and must rely solely on their own judgement and such legal or other expert advice.

3. Under no circumstances will Victoria University of Wellington and its Council, its members, staff, employees, students or agents be liable in any way whatsoever, whether in contract, tort (including negligence), for breach of any statutory or regulatory duty (to the fullest extent permissible by law), or otherwise, to any user (whether direct or indirect) of the MIS Research Project for any loss or damage whatsoever arising directly or indirectly as a result of the use in any way of the MIS Research Project.

4. Each exclusion in the clauses of this disclaimer and each protection given by it is to be construed as a separate exclusion applying and surviving even if for any reason any of the exclusions or protections are held inapplicable in any circumstance. 


\section{Abstract}

Self-service technologies are prevalent in our society, and libraries are no exception. The general consensus emerging from the literature outlines the main benefits of self-service implementation: namely resource saving and enhanced customer services. However a more negative view emphasises potential challenges such as cost, staff and customer resistance, as well technical difficulties, not to mention the "dehumanizing of the library".

Much of this current research has tended to focus on the experiences of larger urban libraries with correspondingly large budgets and economies of scale. To address an apparent gap in the literature, this paper aimed to find out how well self-service is accepted in the small, rural public library of New Zealand by conducting a case study on one technology at one library: self-issue at Selwyn Library.

A threefold approach was taken: first the statistics were analysed to give a picture of what was happening in terms of self-issue usage; second, staff were interviewed to get their insights and viewpoints; third, customers, both users and non-users of self-issue, were surveyed for their perspectives.

The study concluded that self-issue did have a place within the small rural New Zealand public library context. Though some barriers existed there was a section of library customers who embraced it and staff were positive about the potential benefits self-issue could effect.

The context also meant that there was a degree of flexibility that may be unavailable to larger institutions. The dual characteristics of not having expensive security systems to integrate with coupled with close customer relationships, allowed smaller libraries to try their own self-issue systems without exorbitant expenditure.

The study's main limitation is that it is based on the experiences and data from one library which has only had self-issue for just over a year, and the particular situation that exists there may not be applicable to other libraries.

\section{Key words:}

Self-service technology, self-issue, rural public library, community library, library circulation and loans, automation 


\section{Acknowledgement:}

The author would like to thank the management and staff of Selwyn Library for their permission to use data collected from reports and interviews, participation in this research and for their help in the undertaking of this study. Research was being conducted during the lead up to and implementation of a library system upgrade; this was both a busy and stressful time for all, and the author is very appreciative of the efforts made. 


\section{Table of Contents}

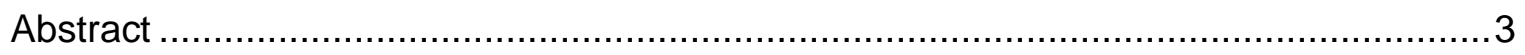

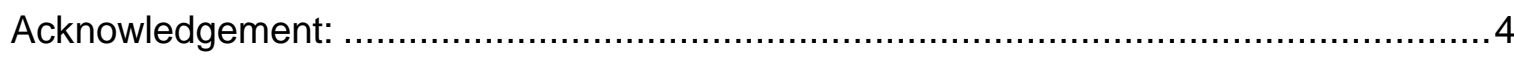

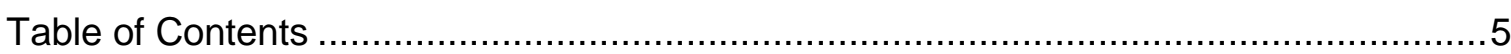

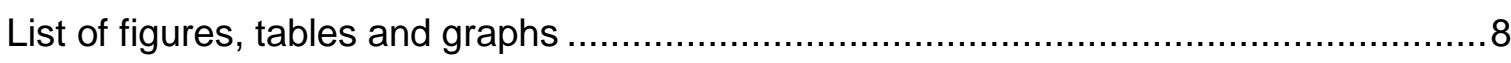

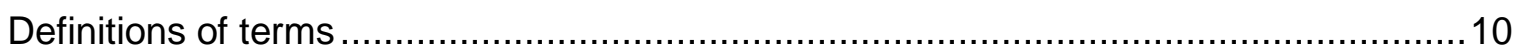

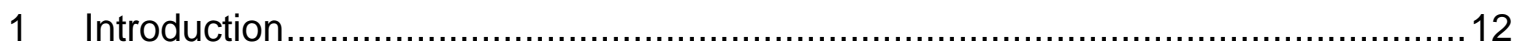

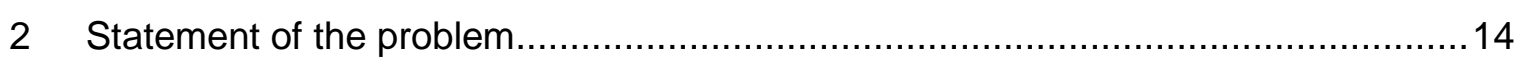

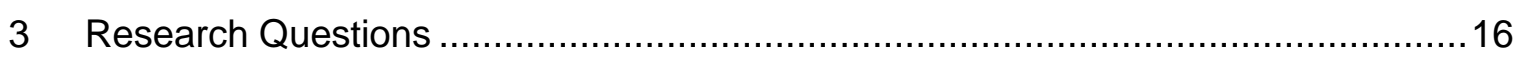

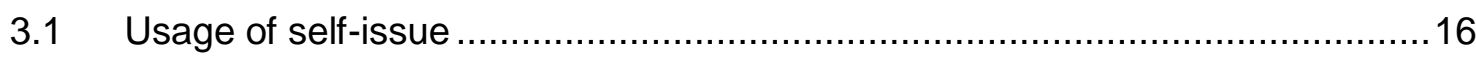

3.2 Customer perceptions of self-issue ..................................................... 16

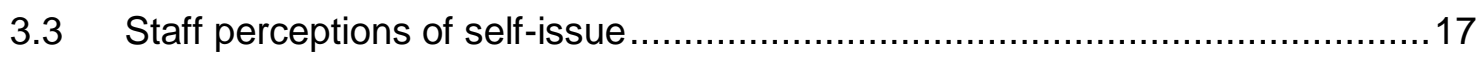

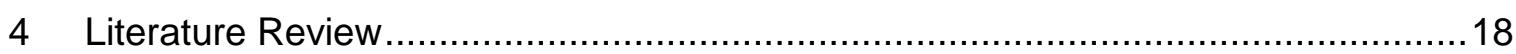

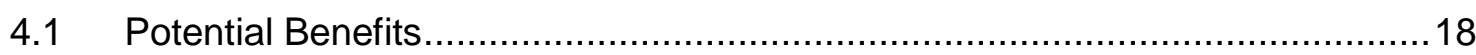

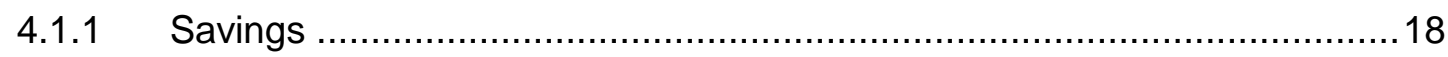

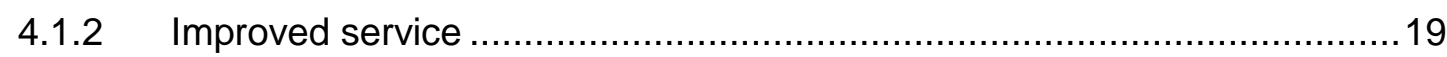

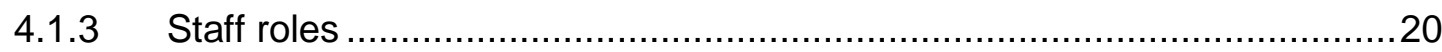

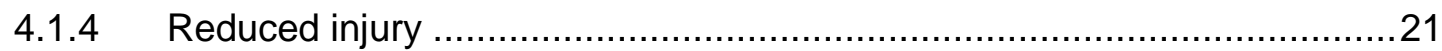

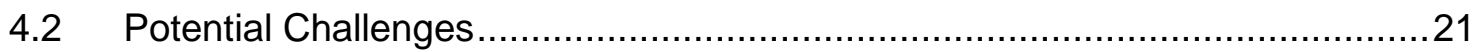

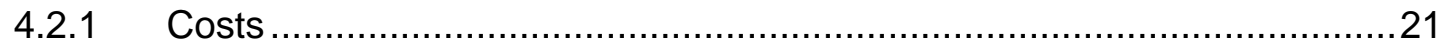

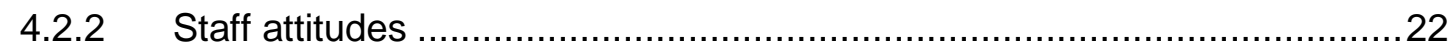

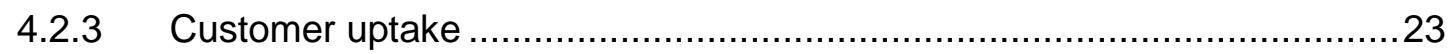

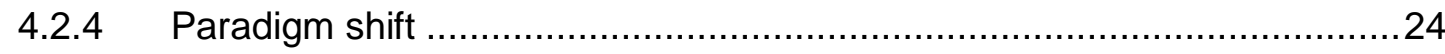

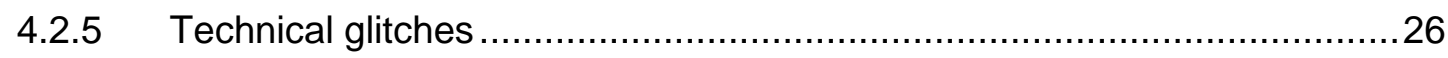

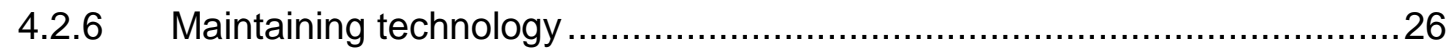

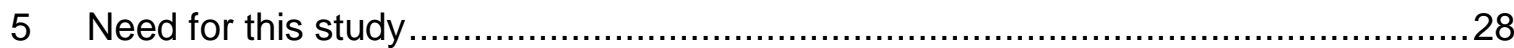

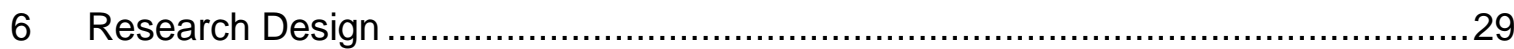

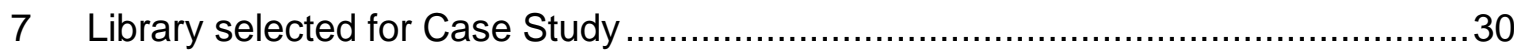

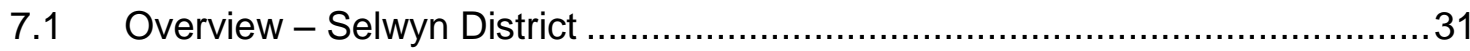

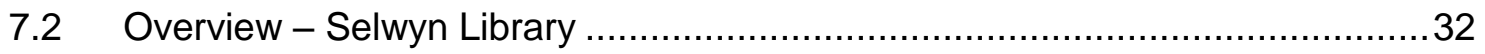

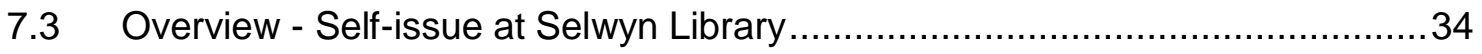

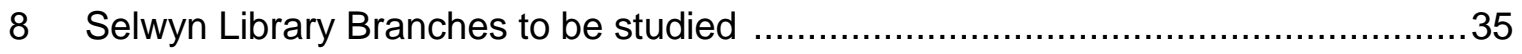




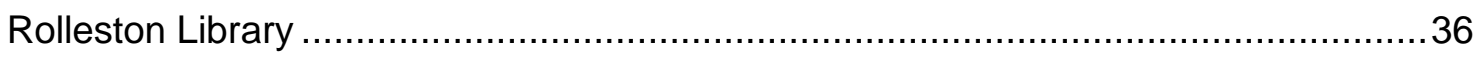

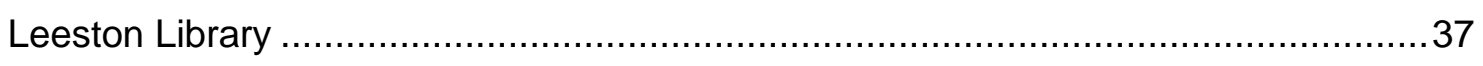

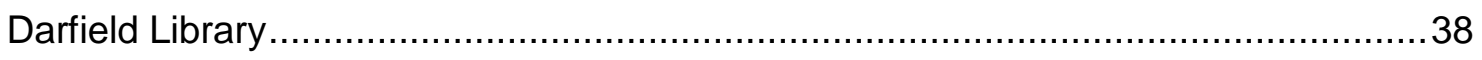

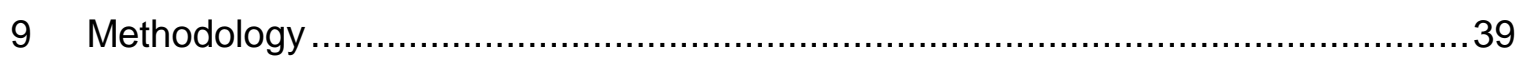

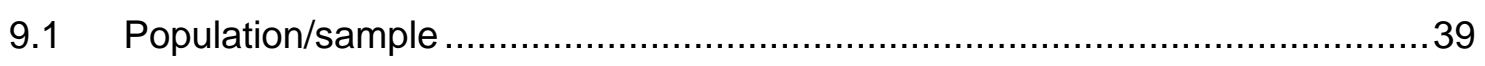

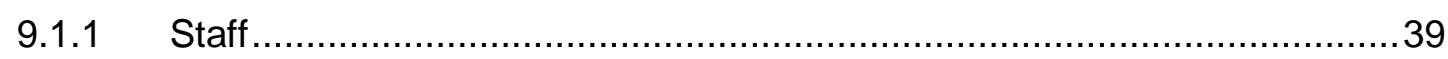

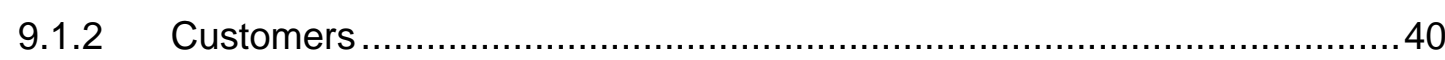

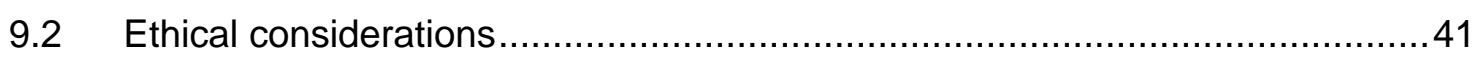

9.2.1 Circulation reports and issues statistics ........................................... 41

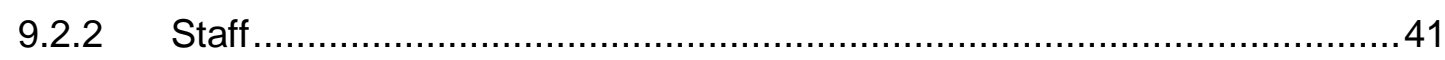

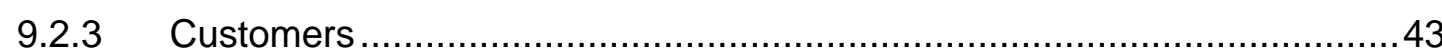

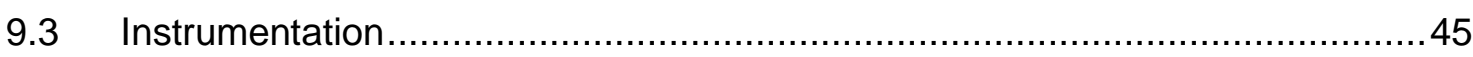

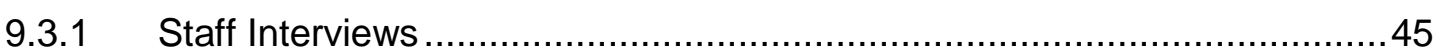

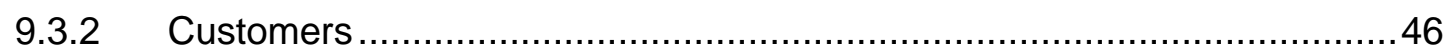

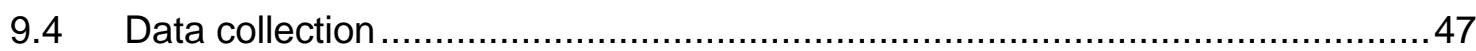

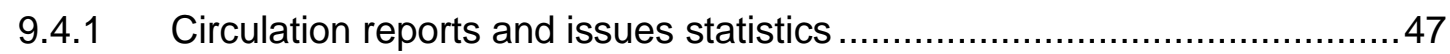

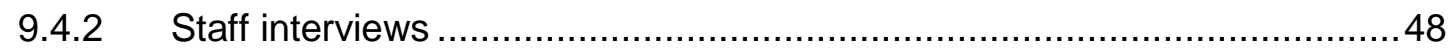

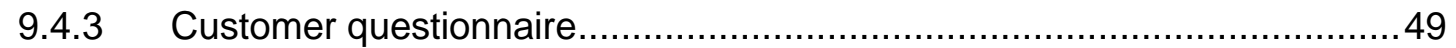

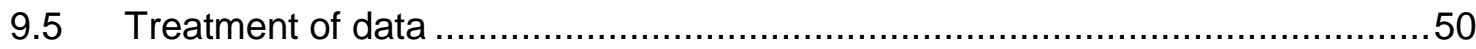

9.5.1 Circulation reports and issues statistics ..............................................50

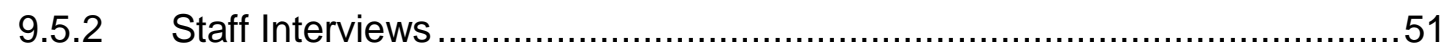

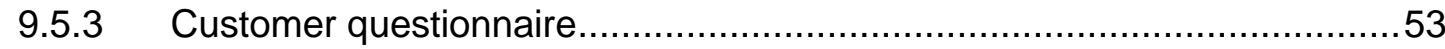

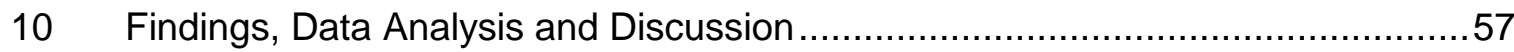

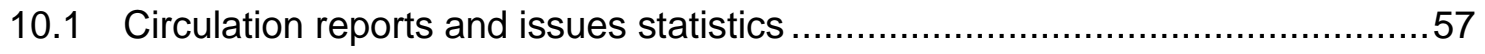

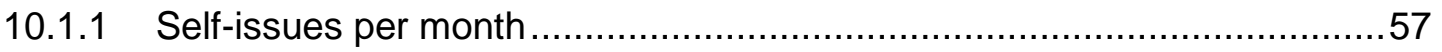

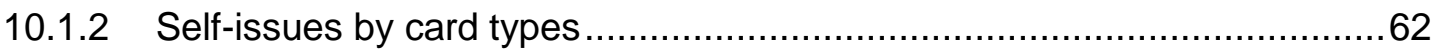

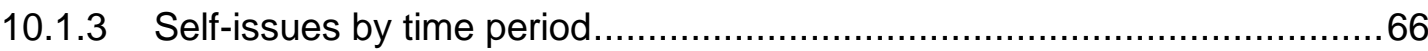

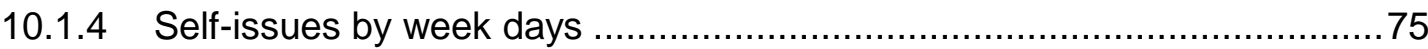

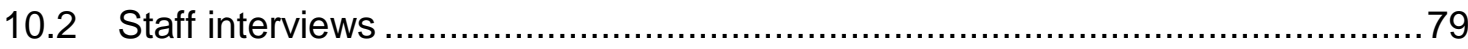

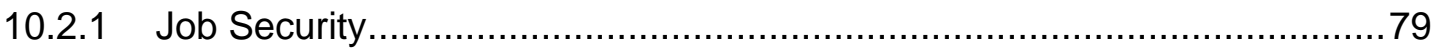

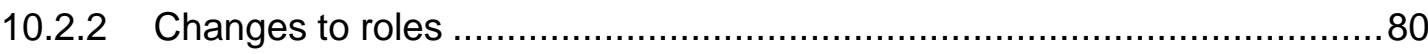

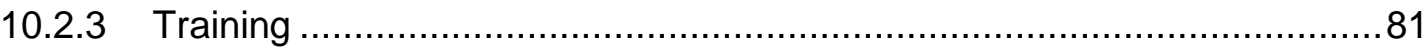

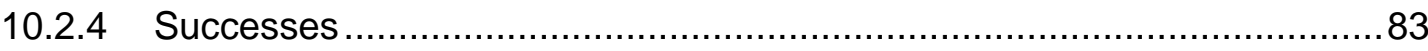

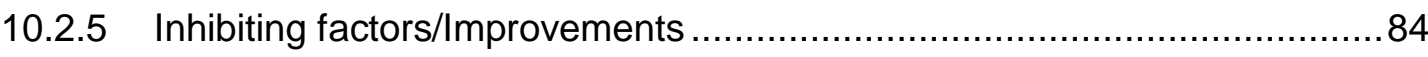

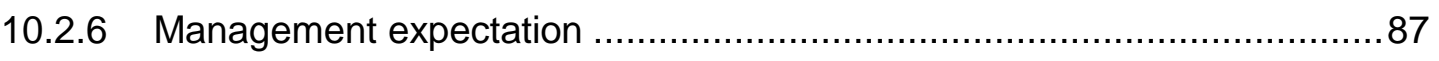




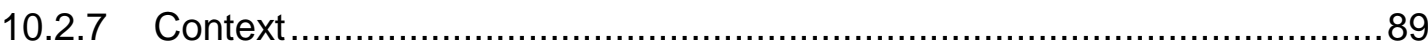

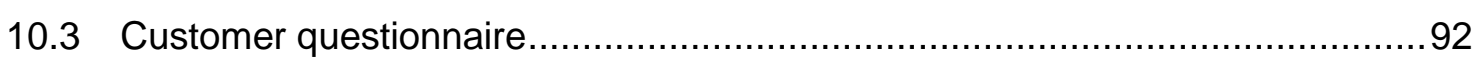

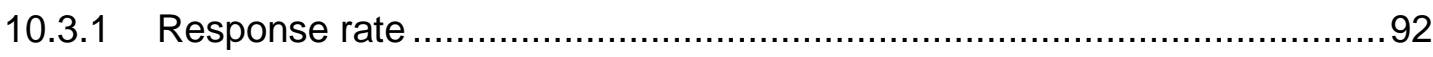

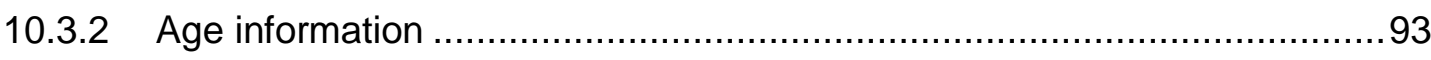

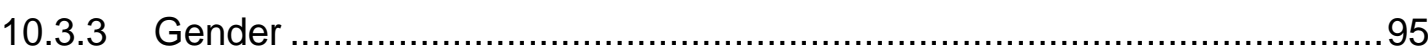

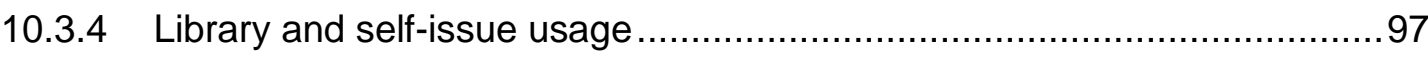

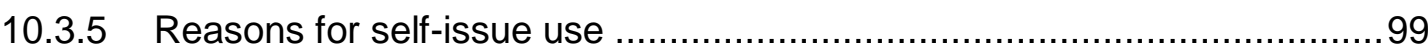

10.3.6 Evaluation of self-issue experience............................................... 101

10.3.7 Suggestions for improvement ...................................................... 103

10.3.8 Reasons for not using the self-issue facility .................................... 107

10.3.9 Extra issues with the questionnaire ............................................... 110

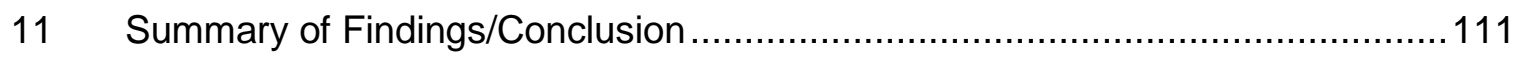

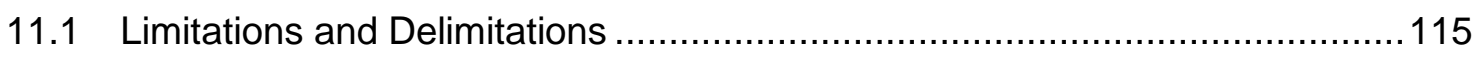

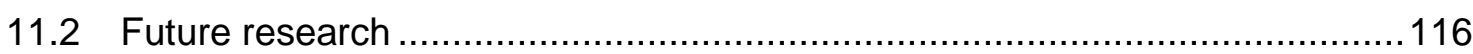

Appendix I - Participant Information Sheet - Staff................................................ 117

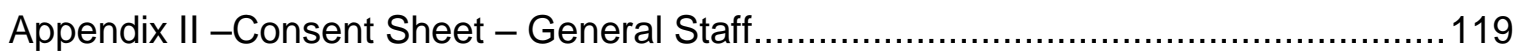

Appendix III - Consent Sheet - Libraries Manager ............................................... 120

Appendix IV - Participant Information Sheet - Customers...................................... 121

Appendix V - Interview Questions - Libraries Manager.............................................. 122

Appendix VI - Interview Questions - Branch managers ........................................... 124

Appendix VII - Interview Questions - Frontline staff ............................................... 126

Appendix VIII - Customer Survey Questionnaire ................................................... 127

Appendix IX - Self-issue by time period data.......................................................... 130

Appendix X - Customer Survey Questionnaire Data................................................ 131

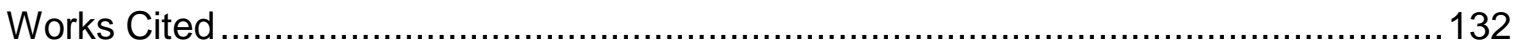




\section{List of figures, tables and graphs}

\section{Figures}

Figure 1: Maps showing boundaries of the Selwyn district (Selwyn District Council (a), n.d.) and its location in the South Island (Wikipedia, 2012).

Figure 2: Graph showing the Selwyn District population distribution by age and sex (Statistics New Zealand (d), 2006)....

Figure 3 Self-issue facility at Rolleston

Figure 4 Site map of Rolleston Library showing location of self-issue facility in relation to entrance and issues desk

Figure 5 Self-issue facility at Leeston. 37

Figure 6 Site map of Leeston Library showing location of self-issue facility in relation to entrance and issues desk

Figure 7 Self-issue facility at Darfield 38

Figure 8 Site map of Darfield Library showing location of self-issue facility in relation to entrance and issues desk

Figure 9 The "Secure Receptacles" for completed customer questionnaires, that where placed at each of the library branches with self-issue facilities.

Figure 10 Screen shot showing the node structure in QSR NVivo 9. Note the Interview questions and Interviewee nodes can be expanded, hence their 0 references and sources.

Figure 11 Extract from customer survey data spreadsheet showing multiple coding technique

Figure 12 Coding schedule for customer questionnaire

Figure 13 Showing the customer questionnaire Age Information and Gender sections proximity

\section{Tables}

Table 1 Showing the coding schedule used to code data from both the customer questionnaire and the staff interviews

Table 2 Monthly issues figures for Darfield, Leeston and Rolleston for period November 2011 to February 2013.

Table 3 Average self-issue usage from implementation to Feb. 60

Table 4 Membership types at Selwyn Library. 62

Table 5 Showing self-issue by card type for four specified weeks 
Table 6 Screen shot of raw data showing selection of self-issue records. 68

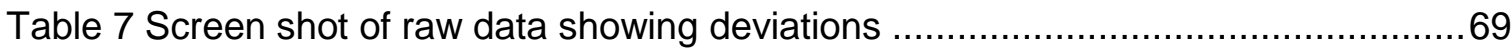

Table 8 Colour coding key for self-issue by time period data ......................................69

Table 9 Number of respondents in each age category .............................................. 93

Table 10 Responses to self-issue evaluation ............................................................ 101

Table 11 Evaluation of self-issue experience - positive and negative responses.........102

Table 12 Response numbers for experience and improvement ..................................104

\section{Charts}

Chart 1 Comparison of monthly self-issue statistics for the three self-issue enabled branches, from implementation until February 2013.

Chart 2 Average percentage of self-issue statistics for the three self-issue enabled branches and collated figure for Selwyn Library self-issue as a whole, from implementation until February 2013. 60

Chart 3 Averages of self-issue by card type for selected weeks .........................................6 66

Chart 4 Average distribution of self-issue by time periods. 71

Chart 5 Aggregated distribution of self-issue by time periods - comparison self-issue with totals

Chart 6 Average daily distribution of self-issue by time periods - Darfield and Leeston 76

Chart 7 Average daily distribution of self-issue by time periods - Rolleston .77

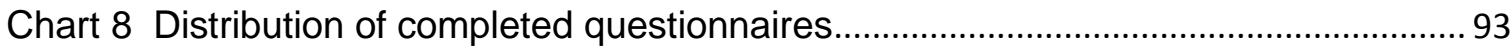

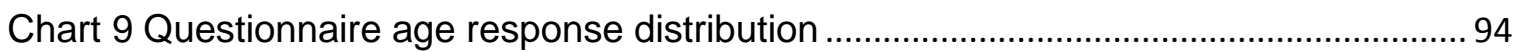

Chart 10 Questionnaire respondents gender distribution.................................................... 96

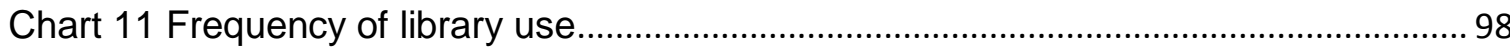

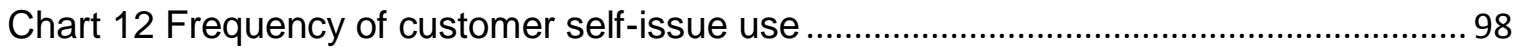

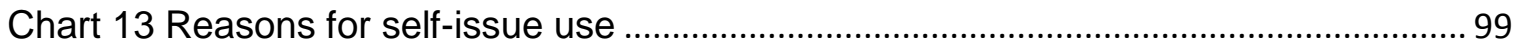

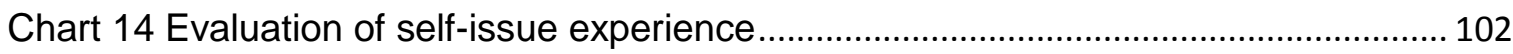

Chart 15 Reasons for not using self-issue distribution .................................................... 107 


\section{Definitions of terms}

\section{Likert scale}

A rating scale commonly used to assess people's attitudes to phenomenon of interest on a continuum, for example from "inadequate" to "excellent", or "strongly approve" to "strongly disapprove" (Leedy \& Ormrod, 2012, p. 192). The name is attributable to developer Rensis Likert.

\section{RFID}

Radio frequency identification technology that uses a microchip embedded tag to store information about an item, such as title, accession number and status (Association of Public Library Managers Inc, 2012, p. 39).

\section{Self-issue}

Refers to the process of customers checking out their own items (Holt, Larsen, \& van Vlimmeren, 2002, p. 7).

\section{Self-service technology}

Refers to services that customers can now perform for themselves using automated systems which previously required staff intervention (Holt, Larsen, \& van Vlimmeren, 2002, p. 7) 


\section{Small New Zealand public library}

Refers to population size served and items held, rather than physical size of the library or geographical area covered. In this study this refers to Selwyn Library which serves a population of 38,855 (Selwyn District Council (b), n.d.) and holds approximately 100,000 items in its collection (Selwyn Library (a), 2013). 


\section{Introduction}

We live in a world where a culture of self-service is ever increasing; buying our groceries at the supermarket, banking via automatic teller machines, check-in at the airport when travelling (Fitzsimmons, 2003, pp. 443-444), as well as the rapid growth of e-commerce. As businesses struggle to improve their productivity and efficiency while simultaneously reducing their costs against global competition, self-service trends predict further automation with increasingly sophisticated and interactive systems (selfserviceworld.com, 2013). It is no surprise then that self-service is prevalent in libraries; for many libraries static or decreasing staff allocations and limited budgets balanced with increased circulation statistics mean self-service is viewed as a godsend. Research, predominantly conducted overseas, demonstrates that it has been widely, albeit not always positively, embraced (Werne, 2007, p. 20).

The general consensus emerging from the literature outlines the main benefits to be gained from the implementation of self-service technologies into libraries: saving resources (be they time, labour or money), and enhanced services to customers. Furthermore, some authors pointed out additional positive outcomes of self-service such as increased job satisfaction and opportunities for professional career development, as well as reduced risk of occupational injury. The alternative perspective reveals that some staff and customers may see self-service in a more negative light: threatening rather than innovative, with the extreme view claiming it is responsible for "dehumanizing the library" (Berry, 2004, p. 10). A number of potential 
challenges were also noted including costs, staff and customer attitudes, potential technical difficulties, as well as the significance of keeping technologically up-to-date.

Notwithstanding the polarity of these view-points, the presence of self-service technology is an accepted norm in many libraries throughout New Zealand, though the options available vary greatly as sophisticated technologies, such as RFID or automated returns, can be out of reach of smaller libraries. This may be due to the large disparity in library sizes and funding in New Zealand public library services: for example Auckland Libraries serves just over a third of New Zealand's population with 55 branches over 4,900 square kilometres (Association of Public Library Managers Inc, 2012, p. 8), whereas Hurunui District covers an area of over 8500 square kilometres (Local Government Online (a), 2010) home to an estimated 10,476 residents (Statistics New Zealand (e), 2006) with five branch libraries and three volunteer run libraries (Hurunui District Council, 2013).

Much of the current research tends to pertain to larger, metropolitan libraries and, while many smaller libraries in New Zealand do offer a self-service option, there is little information available on their experiences and how the service is perceived by their staff and customers. This research investigates the usage and perceptions of self-service technology within the context of the small, New Zealand rural public library. 


\section{Statement of the problem}

In line with a general trend towards self-service technologies, many public libraries in New Zealand have implemented self-service facilities to enhance the efficiency and quality of their services, though the options available vary greatly as sophisticated technologies can be out of reach of smaller libraries.

Smaller public libraries in New Zealand often serve provincial or rural communities where both staff and customers may have different experiences and expectations than in larger urban/metropolitan libraries. For example the existence of close firstname relationships between the one or two library staff that man the library and regular customers (who may be the majority).

Little definitive information is available about how self-service facilities are received within these libraries and whether the potential benefits of such facilities outweigh the potential challenges of their implementation. This research focuses on one selfservice option, namely self-issue, and investigates it in the context of the small New Zealand public library. By looking in-depth at the experiences of one library this research will:

- Explore how self-issue fits into the small New Zealand public library context by:

a. Ascertaining how well self-issue facilities in small New Zealand public libraries are received by staff in the library 
b. Ascertaining how well self-issue facilities in small New Zealand public libraries are received by customers in the library

c. Ascertaining how well self-issue facilities in small New Zealand public libraries are used by customers in the library

d. Determining whether there are any particular factors possibly unique to small New Zealand public libraries that may influence/affect the use of the self-issue facility.

- Identify what, if any, barriers exist to the use of self-issue facilities in small New Zealand public libraries 


\section{$3 \quad$ Research Questions}

The research objective of this study is to investigate usage and perceptions of selfissue in the context of the small New Zealand public library by addressing the following questions:

\subsection{Usage of self-issue}

a. To what extent are the self-issue facilities being used?

b. Who is using the self-issue facilities?

c. What factors may inhibit use of the self-issue facilities?

d. What can be done to improve usage of the self-issue facilities?

\subsection{Customer perceptions of self-issue}

a. To what extent are different types of customers aware of the self-issue option?

b. What do customers think of self-issue in their library? 


\subsection{Staff perceptions of self-issue}

a. How do staff feel about the self-issue facilities in the library branch where they work?

b. To what extent has the implementation of self-issue facilities met library management expectations?

c. What factors have specifically contributed to the success of the self-issue facilities?

d. What factors have specifically detracted from the success of the self-issue facilities? 


\section{$4 \quad$ Literature Review}

A study of the literature surrounding the topic of self-service in public libraries reveals a number of major themes which may be roughly categorised into Potential Benefits and Potential Challenges.

\subsection{Potential Benefits}

\subsubsection{Savings}

It is no secret that public libraries walk a thin line when it comes to budgets, so unsurprisingly one of the attractions of self-service for their management and/or funding bodies is the potential savings to be made (Morris, Thornley, \& Snudden, 2001, p. 10). The seminal 2002 report, "Customer self service in the hybrid library," claims that self-service strategies can be a significant catalyst for reallocating resources from traditional processes to "higher-level cognitive tasks (Holt, Larsen, \& van Vlimmeren, p. 13). Brady \& al. concurred with this and reported that some libraries found the implementation of self-service technologies resulted in cost savings that allowed them to extend their opening hours (2009-2010, p. 16).

As public libraries are notoriously under resourced, it may be naïve to think that funding bodies will not be tempted by the idea of savings through the reduction of staff numbers. The existence of $100 \%$ self-service staff-less libraries such as that in Singapore (Brady, Kearsey, Monigatti, Sindel, \& Tsui-Po, 2009-2010, p. 32) and more recently in many local Danish communities (Johannsen, 2012), as well as 
vending machines, such as the Library-a-Go-Go service in the United States and Sweden (Kantor-Horning, 2009, pp. 16-17), give irrefutable, if somewhat extreme, proof that this strategy is deemed viable.

\subsubsection{Improved service}

In line with the evolution of customer expectations of quicker more efficient library experiences (Zeiher, 2006, p. 7), much of the literature to-date discusses the streamlining effects of self-service in libraries, focussing on the:

- reduction of queues

- speeding up of transactions

- freeing-up of staff from mundane tasks

Brady \& al. concur with these, pointing out that the flow on effects of efficiency are that libraries can offer more sophisticated reference services and community tailored value-added services (2009-2010, pp. 3, 12). Their definition of value-added services is virtually unlimited, potentially including anything "beyond the core services expected of a library" (2009-2010, p. 33).

Holt claimed that the meaning of value-added library services was being redefined by the introduction of self-service technologies (2002, p. 10), emphasising that making services more convenient and tailored for customer needs is in itself a way of providing value-added and targeted service (2002, pp. 14, 17). On the other hand Sheffer draws attention to the fact that self-service can allow greater personal interaction with customers (2008, p. 7). 


\subsubsection{Staff roles}

Not only customers profit from self-service driven efficiencies; staff also benefit through improved professional opportunities (Brady, Kearsey, Monigatti, Sindel, \& Tsui-Po, 2009-2010, p. 30). Zhong argued that after self-service has been implemented, staff interactions with customers become predominantly of the more advanced query types, and emphasised changes to the librarian role, with them performing in a guiding capacity as "navigators", rather than repetitive routine tasks (2007, pp. 103-4). The logical expectation of increased job satisfaction culminating through professional development of the librarian role is that happier, fulfilled staff will be more content in their careers.

In this way Sheffer credits self-service as having a positive impact on the recruitment and retention of library staff. $(2008$, p. 7$)$. An opposing view reported that some nonprofessional staff had complained of an increase in mundane work after the implementation of self-service, which backs up an earlier forecast that "promises are frequently made that technology will eliminate dull and repetitive tasks, only for them to be replaced by equally unexciting tasks" (Morris \& Dyer, (as cited in Morris, Thornley \& Snudden, (2001). Self-issue and return systems: experiences in the UK)., p. 16). However, it was acknowledged that these interviews were carried out early on in the process which may have skewed/affected the results. 


\subsubsection{Reduced injury}

Self-service has also been linked to the improvement of working conditions through controlling the incidence of occupational related injury by many researchers, including Holt et al., (2002, p. 54),Cunningham (2010, p. 21), and Morris et al (2001, p. 10). Such occupational related injuries mentioned here are often referred to as RSI, OOS, GPI or WRULD ${ }^{1}$ (Department for Work and Pensions, 2009) (Southern Cross Healthcare Group, n.d.). Some libraries reported this as one of their fundamental reasons for introducing self-service technologies (Brady, Kearsey, Monigatti, Sindel, \& Tsui-Po, 2009-2010, p. 18).

\subsection{Potential Challenges}

\subsubsection{Costs}

While self-service clearly has many potential benefits, there are also a number of possible challenges to be faced during its introduction; foremost for many libraries is cost. Although as previously discussed self-service can offer many cost saving benefits, it represents a significant investment. A correlation between self-service options and availability, and population size served was demonstrated by Dempsey, whose report on a Library Journal nationwide survey stated that the larger the population, the more self-service options were offered (2010., p. 24). This is perhaps unsurprising when considering the funding base for large libraries versus that for small libraries; in New Zealand a reported disparity in funding of 50\% per person

\footnotetext{
${ }^{1} \mathrm{RSI}$ - Repetitive Strain Injury, OOS - Occupational Overuse Syndrome GPI - Gradual Process Injury WRULD - Work Related Upper Limb Disorder
} 
exists between libraries serving large populations of more than 100,000 as opposed to those of less than 25,000 (Association of Public Library Managers Inc, 2012, p. 34).

However while the cost of self-service technology is potentially very large, perhaps it need not be prohibitively so: Dempsey argues it can be a matter of degree. For example smaller libraries may only adopt aspects of self-service such as user-driven photocopying or printing, whereas larger libraries may go further with self-issue and/or returns technologies. Furthermore, she points out that more modest "inhouse" solutions can be investigated such as self-issue stations consisting of a computer terminal, scanner and receipt printer (2010., p. 27).

\subsubsection{Staff attitudes}

The majority of studies view the attitudes of staff as a critical factor in the successful implementation of self-service, but staff may be reluctant to promote a seemingly job-threatening technology. Fear of job losses is inevitable and not always without justification (Morris, Thornley, \& Snudden, 2001, p. 16): Brady et al. reports that staffing levels were reduced after the implementation of self-service in one of the libraries studied and how the staff-less SengKang Library cited cost-cutting as driving their 100\% self-service implementation (2009-2010, p. 17). Back in 1997 Stafford highlighted the importance of open communication throughout the whole process, (pp. 47-48), and this is reiterated by more recent research: Brady et al. found a communication strategy essential element to ensure success during a time 
of change (2009-2010, p. 11), while Zeiher counselled that staff fears must be acknowledged and addressed to ensure staff are on board before introducing the new services to customers $(2006$, p. 8$)$. This was supported by Whitney \& Garrett who advocated extensive training because they found that staff who were not confident with the technology, were less likely to train customers to use it (2008, p. 10).

\subsubsection{Customer uptake}

As is consistent with human behaviour, customers often resist the change to selfservice technology (Dempsey, 2010., p. 26). Ensuring customer uptake of selfservice requires a mixture of training, encouragement, clear strategies and a firm hand. There are a number of reasons customer uptake may be slow. For example customers who:

- are unsure or afraid of new technology (Werne, 2007, p. 19)

- prefer face-to-face interaction (Dempsey, 2010., p. 26)

- worry about potential threat to staff jobs (Mackenzie \& van Vimmeren, 2004, p. 24).

While staff attitudes are consistently cited as the factor with the highest potential to influence customer uptake of self-service technology (Zeiher, 2006, p. 7; Holt, Larsen, \& van Vlimmeren, 2002, p. 59), research has also indicated other fundamental points:

- customers will tend towards what they know unless pushed to do otherwise 
- their first experience is pivotal

Zeiher argues that to ensure success, self-service should be practically compulsory because customers would only accept self-service if it was obviously advantageous for them and if they had little other choice $(2006, p .7)$. This view is supported by Holt and van Vlimmeren who emphasise the importance of the self-service option being perceived as "an improvement, not an imposition" (2002, pp. 58-59), and Morris et al. who noted that when other choice is restricted, users will voluntarily opt for selfservice (2001, p. 14).

Once the benefits such as convenience, less waiting in queues and speed are realised, the customer will likely be a self-service convert, however studies show that if the customer's first experience of self-service is less than satisfactory, they will be unlikely to adopt it for future use. Morris et al. deem a positive first use as vital (2001, p. 15) and Brady et al. agree, adding that reliability of service is important to build customer trust (2009-2010, p. 9). Above all, self-service should be easy to use, conveniently and clearly located, and well supported by staff (Mackenzie \& van Vimmeren, 2004, pp. 10-12).

\subsubsection{Paradigm shift}

In addition to fostering a positive reception from both staff and customers, successful self-service implementation needs to be well planned, clearly defined and understood as encompassing a paradigm shift. The articulation of clear objectives and outcomes at the outset are recommended (Brady, Kearsey, Monigatti, Sindel, \& 
Tsui-Po, 2009-2010, p. 19), particularly a numerical target (Mackenzie \& van Vimmeren, 2004, p. 9) which is important to measure/monitor progress/success (Morris, Thornley, \& Snudden, 2001, p. 11). Zeiher outlines the importance of promoting the new technologies and ensuring library policies are flexible enough to accommodate them without causing undue problems (2006, p. 8).

Moreover, full commitment is needed to ensure success; Zeiher agrees with Dempsey's notion of self-service options needing to be a "commanding presence" in the library (Dempsey, 2010., p. 26), reporting that in their research staff found that one self-service unit did not work, they needed to be part of an overall philosophy of change within the library (Zeiher, 2006, p. 7). This represents a shift away from traditionally held library values towards embracing a different dynamic within the library, one where customers are empowered to take charge of their own library experience. Brady et al. termed this as a move away from "serving the customer" to "good customer service" (2009-2010, p. 23), citing one library where staff had to be re-educated to not intervene unless the customer was having obvious difficulties (2009-2010, p. 14). This theme is echoed by the distinction between librarians "helping readers" and librarians "helping readers to help themselves," elucidated in Zhong's study of self-service in Chinese public libraries (2007, p. 105). This paradigm shift is illustrated by the transformation of circulation desk staff into "Information Concierges" (Dempsey, 2010., p. 26) or "roving librarians" (Brady, Kearsey, Monigatti, Sindel, \& Tsui-Po, 2009-2010, p. 13). 


\subsubsection{Technical glitches}

As always with the introduction of new technology there are some technical hurdles to be overcome. Many studies reported issues with compatibility and migration (Morris, Thornley, \& Snudden, 2001, p. 12) (Whitney \& Garrett, 2008, p. 47), as well as more fundamental problems such as dealing with payments, fines and secure material like DVD's. Dempsey pointed out that such difficulties were not only frustrating for library staff and customers; they impacted negatively on the library's image (2010., p. 26). A possible solution was put forward by Brady et al. who suggested a phased approach when implementing new technologies to ensure any technical anomalies are detected and resolved as you go (2009-2010, p. 19).

\subsubsection{Maintaining technology}

Self-service is not a new concept in libraries, it is widespread and will become even more so in the future. Therefore it is imperative that libraries keep up with technology to maintain their competitiveness (Morris, Thornley, \& Snudden, 2001, p. 10) or they risk being viewed as inflexible, uncool or, even worse, irrelevant. Responding to the changing needs of the community is an important way for libraries to remain relevant (Association of Public Library Managers Inc, 2012, p. 36) and self-service can contribute to this by freeing up resources to provide value-added programmes, as well as facilitating access through extended hours and services (Brady, Kearsey, Monigatti, Sindel, \& Tsui-Po, 2009-2010, p. 13). Childs emphasises the myriad of attractive options for customers, making it even more important for libraries to embrace technological change to remain competitive in an increasingly resource-rich environment (2006, p. 150). In addition to the danger of being labelled Luddites, 
Dempsey rightly bemoans the missed opportunities for libraries that fail to maximise the potential benefits of self-service technologies (2010., p. 28). 


\section{$5 \quad$ Need for this study}

In New Zealand there are many libraries that serve small populations and so have limited resources with which to work. In areas where the population is 25,000 or less, the Council spends 50 percent less per head of population on library services than those serving 100,000 or more, meaning there is a marked disparity in the funds available to provide services to rural and provincial areas of New Zealand (Association of Public Library Managers Inc, 2012, p. 34).

While research demonstrates that self-service technologies have both benefits and challenges, much of the current literature is based on studies of overseas libraries that serve substantial populations, where economies of scale aid the justification to install sophisticated, and expensive, self-service technologies. What about the experiences of the smaller New Zealand public library that may only have a handful of staff and operates within remote or rural communities; does self-service have a place there?

To address this apparent gap in the research, this paper examines self-issue in small rural New Zealand public libraries by concentrating on the experiences of one library. This research will evaluate practices and policies surrounding the library's current self-issue facilities and be of particular value for any future implementations. 


\section{Research Design}

A case study approach was taken in this research. This comprised a qualitative methodology where data from in-depth interviews of library staff were augmented by quantitative analysis of issues statistics and a voluntary survey recording customer perceptions of self-issue.

The case study approach was deemed appropriate because an intensive analysis of a process, self-issue, was made for a single entity (Creswell, 2003, p. 17). Moreover the case study approach allowed for a mixed methodology where both quantitative and qualitative data were gathered in order to effectively address the research questions. This allowed the researcher to collect the widest range of data using the largest number of techniques possible, providing an informed and well balanced response to research problems that had both a quantitative and qualitative dimension (Leedy \& Ormrod, 2012, p. 258).

- Interviews were conducted for all levels of staff to ensure different perspectives were represented in the findings; for example strategic versus frontline.

- The voluntary self-completion questionnaire was selected as the most efficient way to conduct a study of library customers across the three branches offering a self-issue facility. 


\section{$7 \quad$ Library selected for Case Study}

Selwyn Library was selected for study because as a small rural public library in New Zealand it met the criteria for the research. Service is delivered via four community library/service centres and a mobile library bus. Self-issue is relatively new at Selwyn Library; three of the branches currently offer a facility and have done so for just over a year; these three branches will comprise the study subject. The other branch will be relocating to a larger building which is currently under construction, and plans to offer self-issue then; this library will not be studied. To date use of self-issue has been greatly varied, but consistently on the low side (G Walker, personal communication, 18 January 2013).

Following are overviews of:

- Selwyn District

- Selwyn Library

- Self-issue at Selwyn Library 


\subsection{Overview - Selwyn District}

The Selwyn District covers an area of 6492 square kilometres (Local Government Online (b), 2010). The landscape is diverse; made up of the plains where most people live and the sparsely populated high country. The area is served by twenty-five schools and one university (www.school.nz, 20092013).

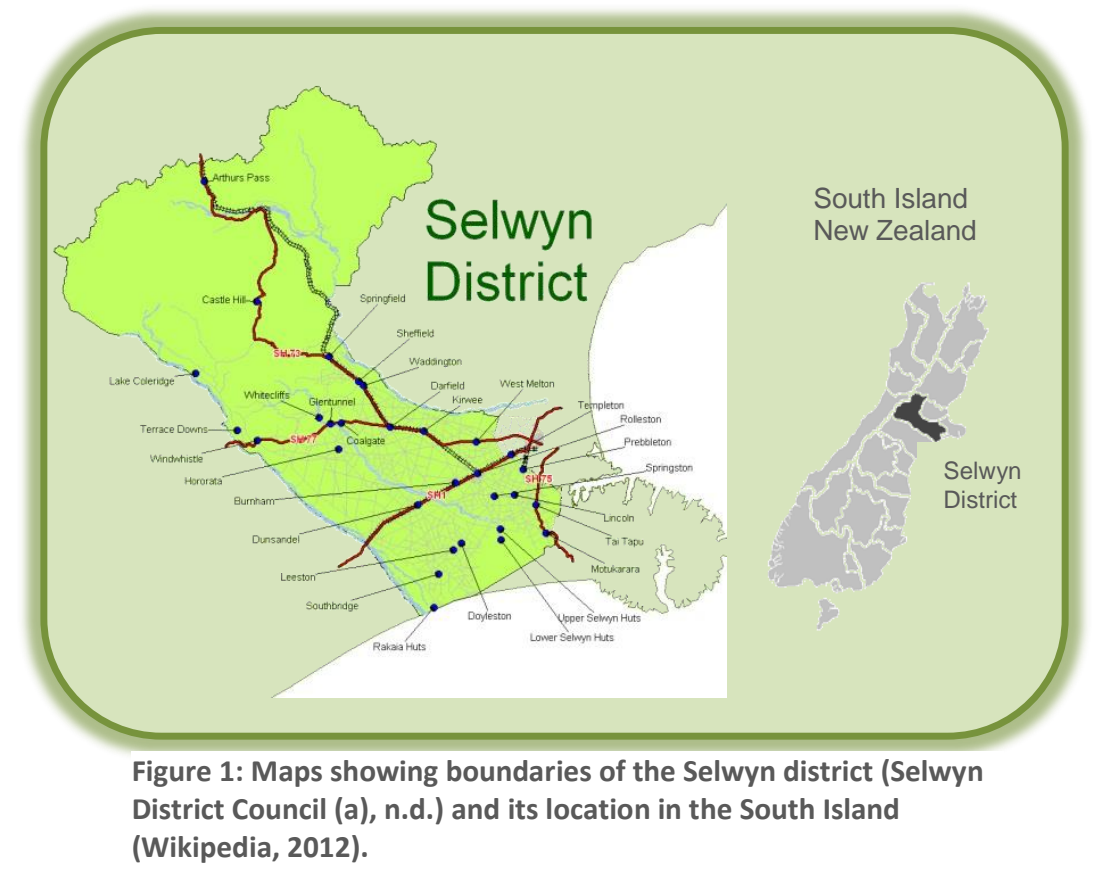

While some of the more recent rapid urbanisation of the district's townships is

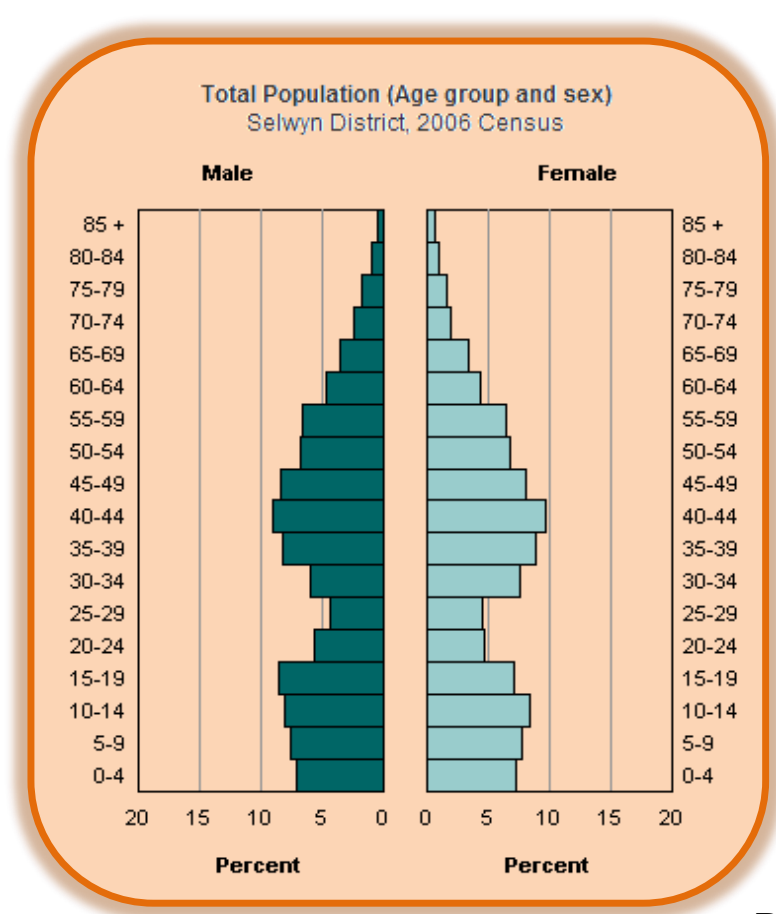

Figure 2: Graph showing the Selwyn District population distribution by age and sex (Statistics New Zealand (d), 2006) undoubtedly due to the $2010 / 11$ Canterbury earthquakes, the Selwyn District has been one of the fastest growing areas in New Zealand for many years; the last Census figures from 2006 put the population at 33,669 (Statistics New Zealand (a), 2006), but a more recent estimate puts the district's populations as closer to 42,000 (Statistics New Zealand (b), 2011).

Population demographics are a fairly standard 
distribution (see Figure 2), with a slightly higher than average number of people aged under fifteen years; 23 percent in Selwyn compared to 21.5 percent for the rest of New Zealand, and slightly lower than average number of senior citizens; nine percent in Selwyn compared to 12.3 percent in the rest of New Zealand.

Note: Data from the recent New Zealand Census carried out on 5 March 2013, will not be released until December 2013 (Statistics New Zealand (f), 2013) and so was unable to inform this research.

\subsection{Overview - Selwyn Library}

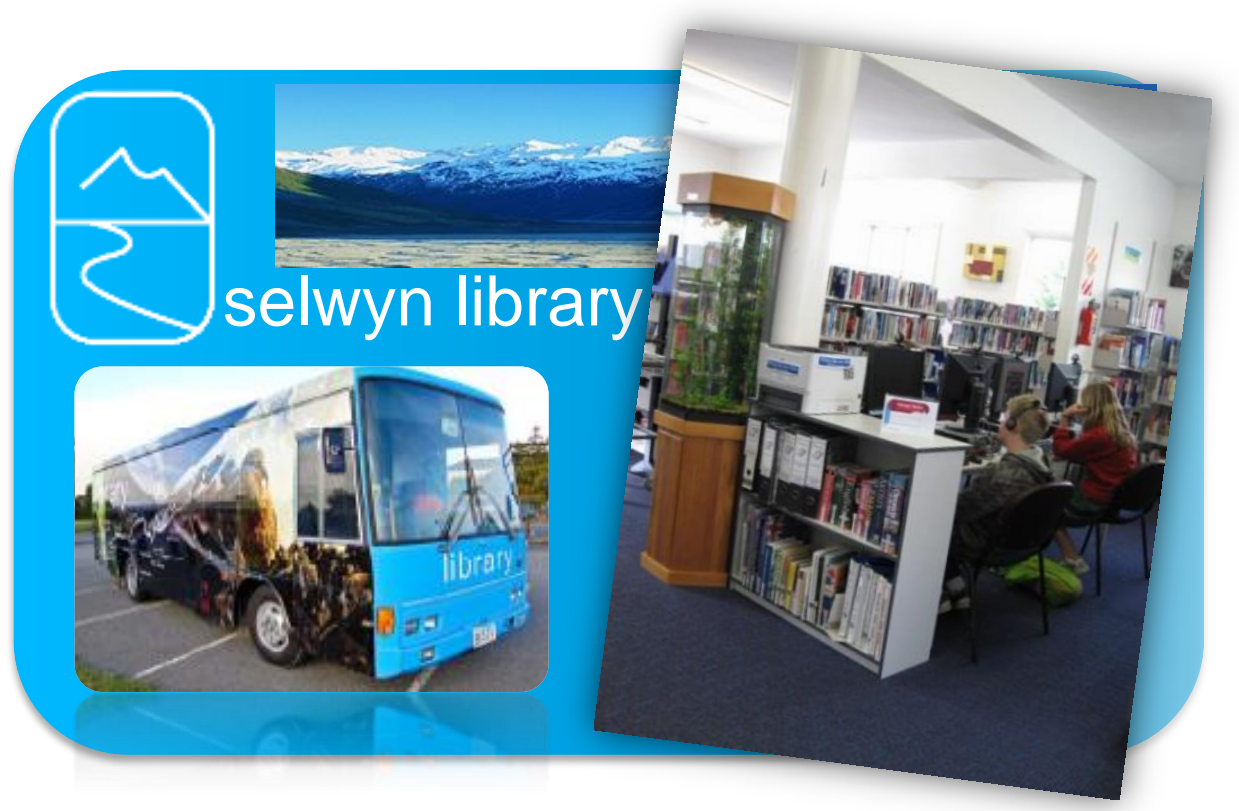

Originally begun and run independently for many years by volunteers, library services in Selwyn were formalised under a paid librarian in the 1990's. Currently the Selwyn District is serviced by four staffed branch libraries, a mobile library bus and the online service available via the Selwyn library website. Total membership is 
currently at around 21,000 (G Walker, personal communication, 18 January 2013), which represents around 54 percent of the Selwyn population.

The library's collections comprise around 100,000 physical items, of which approximately one quarter is on loan at any given time. Collections currently include books, music CD's, audio books, newspapers and community publications, DVD's, heritage items, reference materials, and puzzles. E-books have recently been added to the collection (April 2013).

The libraries employ a total of 25 people; a mixture of full-time and part-time roles amounting to 16 Full Time Equivalents. Due to space constriction two branches have recently moved to larger new or refurbished buildings, another new facility is currently being built and the other library will need expansion in the very near future (G Walker, personal communication, 18 January 2013).

Selwyn Library operates on a budget of just over two million dollars per annum; of which around 25 percent is earmarked for servicing building capital costs. Funding is sourced predominantly from residents' rates payments, though the Libraries are required by the Selwyn District Council to generate ten percent of their running costs through library charges. (G Walker, personal communication, 18 January 2013). 


\subsection{Overview - Self-issue at Selwyn Library}

The self-issue facilities currently available at three of the library branches use open source software developed by an American librarian, Eric Melton. He wrote a relatively simple programme that was able to interact with library systems that were unencumbered by security systems, and put it online for others to use. Selwyn Library was able to customise the software enough to work with their system and provide a workable user interface. Equipment requirements for the setup were minimal and utilised some existing hardware: old computers, screens and mice were coupled together with some new receipt printers. In the words of the libraries manager, "it's been a fantastic solution for something we couldn't otherwise afford" (G Walker, personal communication, 28 March 2013). 


\section{$8 \quad$ Selwyn Library Branches to be studied}

- Township population statistics have been obtained from the Selwyn District Council website as being the latest official data, however it is acknowledged that these figures may have increased (Selwyn Growth Projections, n.d.)

- Photographs have been obtained from the Selwyn Library website (Selwyn Library (b), n.d.) or taken within the libraries, and are used with permission.

- Statistics, averaged over the last four years, have been obtained Selwyn Library internal reports or from the Libraries Manager and are used with permission. 


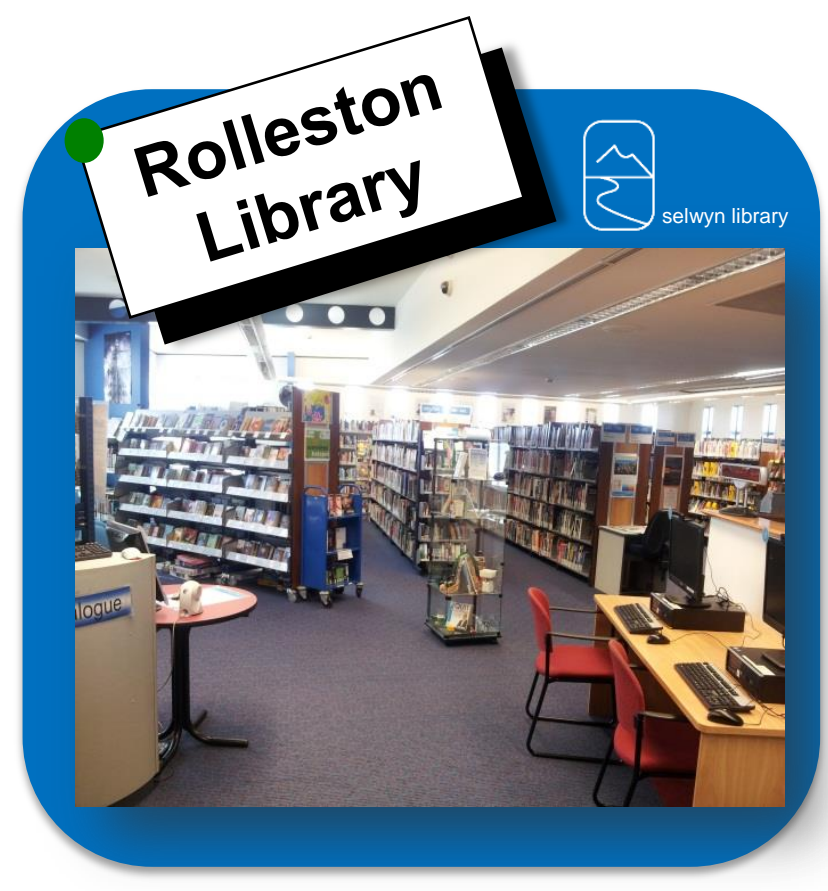

\begin{tabular}{|lr|}
\hline \multicolumn{2}{|c|}{ Overview } \\
\hline Township populations & 7197 \\
\hline Issues per year & 105,515 \\
\hline Visits per year & 110,563 \\
\hline Items held & 24,423 \\
\hline Staff total (FTE) & 3.5 \\
\hline
\end{tabular}

Rolleston Library was the first branch to introduce a self-issue option, which it did in November 2011.

\section{Self-issue facility}

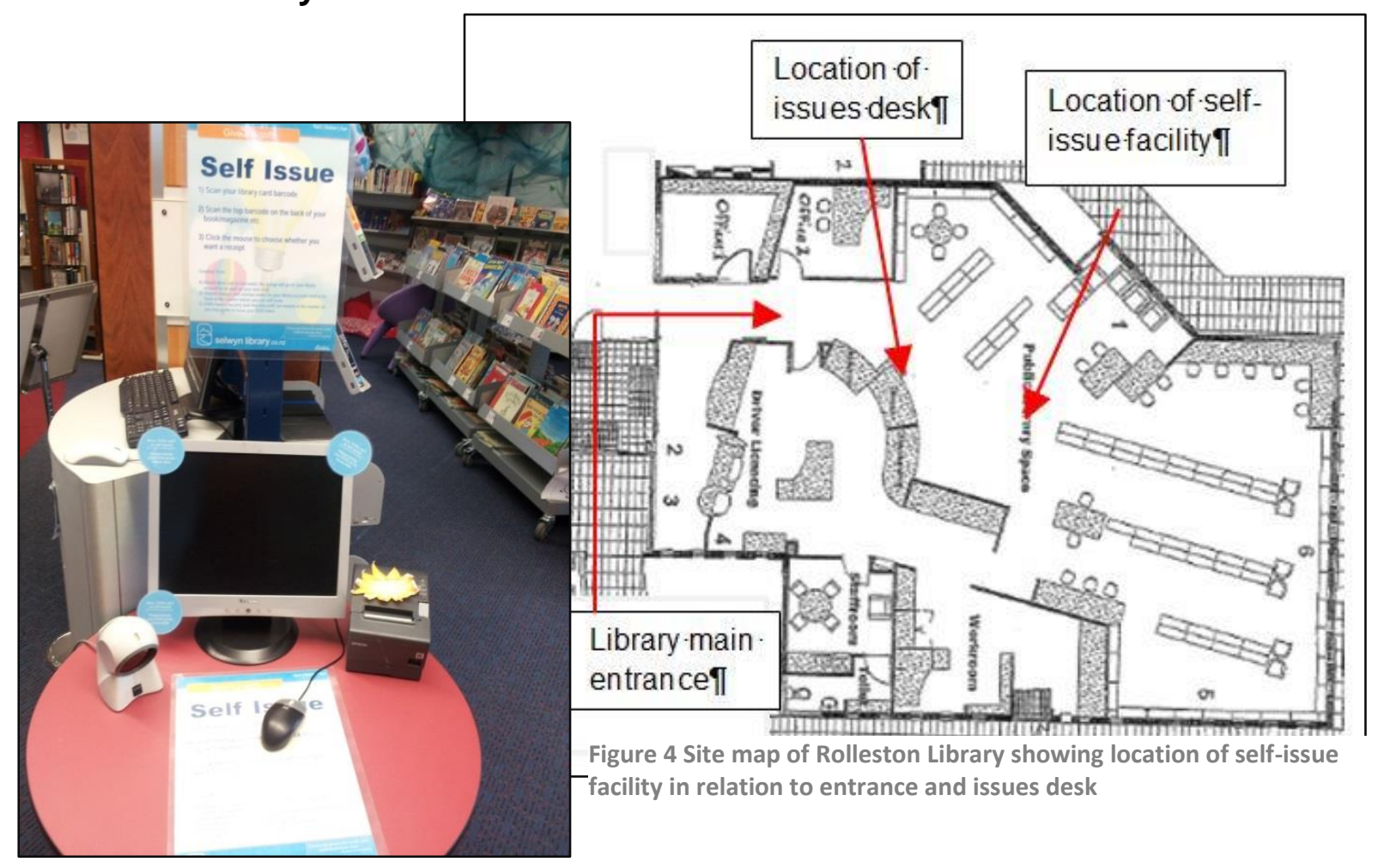

Figure 3 Self-issue facility at Rolleston 


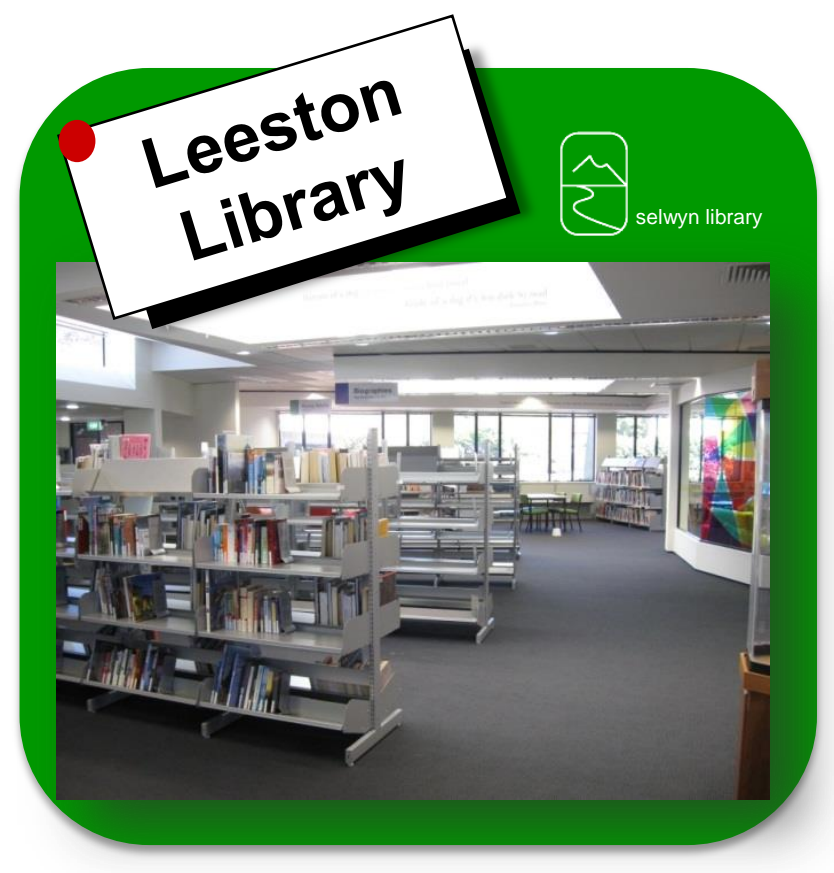

\begin{tabular}{|lr|}
\hline \multicolumn{2}{|c|}{ Overview } \\
\hline Township population & 1473 \\
\hline Issues per year & 65,403 \\
\hline Visits per year & 78,635 \\
\hline Items held & 26,374 \\
\hline Staff total (FTE) & 3 \\
\hline
\end{tabular}

A self-issue facility was implemented in the Leeston Library in January 2012.

\section{Self-issue facility}

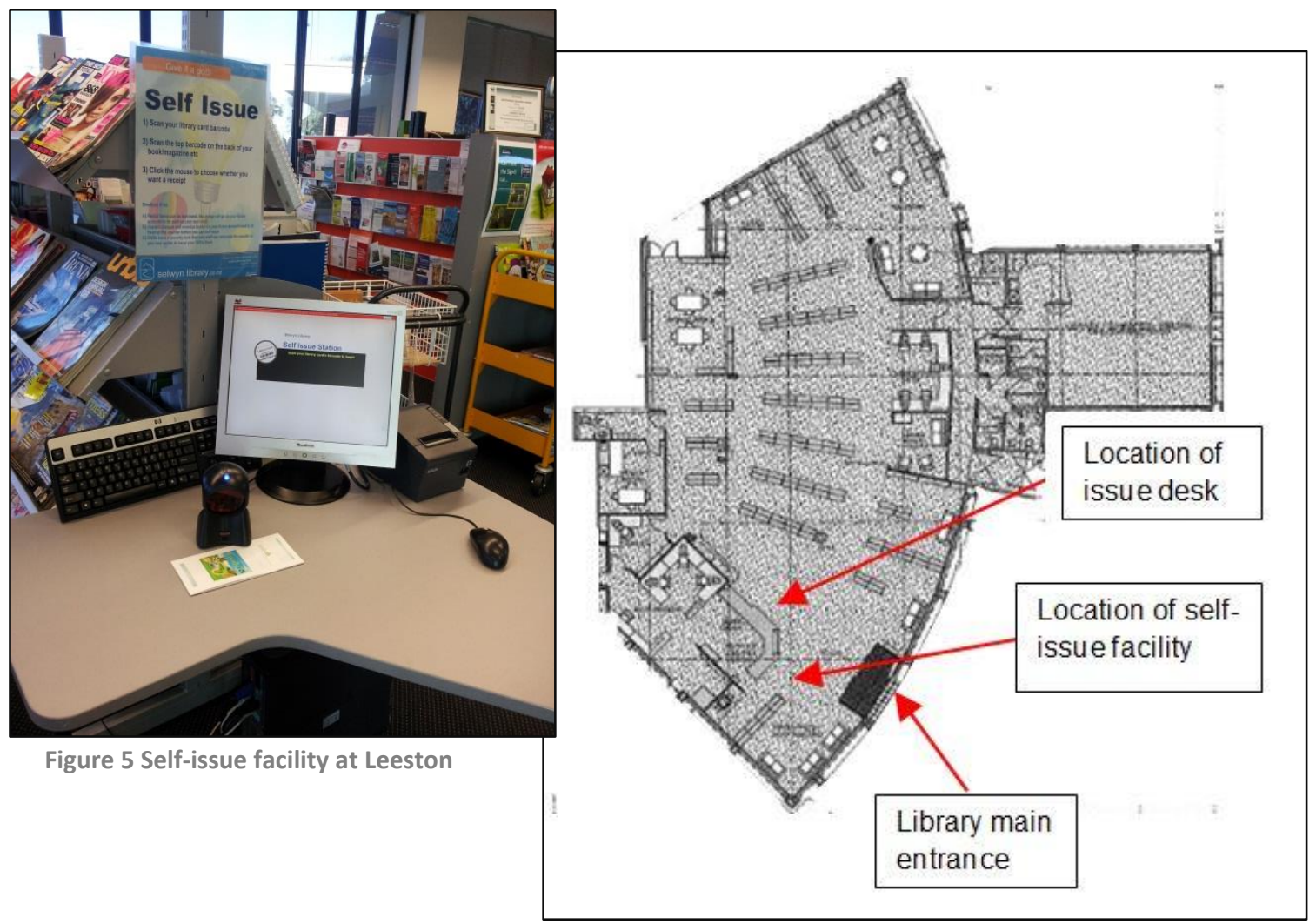

Figure 6 Site map of Leeston Library showing location of self-issue facility in relation to entrance and issues desk 


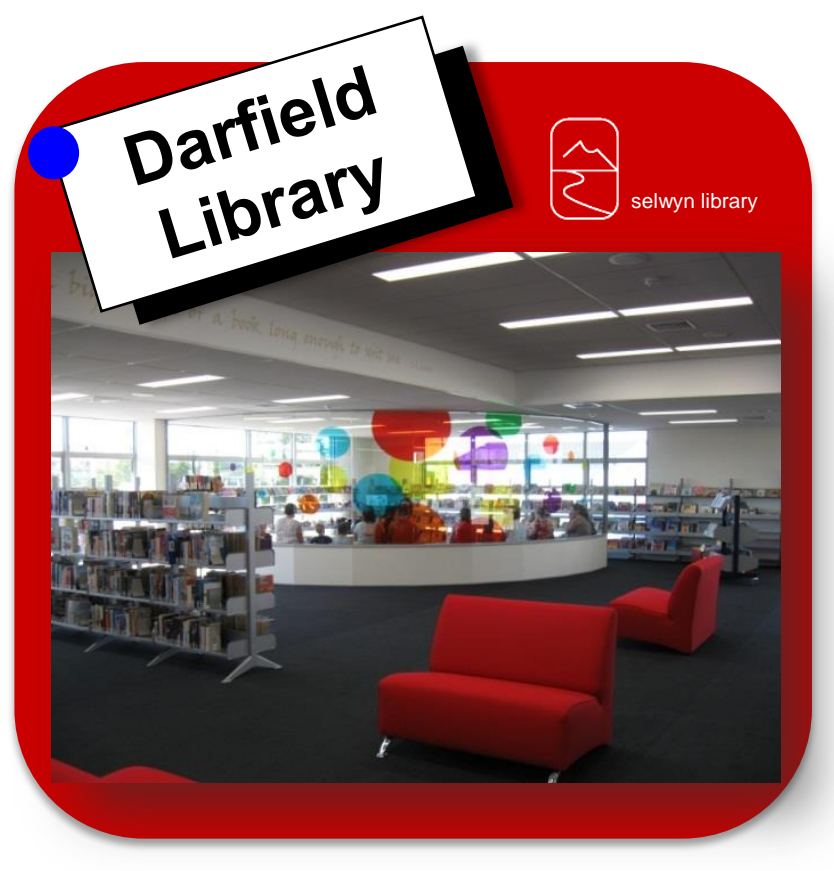

\begin{tabular}{|lr|}
\hline \multicolumn{2}{|c|}{ Overview } \\
\hline Township population & 2176 \\
\hline Issues per year & 76,345 \\
\hline Visits per year & 72,696 \\
\hline Items held & 25,244 \\
\hline Staff total (FTE) & 3 \\
\hline
\end{tabular}

The self-issue unit was set up in the Darfield Library in December 2011.

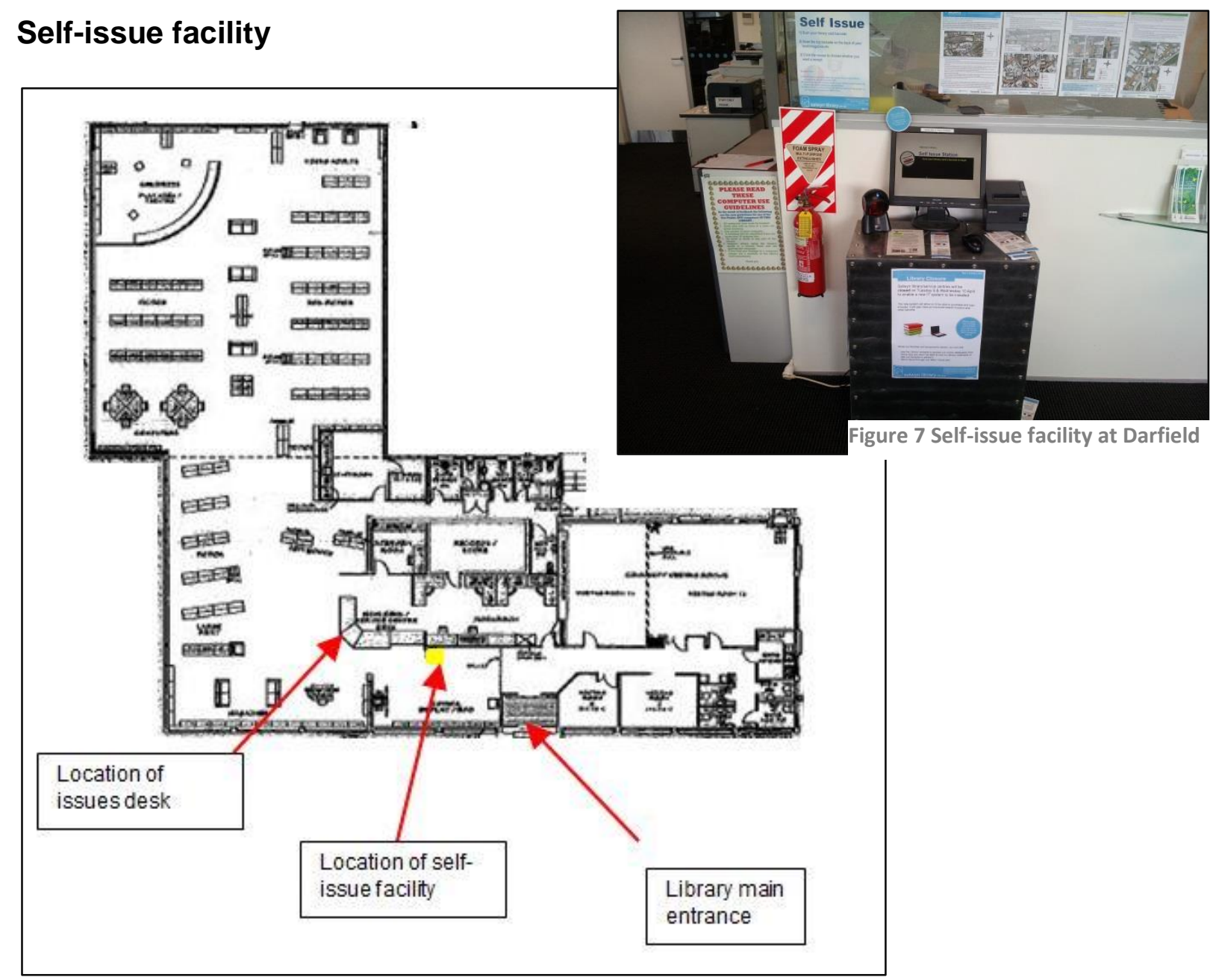

Figure 8 Site map of Darfield Library showing location of self-issue facility in relation to entrance and issues desk 


\section{$9 \quad$ Methodology}

This study examined numeric data about the usage of the self-issue facilities at Selwyn Library, as well as qualitative data regarding how self-issue is perceived by both library staff and customers. A mixed approach such as taken here allowed for the topic to be investigated from several differing perspectives.

- Analysis of issue statistics can help paint the picture of how well the self-issue facilities have been utilised at the different branches offering it as an option.

- The qualitative angle focuses on how the self-facilities fit into the particular contexts operating at Selwyn Library branches

\subsection{Population/sample}

\subsubsection{Staff}

A multi-level investigation was needed to explore different perspectives of self-issue at Selwyn Library branches (note: only the three branches that currently offer a selfissue option will be part of this study). The levels consisted of:

- Strategic

- Libraries Manager - one interview was conducted

- Operational management

- Branch managers - two interviews were conducted

- The third branch manager resigned unexpectedly from Selwyn Library and it was deemed inappropriate to interview the person filling in 
- Frontline

- Library assistants - three individuals, and one group of two were interviewed

- Several difficulties were faced when trying to interview groups of library assistants which resulted in the above interview configurations:

- Having a small staff base of mostly part-time staff means they are not there at the same time

- The problem of providing cover for the duration of the interviews

- The introduction of new staff who were unable to contribute

- Sickness and willingness to participate

\subsubsection{Customers}

- The respondents for the Customer Questionnaire were a convenience sample from the Selwyn Library customer's population, who frequent the three branches with self-issue facilities:

- Rolleston

○ Darfield

- Leeston 


\subsection{Ethical considerations}

Due to the mixed methodologies involved in this study, individual applications for ethics approval were sought and gained for both the staff interviews and the customer questionnaire. Details pertaining to the different ethics conditions are discussed in the following sections.

\subsubsection{Circulation reports and issues statistics}

The research required in-depth access to a variety of library circulation data and reports. Accordingly, permission from the Libraries Manager was sought and given for:

- Research to be conducted at Selwyn Library and for Selwyn Library to be named in the final report

- Data from library reports and the library website to be used in the research

All files containing original raw data or manipulated secondary data were kept secure through the use of password-protection restricting access to those files.

\subsubsection{Staff}

Staff were provided with an information sheet (see Appendix I) by email a week or so before the interviews were scheduled to take place in order to give them time to ask any questions they had. As previously stated, arranging group interviews with the library assistants proved to be problematic and consequently only one "group" was able to be interviewed, as well as three individual interviews conducted. 
Before each interview commenced, the staff involved were asked to sign a consent form outlining their permissions and rights regarding the research (see Appendix II). A different consent form was given to the Libraries Manager (see Appendix III) which contained additional clauses pertaining to permissions for:

- Research to be conducted at Selwyn Library and for Selwyn Library to be named in the final report

- Interviews to be conducted with staff at the libraries

- Data from library reports and the library website to be used in the research The Libraries Manager also gave informal consent for the free rental item offered as an incentive to those library users who completed the customer questionnaire. All interviews were recorded to enable the researcher to give their full attention to the interviewee without needing to take notes, as well as ensuring accuracy. All recordings were transcribed within two to three weeks of the interviews being conducted, and distributed to the relevant interviewee for approval. Despite expressing their unanimous embarrassment at what they termed their "waffling on", all interviewees concurred that the transcripts accurately portrayed their interviews and agreed for their answers to be used in the study.

Confidentiality was an important consideration, especially for staff to be able to speak freely about their feelings without fear of having those views attributed to them personally. There was an issue that some interview comments could be traceable due to the relatively small number of participants in the research. To minimise this risk several measures were taken: 
- Maintain confidentiality through not revealing names or branch when reporting data from the staff interviews.

- Assign codes to each interviewee and keep raw data secure in passwordprotected electronic files

- Findings are presented in such a way to ensure anonymity where practical; for example as there is only one Libraries Manager it is impossible to do so, but with two Branch Managers there is able to be a greater degree of confidentiality such as reporting results as percentages, ratios or proportions.

\subsubsection{Customers}

Questionnaire forms were made available in each of the library branches with a selfissue facility for one month. A covering sheet (see Appendix IV) outlined information about the research, assured participants of their anonymity and offered them an incentive; this was in the form of a complimentary rental item such as a DVD or new release book. The customer received their free item by giving the ripped off cover sheet to the librarian subsequent to dropping the completed form in the provided receptacle.

All forms were numbered to ensure data was collected from valid forms only. Implied consent for use of the customer's data was taken as given by completion of the questionnaire. Customer anonymity was preserved by the following measures:

- No name was required on the questionnaire form, and only basic demographic data was requested 
- It was decided not to report the "library branch I would most likely visit" findings as some of the comments could be traceable due to the small number of respondents at some libraries, and the close relationships with staff

- Customers were able to fold and place their own completed forms in the collection box, without needing staff intervention

Signage was provided to each of the libraries to advertise the survey and the support/promotion of the staff at the libraries was gratefully received. Secure receptacles were placed at each of the libraries to ensure that completed forms were kept safe, and were unable to be tampered with after they had been "posted" inside. These receptacles were constructed by the researcher using covered photocopy boxes and securing the lids with cable ties.

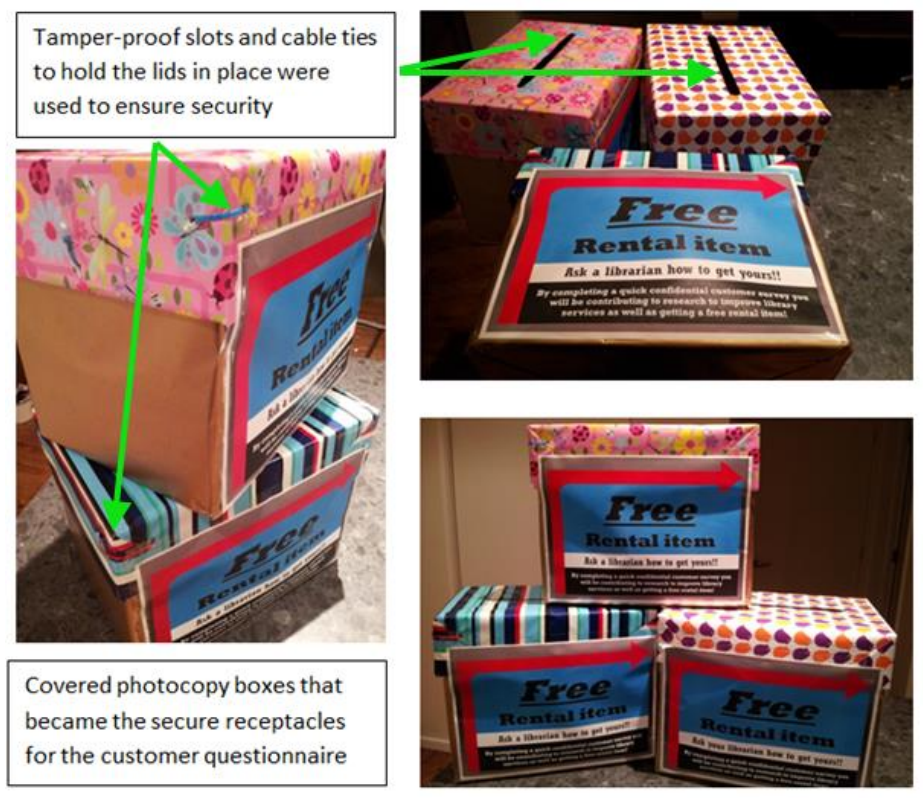

Figure 9 The "Secure Receptacles" for completed customer questionnaires, that where placed at each of the library branches with self-issue facilities 


\subsection{Instrumentation}

\subsubsection{Staff Interviews}

The interviews for this research were tailored to each level of staff: senior management, branch management and frontline staff. They were comprised of both open and closed questions that were designed to elicit responses appropriate for that staff member:

○ Libraries Manager (see Appendix V) - Fifteen questions covered:

- Big picture view: objectives and targets of self-issue

- Background to Selwyn Library's self-issue implementations

- Strategy and policy considerations

- Branch managers (see Appendix VI) - Sixteen questions covered:

- Staff acceptance

- Customer acceptance

- Implications for task management/allocation

- Training requirements/issues

- Frontline staff (see Appendix VII) - Eleven questions covered:

- Attitudes towards self-issue

- Impressions of customer perceptions

- Problems/issues

- Changes to their roles 


\subsubsection{Customers}

The voluntary self-completion questionnaire was made available at self-issue enabled branches. The most efficient way of doing this was by printing paper copies that were distributed to each branch (see Appendix VIII for sample questionnaire). Initially fifteen forms were given to each branch; forms were numbered with a different sequence per branch to save any confusion when they were collated, for example 100 series for Rolleston, 200 series for Darfield and 300 series for Leeston. Additional forms were supplied to the branches if required.

The questionnaire was deliberately kept short and direct in order to ensure the maximum completion rate. Accordingly it was mainly comprised of check list and/or Likert rating scale type questions, though there was the option to include qualitative data through the inclusion of four extra information sections.

There was accommodation made for those respondents who were not self-issue users and it was stressed to library staff that completed questionnaires for both users and non-users of the self-issue facilities were desirable. 


\subsection{Data collection}

\subsubsection{Circulation reports and issues statistics}

A variety of circulation statistic reports were generated for each of the three branches that offer self-issue, as well as examination of operational management data collated from reports and foot-count numbers. It was important to prioritise this stage of the data collection because Selwyn Library completed a system changeover to the Kotui consortium at the beginning of April 2013 and it was unclear whether historic data would be available. All statistics were based on data extracted from the 'old' system to show for each branch:

- Self-issued items per month, as a percentage of total issues per month

- Self-issues categorised by customer types (Adult or Child card types) as a percentage of total issues for specific, given periods

- Self-issue statistics for particular days of the week, as a percentage of total issues for the same days

- Self-issue statistics for particular days broken into time periods, as a percentage of total issues for the same days/times

It was decided to collect statistics for the same specific, given periods for the customer type, days of the week and particular time periods data, because it was considered impractical and unfeasible to collate these data for the whole year selfissue had been in operation. Accordingly four individual week time periods were selected at random to represent 'normal' operation of the year, (Note: these included Saturdays as all Selwyn Library branches are open for the mornings):

- 5 March 2012 to 10 March 2012 
- 23 July 2012 to 28 July 2012

- 1 October 2012 to 6 October 2012

- 18 March 2013 to 23 March 2013

In order to avoid as much as possible atypical results, the weeks selected fell outside the school holiday periods for the given years. The statistics were collated using spreadsheets in Microsoft Excel because of its flexibility when recording and manipulating quantitative data in tables and graphs, and also because the researcher has some proficiency with the software.

In addition, discussions with relevant staff were held to gain background and statistical information, as well as ascertaining how to obtain some of the more obscure data.

\subsubsection{Staff interviews}

A total of seven staff interviews were conducted at Selwyn Library branches; these were undertaken all in one day, mainly for reasons of timing and availability, but also in the interests of obtaining genuine answers and to avoid collaboration amongst staff.

As stated, interviews were recorded by using recording applications on two different devices to ensure there were no issues resulting from equipment malfunction. In the following two weeks, the resulting audio files were transcribed into individual 
documents in Microsoft Word and emailed to the relevant interviewee for approval. These files were uploaded to QSR NVivo 9 for coding and analysis.

Both audio and document files were organised using the library name and level of interviewee as the file name, and are kept in a password protected electronic file. These will be deleted two years after the conclusion of the research.

\subsubsection{Customer questionnaire}

The completed questionnaires were collected from all the library branches on the same day, one month after they had been displayed in the branch. The still-sealed boxes were all opened together and the forms organised according to their number allocation (example 100 series for Rolleston, 200 series for Darfield and 300 series for Leeston).

A total number of 59 completed questionnaire forms were collected from the participating libraries, though there was an unequal distribution from each library with the majority of questionnaires coming from two branches in particular. Data from these forms was entered into a spreadsheet in Microsoft Excel. 


\subsection{Treatment of data}

\subsubsection{Circulation reports and issues statistics}

In order to obtain the type and level of information desired for the research a number of reports were used and/or manipulated:

- Self-issued items per month, as a percentage of total issues per month

- Raw data was extracted from an operational management report and was collated in a spreadsheet. Formulas and graphs were used to manipulate/display the data.

- Self-issues categorised by customer types (Adult or Child card types) as a percentage of total issues for specific, given periods

- Raw data was extracted from a report and collated in a spreadsheet.

Formulas and graphs were used to manipulate/display the data.

- Self-issue statistics for particular days of the week, as a percentage of total issues for the same days

- Raw data was exported from a report into a spreadsheet, where it was parsed and sorted several times to extract the required statistics.

These figures were collated in another spreadsheet where formulas and graphs were used to manipulate/display the data.

- Self-issue statistics for particular days broken into time periods, as a percentage of total issues for the same days/times

- Raw data was exported from a report into a spreadsheet, where it was parsed and sorted several times to extract the required statistics.

These figures were collated in another spreadsheet where formulas and graphs were used to manipulate/display the data. 


\subsubsection{Staff Interviews}

As already stated the staff interviews were recorded and then transcribed. During the transcription process tentative themes and trends began to emerge that highlighted similarities and definite points of difference. These were noted and formed the basis for a coding schedule to be used for organising the raw data from the interviews.

It was decided to use QSR NVivo 9 for coding and analysing the staff interview data because the data was all qualitative and so required a different treatment than the statistical quantitative data collected and the quantity of data made it inefficient to code and organise manually. While time constraints did ensure there was a steep learning curve required to become familiar with the software, it was decided that the benefits outweighed the difficulties and a pragmatic approach was decided whereby the basic features of the software were utilised for ease of coding, and some of the more advanced, hi-tech capabilities were ignored.

The documents containing the staff interview transcriptions were uploaded to QSR NVivo 9 and the coding schedule set up. Coding in QSR NVivo 9 is achieved through the use of Nodes and Classifications. Data is able to be both automatically and manually coded in a variety of ways in QSR NVivo 9 so that the staff interview data was coded not only according to the coding schedule below, but also collated at question level for each type of staff interviewed (branch manager, frontline, libraries manager), as well as by interviewee. This allowed for greater flexibility when organising and accessing the data, as well as enabling different classifications to be imposed on the Nodes. The attributes used to classify the staff interview data were: 
- Location

- Staff level

The same coding schedule was used for both the staff and customer data in order to capture overlaps, and highlight similarities and/or points of difference.

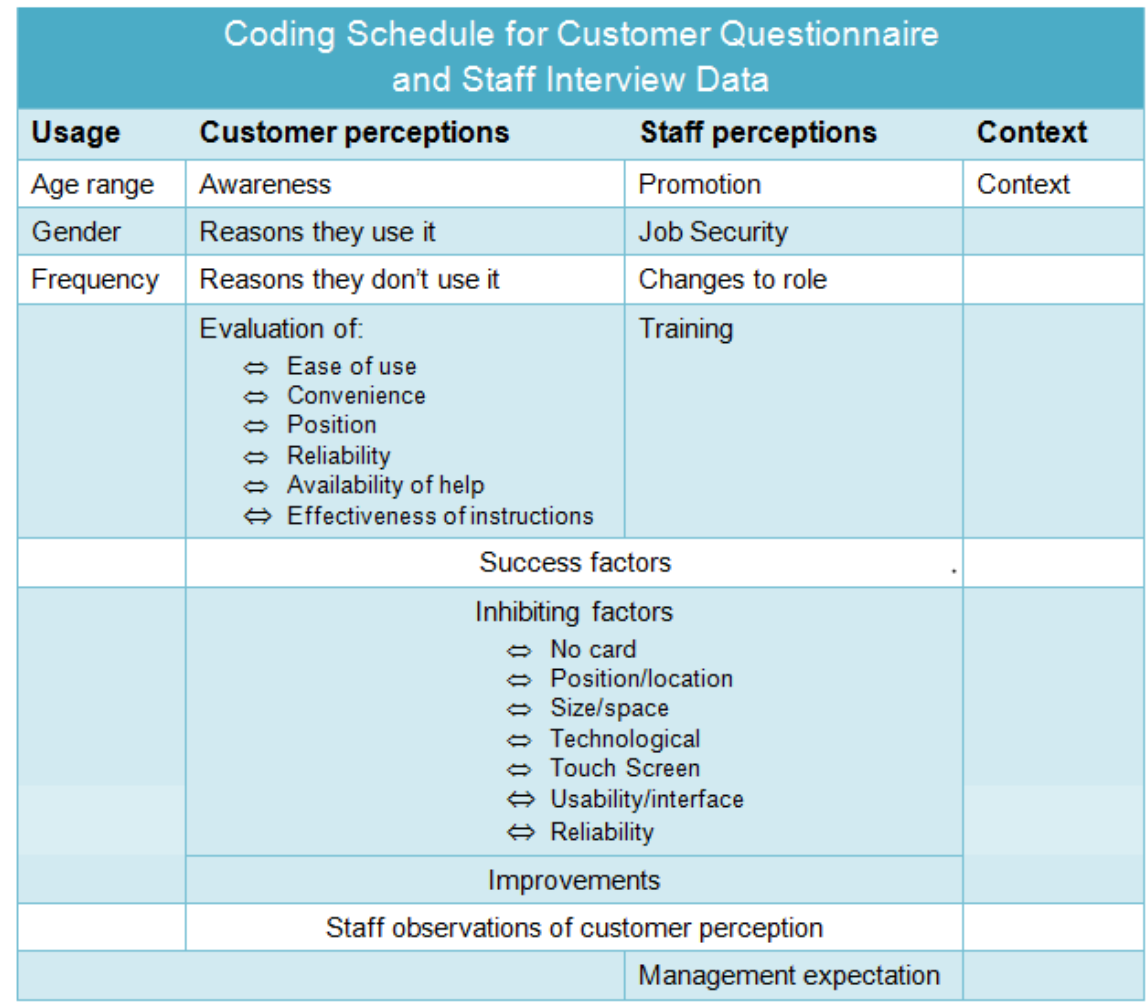

Table 1 Showing the coding schedule used to code data from both the customer questionnaire and the staff interviews 


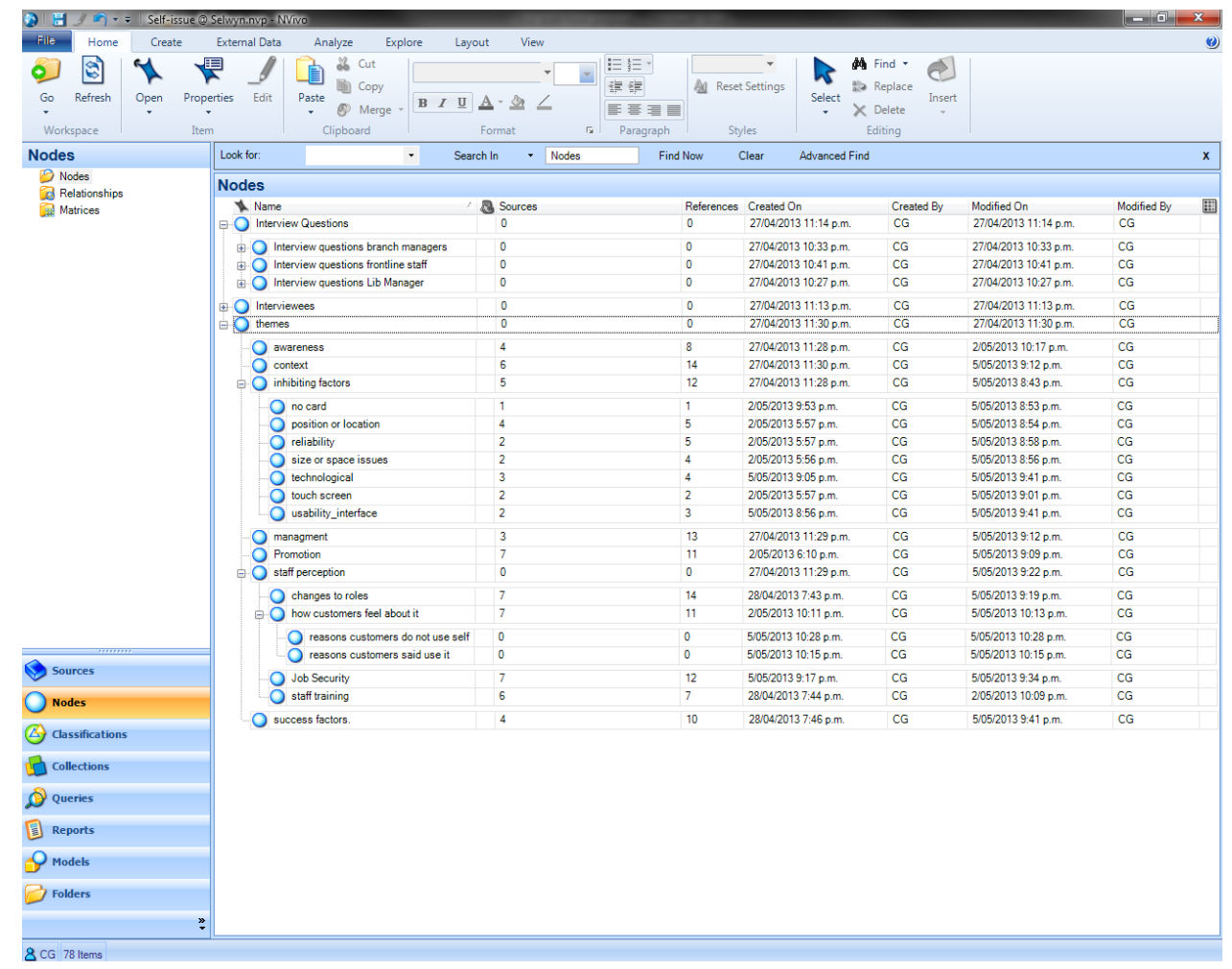

Figure 10 Screen shot showing the node structure in QSR NVivo 9. Note the Interview questions and Interviewee nodes can be expanded, hence their 0 references and sources

\subsubsection{Customer questionnaire}

As previously stated data from the customer questionnaires was entered into a spreadsheet with each form being represented by one row of the sheet, thus becoming a single record (Appendix X). Each of these records was allocated a unique identifier which was made up of a letter and number; the letter corresponded to the library branch and the number was the last two digits from the original number allocation of the form. It was decided to use this combination for ease of sorting and recognition when manipulating large amounts of data. In order to ensure consistency and as a way of validating the data entered, a series of lookup tables was constructed for some of the responses, for example:

- The age range 
- Use of both the library and self-issue options

- The Likert scale responses for the evaluation section

It was decided to analyse the customer data using the spreadsheet software rather than importing it into QSR NVivo 9 as had been done with the staff interview data. There were several reasons for this:

- The customer data was predominantly check box or Likert scale selection; there were only four optional sections where the customer was invited to include their own comments, so the potential amount of qualitative data analysis required was relatively small.

- Not all of the respondents had chosen to add their own comments to the questionnaire, making the actual amount of qualitative data to be analysed significantly smaller than it could have been.

- Level of expertise and familiarity with the software was also an influential factor in the decision to use Microsoft Excel for the analysis of the customer questionnaire data.

Despite deciding not to use QSR NVivo 9 for the analysis however, it was still considered imperative to follow the same coding schedule in order to compare and contrast the different perspectives of self-issue from both customers and staff. Accordingly the qualitative data from the customer questionnaire was coded by using a colour coding system, where each cell of the spreadsheet containing particular comments was filled with the appropriate colour. Where there was an overlap, for example when a particular comment was coded with two or more different coding 
terms, an appropriately coloured text box was added to the cell to indicate there were multiple codes applicable to the comment.

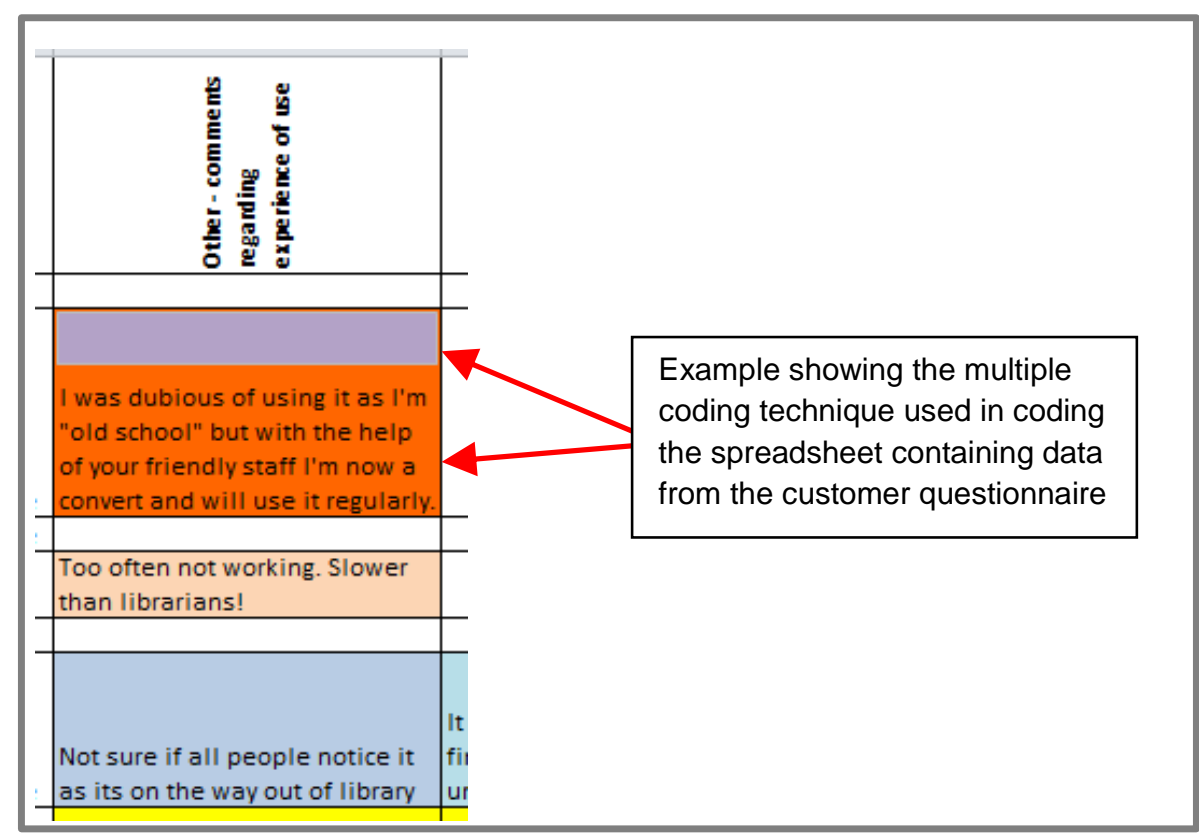

Figure 11 Extract from customer survey data spreadsheet showing multiple coding technique

Colour coding was only applied to those cells containing data appropriate for coding, for example cells containing age range or gender were not coloured. 
Coding Schedule for Customer Questionnaire

\begin{tabular}{|c|c|c|c|}
\hline Usage & \begin{tabular}{|l} 
Customer \\
perceptions
\end{tabular} & Staff perceptions & Context \\
\hline Age range & Awareness & Promotion & Context \\
\hline Gender & $\begin{array}{l}\text { reasons customers } \\
\text { said use it }\end{array}$ & Job security & \\
\hline \multirow[t]{20}{*}{ Frequency } & $\begin{array}{l}\text { reasons customers do } \\
\text { not use it }\end{array}$ & Changes to roles & \\
\hline & Evaluation of: & Training & \\
\hline & Ease of use & & \\
\hline & Convenience & & \\
\hline & Position & & \\
\hline & Reliability & & \\
\hline & Availability of help & & \\
\hline & $\begin{array}{l}\text { Effectiveness of } \\
\text { instructions }\end{array}$ & & \\
\hline & Success factors & & \\
\hline & Inhibiting factors: & & \\
\hline & No card & & \\
\hline & Position/location & & \\
\hline & Reliability & & \\
\hline & Size/space & & \\
\hline & Technological & & \\
\hline & Touch screen & & \\
\hline & Usability interface & & \\
\hline & \multicolumn{2}{|c|}{ Improvments } & \\
\hline & \multicolumn{2}{|c|}{ Staff observations of customer perception } & \\
\hline & & $\begin{array}{l}\text { Management } \\
\text { expectation }\end{array}$ & \\
\hline
\end{tabular}

Figure 12 Coding schedule for customer questionnaire

Extraction of various data for statistical analysis was effected by use of sorting and filtering the data, as well as the coding technique described above. 


\section{Findings, Data Analysis and Discussion}

\subsection{Circulation reports and issues statistics}

The first step in answering the research questions regarding the usage of the selfissue facilities at Selwyn Library was to analyse the data from a number of different circulation reports.

\subsubsection{Self-issues per month}

The monthly issues statistics for each library were entered in a spreadsheet showing the total issues for the month as well as the total self-issues for the month. From these figures the following statistics were calculated:

- a percentage of self-issue per month for each library from when they first had self-issue available until February 2013

- the average percentage of self-issue for each library based on how long they had offered a self-issue option and until February 2013

Various graphs and charts were also generated to aid analysis and understanding of what the statistics were showing. 
Monthly figures for self issue use

\begin{tabular}{|c|c|c|c|c|c|c|c|c|c|c|c|c|c|c|c|c|}
\hline & $\begin{array}{l}\overline{7} \\
\text { ż }\end{array}$ & 它 & 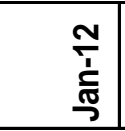 & $\begin{array}{l}\text { ำ } \\
\text { 원 } \\
\text { 世 }\end{array}$ & 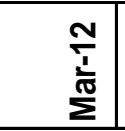 & $\frac{N}{\frac{1}{2}}$ & $\frac{N}{i}$ & $\frac{\mathfrak{N}}{\mathfrak{c}}$ & $\frac{N}{\frac{1}{3}}$ & $\begin{array}{l}\mathbf{N} \\
\frac{1}{2} \\
\frac{1}{4}\end{array}$ & $\begin{array}{l}\text { N } \\
\text { d̀ } \\
\text { ஸे }\end{array}$ & $\frac{N}{\frac{1}{0}}$ & $\begin{array}{l}\sim \\
\frac{1}{2} \\
z\end{array}$ & $\frac{\text { }}{\grave{d}}$ & $\frac{m}{\frac{m}{\grave{T}}}$ & $\frac{m}{\frac{0}{0}}$ \\
\hline \multicolumn{17}{|l|}{ Darfield } \\
\hline Self issue & & 405 & 1036 & 807 & 798 & 864 & 450 & 792 & 866 & 795 & 286 & 396 & 618 & 454 & 863 & 804 \\
\hline Total issue & & 5379 & 8140 & 6432 & 6807 & 6,973 & 6,078 & 6,127 & 6,870 & 5,836 & 5,384 & 6,379 & 5,553 & 4,472 & 7,007 & 6,432 \\
\hline Self issue $\%$ & & $7.5 \%$ & $12.7 \%$ & $12.5 \%$ & $11.7 \%$ & $12.4 \%$ & $7.4 \%$ & $12.9 \%$ & $12.6 \%$ & $13.6 \%$ & $5.3 \%$ & $6.2 \%$ & $11.1 \%$ & $10.2 \%$ & $12.3 \%$ & $12.5 \%$ \\
\hline \multicolumn{17}{|l|}{ Leeston } \\
\hline Self issue & & & 136 & 154 & 285 & 261 & 0 & 198 & 377 & 530 & 574 & 393 & 476 & 242 & 589 & 157 \\
\hline Self issue $\%$ & & & $2.4 \%$ & $2.9 \%$ & $4.9 \%$ & $5.0 \%$ & $0.0 \%$ & $3.8 \%$ & $6.4 \%$ & $8.6 \%$ & $10.9 \%$ & $7.9 \%$ & $8.6 \%$ & $6.5 \%$ & $10.5 \%$ & $3.0 \%$ \\
\hline \multicolumn{17}{|l|}{ Rolleston } \\
\hline Self issue & 557 & 1098 & 1450 & 2039 & 2752 & 2,639 & 2,945 & 339 & 1,619 & 1,817 & 1,359 & 2,456 & 1,367 & 1,236 & 1,564 & 1,995 \\
\hline Total issue & 8881 & 6381 & 10261 & 9504 & 9889 & 10,312 & 10,533 & 8,867 & 9,972 & 9,550 & 7,982 & 9,953 & 8,205 & 6,597 & 9,800 & 9,504 \\
\hline Self issue \% & $6.3 \%$ & $17.2 \%$ & $14.1 \%$ & $21.5 \%$ & $27.8 \%$ & $25.6 \%$ & $28.0 \%$ & $3.8 \%$ & $16.2 \%$ & $19.0 \%$ & $17.0 \%$ & $24.7 \%$ & $16.7 \%$ & $18.7 \%$ & $16.0 \%$ & $21.0 \%$ \\
\hline
\end{tabular}

Table 2 Monthly issues figures for Darfield, Leeston and Rolleston for period November 2011 to February 2013. 


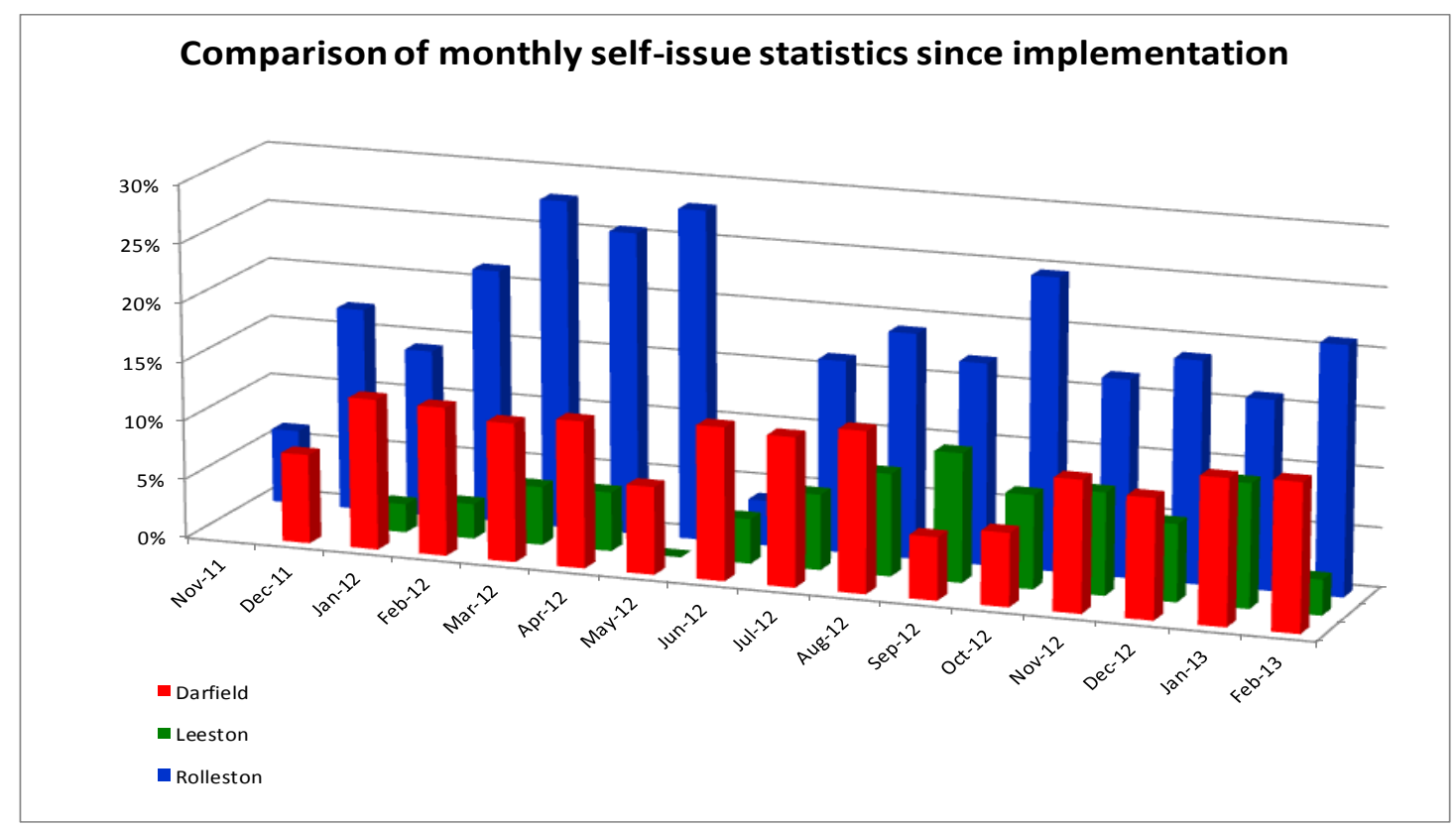

Chart 1 Comparison of monthly self-issue statistics for the three self-issue enabled branches, from implementation until February 2013

Definite differences in the level of self-issue usage could be seen between the three library branches. There was an expectation that the first few months may be low as customers became aware of the new option, though there had been 'coming soon' signage advising of the change in the three branches. This is borne out for Rolleston and Leeston who each took several months to come up to their average usage figures as shown in Table 3. However Darfield seemed to hit relatively high usage almost immediately. From the statistics shown here there is no indication of a trend towards increased uptake of the self-issue facilities at Selwyn Library over time. Rather there seems to be more a pattern of evening out, this is especially noticeable in the last four months of statistics and particularly for Darfield and Rolleston branches. Furthermore, where there has been a period of equipment failure such as it is assumed occurred in Rolleston in June and Leeston in May, there seems to be a period of sporadic use before picking up again. 


\begin{tabular}{|c|r|}
\hline \multicolumn{2}{|c|}{$\begin{array}{c}\text { Average usage per } \\
\text { month }\end{array}$} \\
\hline Darfield & 682 \\
Self issue & 6258 \\
Total issue & $10.9 \%$ \\
Self issue & \\
Leeston & 336 \\
Self issue & 5792 \\
Total issue & $5.8 \%$ \\
Self issue & \\
Rolleston & 1702 \\
Self issue & 9137 \\
Total issue & $18.6 \%$ \\
Self issue &
\end{tabular}

Table 3 Average self-issue usage from implementation to Feb

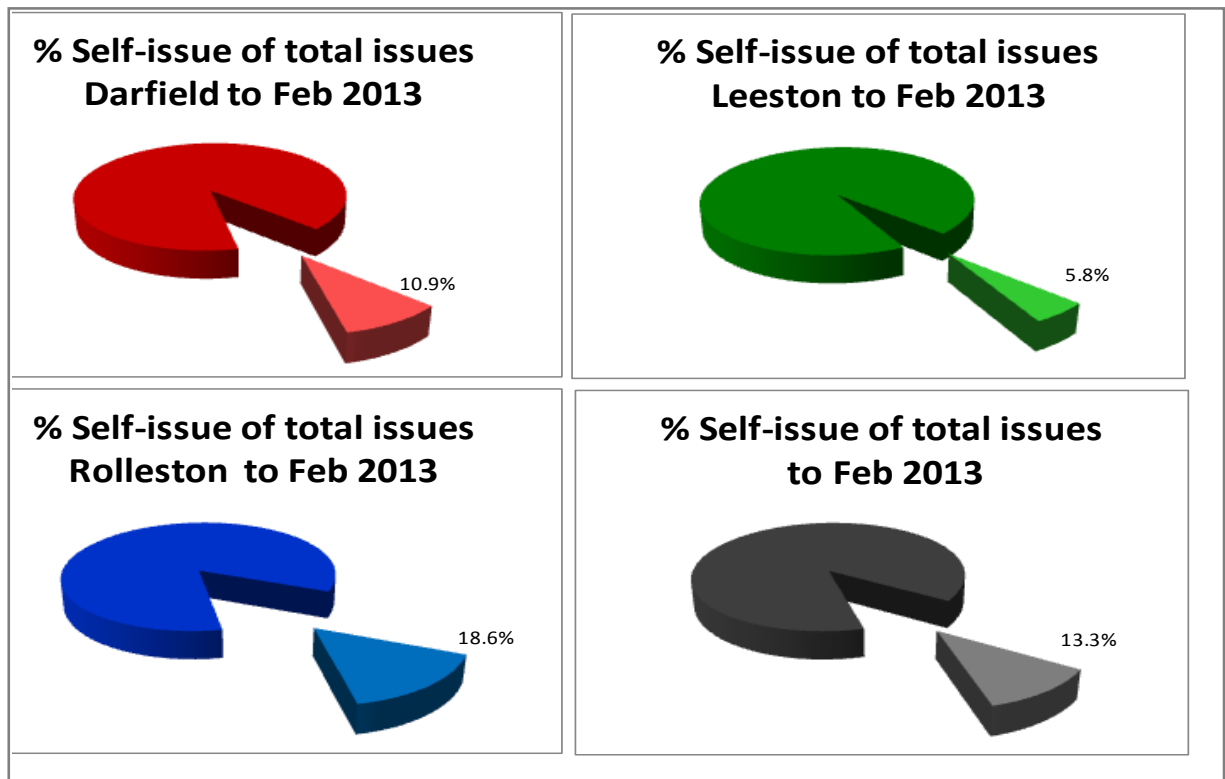

Chart 2 Average percentage of self-issue statistics for the three self-issue enabled branches and collated figure for Selwyn Library self-issue as a whole, from implementation until February 2013.

There were also some fluctuations apparent in the figures:

- Leeston had zero self-issues in May 2012

- Darfield showed relatively low figures for self-issue in September and October of 2012

- Rolleston showed unusually low statistics for self-issue in June 2012 
From other statistics calculated it was revealed that the Darfield self-issue facility had been out of order for several weeks during the period of low figures recorded above, and it was a reasonable assumption that this was the same for the other libraries as well, though none of the branches keep a formal register of problems with self-issue equipment.

It was recognised that these lower figures would skew the average self-issue statistics for each of the branches and the figure across Selwyn Library self-issue as a whole, but it was decided to include them for the following reasons:

- in 'normal' conditions it must be expected that there will be times when equipment failure interrupts day-to-day usage

- it is an accurate portrayal of the actual statistics for the time period; shows what did happen rather than expected or projected figures.

A further factor to be taken into consideration when reading the statistics was the fact that Rolleston branch was the only Selwyn Library branch in the study to have a late night opening each week. Every Thursday night the library remained open until $8.00 \mathrm{pm}$ rather than the normal $5.00 \mathrm{pm}$ closing. It was recognised that this may skew the Rolleston branch average slightly higher each week due to the longer opening period.

While much of the circulation analysis included statistics taken from March 2013, the total figures for this month were unavailable at the time this data was collected and 
so monthly reporting was only able to be recorded until February 2013 . It was

decided to include data for a week in March 2013 in other statistical analysis as

being the most current and therefore up-to-date information available.

\subsubsection{Self-issues by card types}

There were six different card types at Selwyn Library, these consist of:

Card

Type

\section{Membership details}

A Adult; 18 years or over - fees and overdue charges apply

$\mathrm{J}$ Junior; under 18 years of age - few fees and no overdue charges apply

BU Bulk issuing for institutions, housebound, sight or hearing impaired customers - no fees or overdue charges apply

S Staff; includes library and council workers, as well as library volunteers no fees or overdue charges apply

T Temporary; for customers who wish to join on a pay-as-you-go basis. Mainly used by customers who may work in the Selwyn area but live outside it - fees and overdue charges apply

CH Christchurch City Libraries members; a new card type set up after the Canterbury earthquakes during an amnesty period when many of the Christchurch City Libraries were unable to open - fees and overdue charges apply

Table 4 Membership types at Selwyn Library

Reports were able to be produced to extract all daily transactions for each branch classified by:

- type of transaction

$\circ$ and within transactions by issues

- and within issues by self-issue 
- and within self-issue by card type

These figures were used to calculate the statistics and charts showing the numbers and percentages of self-issues at the three self-issue enabled branches of Selwyn Library.

As discussed previously it was decided to calculate statistics for four representative weeks of the period that self-issue has been available. The four periods had been selected at random at the outset of the data collection phase of the study and were as follows:

- 5 March 2012 to 10 March 2012

- 23 July 2012 to 28 July 2012

- 1 October 2012 to 6 October 2012

- 18 March 2013 to 23 March 2013

These periods also included times when the self-issue facilities were not available and so the same fluctuations of use were understood to also exist within the selfissue by card type statistics. 


\begin{tabular}{|c|c|c|c|c|c|c|c|c|c|c|}
\hline \multicolumn{11}{|c|}{ Self issue by card type } \\
\hline & & \multicolumn{2}{|c|}{ 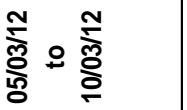 } & \multicolumn{2}{|c|}{ 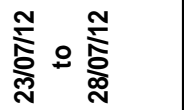 } & \multicolumn{2}{|c|}{ 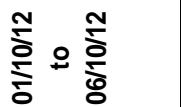 } & \multicolumn{2}{|c|}{ 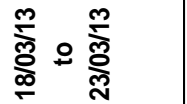 } & \multirow{2}{*}{ 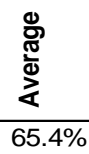 } \\
\hline \multirow[t]{5}{*}{ Darfield } & Adult & 115 & $54.2 \%$ & 92 & $60.1 \%$ & 0 & & 86 & $81.9 \%$ & \\
\hline & Junior & 93 & $43.9 \%$ & 59 & $38.6 \%$ & 0 & & 16 & $15.2 \%$ & $32.6 \%$ \\
\hline & Other & 4 & & 2 & & 0 & & 3 & & \\
\hline & Deviations & 17 & & 4 & & 0 & & 2 & & \\
\hline & Total & 212 & & 153 & & 0 & & 105 & & \\
\hline \multirow[t]{5}{*}{ Leeston } & Adult & 8 & $25.0 \%$ & 30 & $22.4 \%$ & 36 & $37.9 \%$ & 19 & $29.7 \%$ & $28.7 \%$ \\
\hline & Junior & 20 & $62.5 \%$ & 98 & $73.1 \%$ & 59 & $62.1 \%$ & 45 & $70.3 \%$ & $67.0 \%$ \\
\hline & Other & 4 & & 6 & & 0 & & 0 & & \\
\hline & Deviations & 0 & & 2 & & 3 & & 13 & & \\
\hline & Total & 32 & & 134 & & 95 & & 64 & & \\
\hline \multirow[t]{5}{*}{ Rolleston } & Adult & 147 & $48.7 \%$ & 142 & $36.6 \%$ & 204 & $41.0 \%$ & 156 & $31.6 \%$ & $39.5 \%$ \\
\hline & Junior & 153 & $50.7 \%$ & 246 & $63.4 \%$ & 265 & $53.2 \%$ & 338 & $68.4 \%$ & $58.9 \%$ \\
\hline & Other & 2 & & 0 & & 29 & & 0 & & \\
\hline & Deviations & 4 & & 2 & & 32 & & 9 & & \\
\hline & Total & 302 & & 388 & & 498 & & 494 & & \\
\hline
\end{tabular}

Table 5 Showing self-issue by card type for four specified weeks

The raw data revealed some Deviations coded as self-issue returns. These are technically impossible and attempts to deliberately replicate these occurrences in order to understand exactly what was happening were unsuccessful. On further investigation it was believed that these occurred when customers had scanned an item twice by mistake in quick succession, or possibly when little children were scanning items in order to hear a beep. These figures were not included in the calculations on the assumption that

- They were not genuine self-issue operations

- The issue part of the transaction would be included in the appropriate card type totals

- Library management was aware of the problem and had investigated both the extent of it and ways to prevent it. 
The statistics showed that there appeared to be variation in who preferred or chose to use the self-issue facilities at the particular branches:

- At Darfield statistics suggested that those customers using an Adult card were more likely to choose the self-issue option, as for each of the weeks studied Adult card type self-issues were consistently higher than those from customers who used a Junior card type. The last week indicated a particularly high statistic for Adult self-issues and a relatively low week for Junior selfissues and, as previously stated, the third week studied had zero self-issues due to equipment failure. The total number of self-issues had a high degree of fluctuation between the various weeks; lowest 105 and highest 212 making just over $100 \%$ variance between the highest and lowest self-issue total.

- Leeston statistics for self-issue were almost completely opposite to those of the Darfield library. They indicated that far more children chose the self-issue option than adults, and the proportions were relatively consistent over the four weeks studied. One possible explanation for this is that classes from the local school were using this branch while their school library was being refurbished; this has since ceased but it is too soon to see if this will affect the self-issue statistics. However there was a lot of difference between the total number of self-issues carried out during these periods: lowest 32 and highest 134 making a difference of $320 \%$ between the highest and lowest self-issue total.

- Rolleston library showed a more even distribution between Junior and Adult card types, but with a definite weighting towards Junior card types. The total self-issue figures were also the most consistent of the three branches, with a 
$65 \%$ fluctuation between the highest and lowest self-issue total; though it was recognised that higher issue numbers over all may tend to smooth out fluctuations.

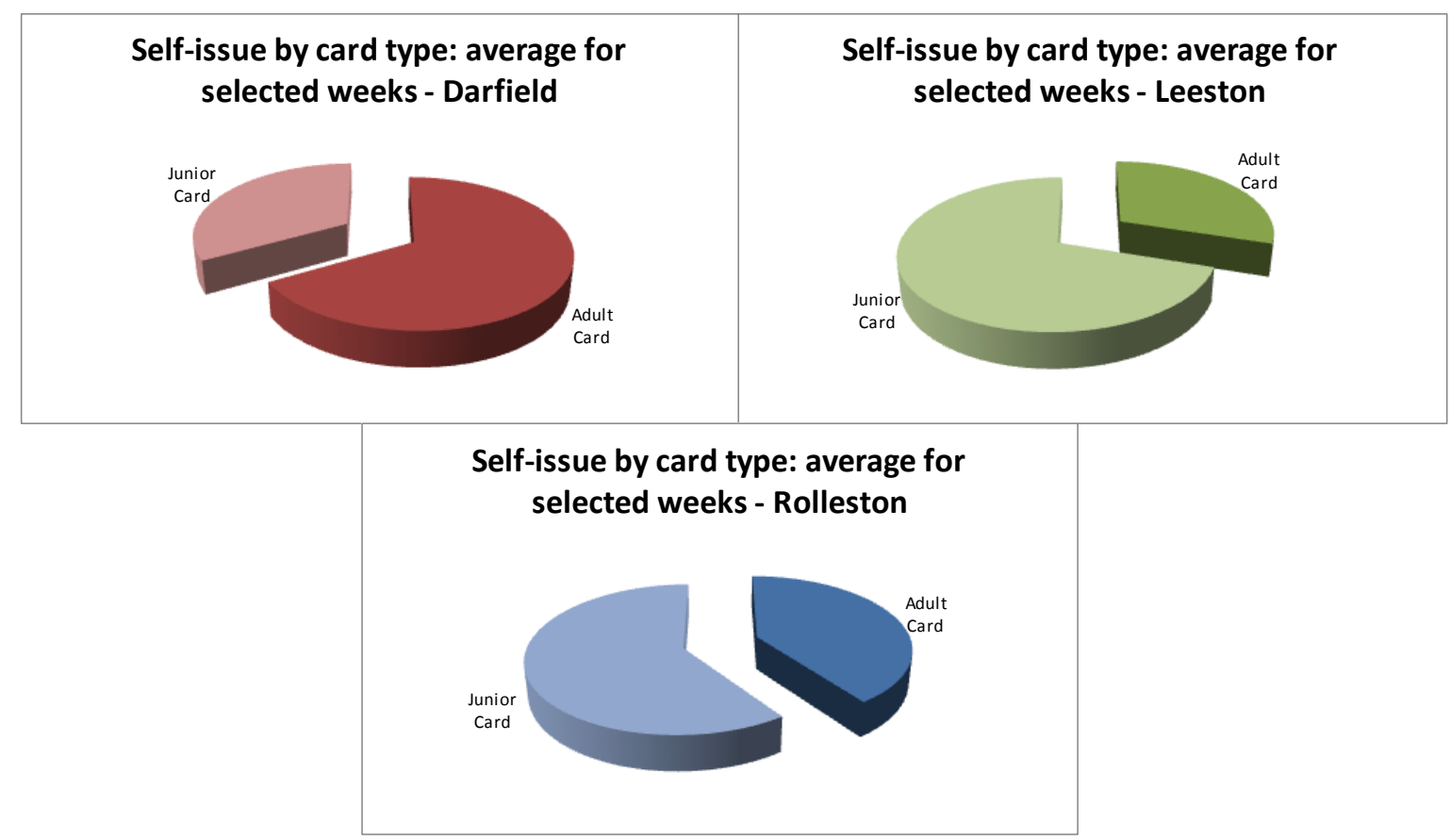

Chart 3 Averages of self-issue by card type for selected weeks

\subsubsection{Self-issues by time period}

The process for calculating the statistics for self-issues by time period was a reasonably lengthy one involving relatively large amounts of data. The same four week period as in the previous section was used for each library branch, with the same provisos as previously noted. As there was no system report to extract this information it was necessary to obtain complete transaction lists for the days in question and export this data into Microsoft Excel. For each of the libraries in 
question this was a substantial number of transactions and, it was felt, justified the decision to select four weeks as representative of the year of self-issue use. The numbers of transactions were as follows:

- Darfield - 13,150 lines of data

- Leeston - 11,451 lines of data

- Rolleston - 21,929 lines of data

Once the raw data had been parsed into a spreadsheet it was sorted by date and then transaction type to group the ISI transactions denoting self-issue, together. The sorted data remained in time order within each of the days and transaction types. All self-issue transactions were highlighted for each date to make them easier to locate within the spreadsheet. It was decided to leave them within the context of the particular day rather than sort all the self-issues together in case any further information of interest was revealed.

Note: screen shots of the raw data have had columns containing personal customer information hidden to preserve confidentiality. 


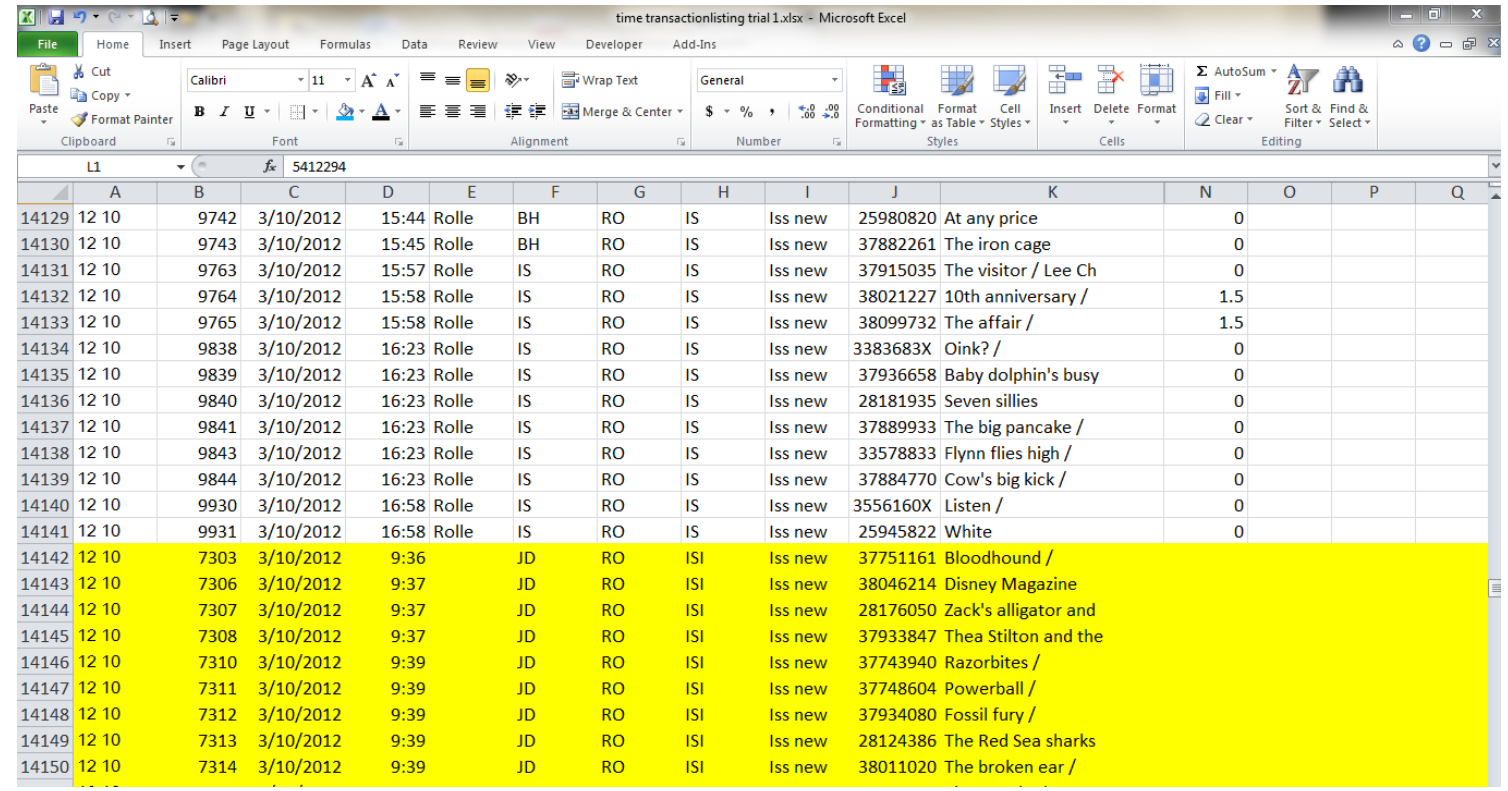

Table 6 Screen shot of raw data showing selection of self-issue records

Then it was simply a matter of transcribing the number of self-issues for each time slot into another spreadsheet. Time slots were half hour periods starting from the library opening time of $8.30 \mathrm{am}$ until the closing time of $5.00 \mathrm{pm}$, with the exception of Thursday which is a late opening night at Rolleston and so the time slots extended until $8.00 \mathrm{pm}$. Also of note is that while Saturdays showed the same time slots, it was understood that all branches were open for only a brief period of three hours: between 10.00 am and $1.00 \mathrm{pm}$ for the first three weeks in question, and new summer hours of between 9.30 am and $12.30 \mathrm{pm}$ for the week in 2013. (Note: these hours were subsequently adopted as the 'normal' Saturday hours henceforth).

As with the self-issue by card type statistics, some IRI self-issue return deviations were noted. These were highlighted a different colour and the totals were also recorded where they occurred. 


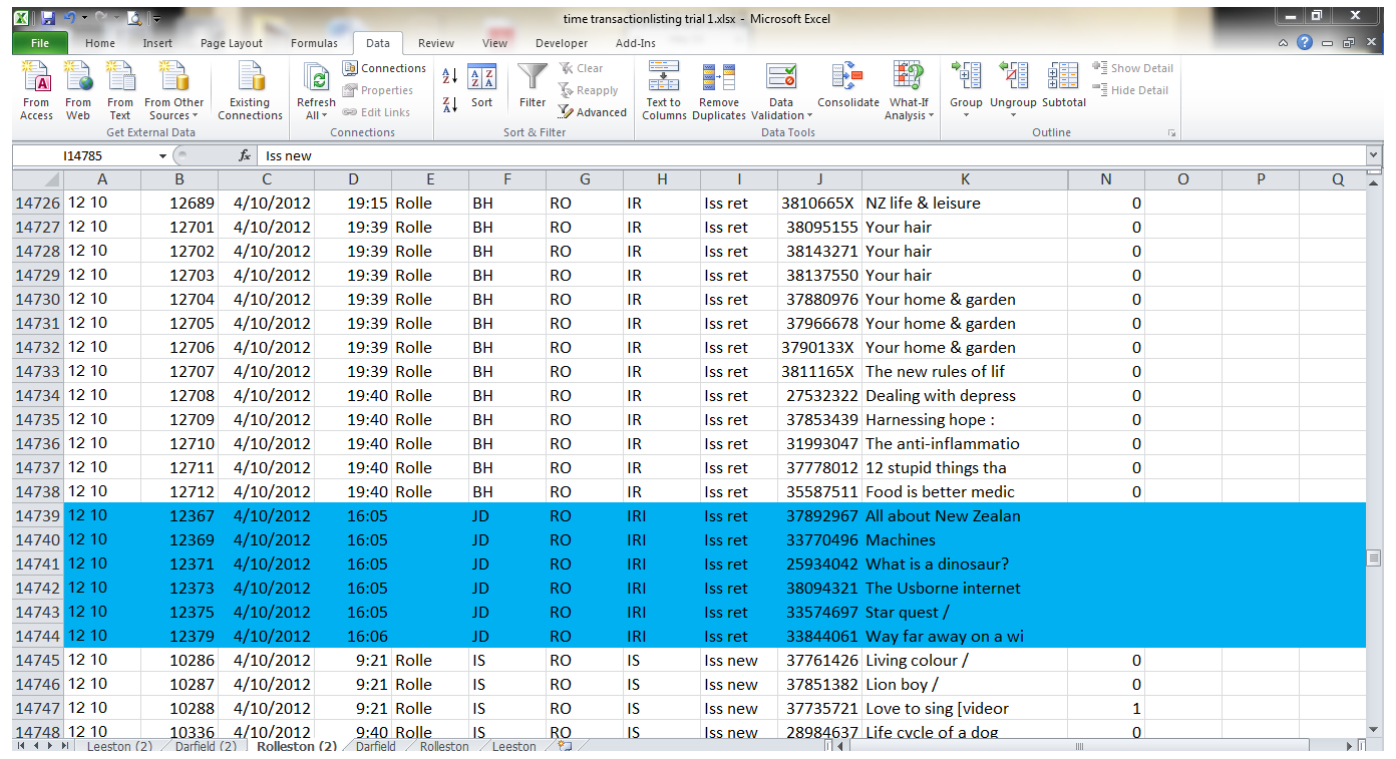

Table 7 Screen shot of raw data showing deviations

Another interesting anomaly was revealed in the examination of the self-issue by time period data. This was a couple of instances where self-issue transactions were recorded outside of normal work hours for that particular day. This only occurred at Rolleston branch and, on further investigation, appeared to be when Community Centre staff (who share the library building space but are open longer hours) had apparently made use of the library themselves, or possibly allowed members of the public in to the library afterhours. This had since been picked up by management and stopped.

The spreadsheets (see Appendix IX) containing the distilled self-issue by time period data was coded to aid readability as follows:

\begin{tabular}{|l|c|}
\hline \multicolumn{2}{|c|}{ Colour key for Timed statistics spreadsheets } \\
\hline Late night (Rolleston only) & Totals \\
Anomalies & Saturdays \\
Deviations & \\
\hline
\end{tabular}

Table 8 Colour coding key for self-issue by time period data 
From the data captured in the spreadsheets, an average weekly distribution was calculated to graph the results in order to see fluctuations in the use of the self-issue facility.

The figures were calculated by totalling the number of self-issues per time slot for the specified weeks, and then dividing them by the number of weeks; for Rolleston and Leeston libraries this was four weeks. For the Darfield branch, who's self-issue had been non-operational in the week of 1 October 2012 to 6 October 2012 (and a couple of days into the following week), the average was done over the other three operational weeks. 

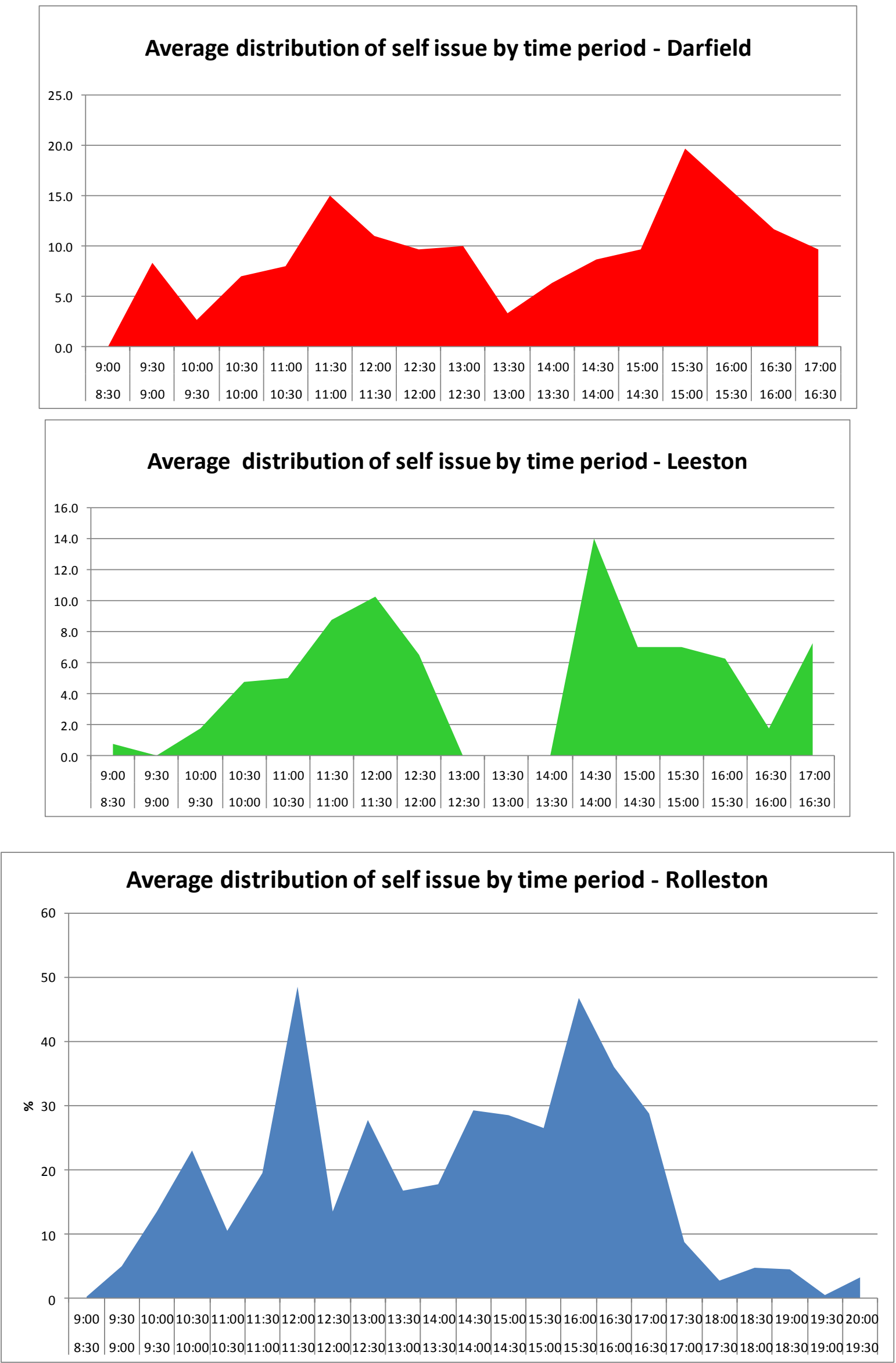

Chart 4 Average distribution of self-issue by time periods 
These graphs offered a clear and simple way of viewing the average trends of selfissue usage throughout a 'typical' day. Observations made were:

- While there were some distinct differences within the trends of self-issue use at each branch, it seemed that there was a universal significant lull in use at some point in the early afternoon, though Leeston was the only branch to have no activity between 1.00 and $2.00 \mathrm{pm}$.

- Both Darfield and Rolleston showed spikes in use round mid-morning, which could indicate busy times when parents call in after the school run

- Rolleston showed a significant spike in self-issue use over the immediate prelunch period

- In general Rolleston usage contained more peaks and troughs than the other two branches

- Leeston use peaked at 2.00 to $2.30 \mathrm{pm}$ and had another spike just on closing time

- Late night use at Rolleston was low, though this could mirror actual library use during this time; anecdotally the library is not particularly busy in the last hour of being open (C Walker; Rolleston Librarian, personal communication 10 May 2013).

It was decided to add the distribution of the total issues for each individual time slot in order to see if significant patterns emerged. This involved repeating the process required for calculating the self-issue statistics for each time slot, but this time taking the total issues for the particular time slot. These figures were also averaged over the four weeks (or three weeks in Darfield's case). By adding this series of data to 
the graphs it was possible to see how the trends of self-issue usage did or did not follow busy times at each library branch.

This was shown to be the case as the peaks and troughs of library issues were generally echoed by those of self-issue. 

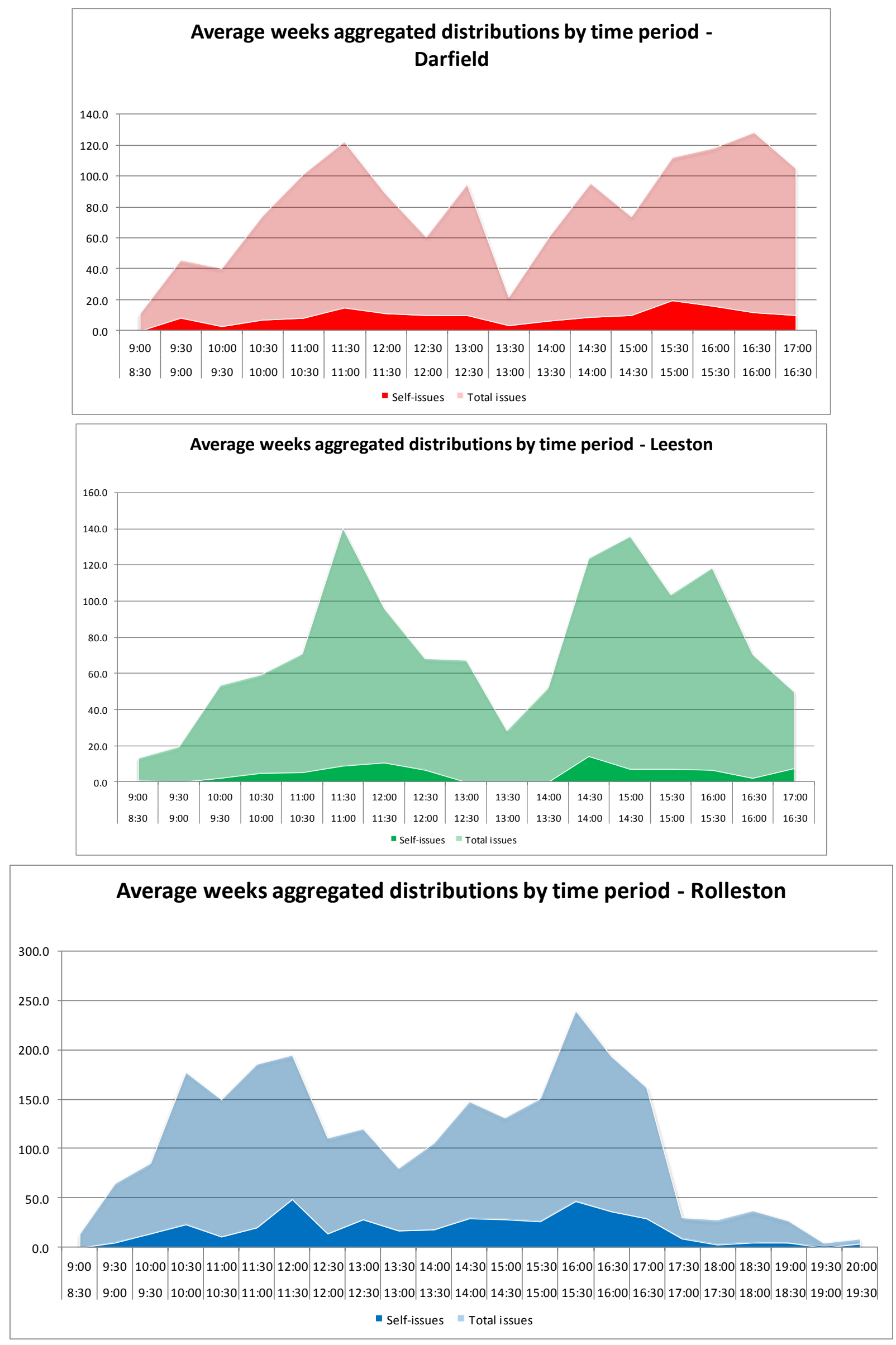

Chart 5 Aggregated distribution of self-issue by time periods - comparison self-issue with totals 


\subsubsection{Self-issues by week days}

The data captured in the timed statistics spreadsheets was also used to calculate a daily average distribution which was used to graph the averages for each day of the week for each branch. This was a simple way of visually comparing the self-issue usage over a 'typical' week for the branch.

The figures were calculated by totalling the number of self-issues per time slot for each of the days of the specified weeks, and then dividing them by the number of weeks; for Rolleston and Leeston libraries this was four weeks. For the Darfield branch, who's self-issue had been non-operational in the week of 1 October 2012 to 6 October 2012 (and a couple of days into the following week), the average was done over the other three operational weeks. 

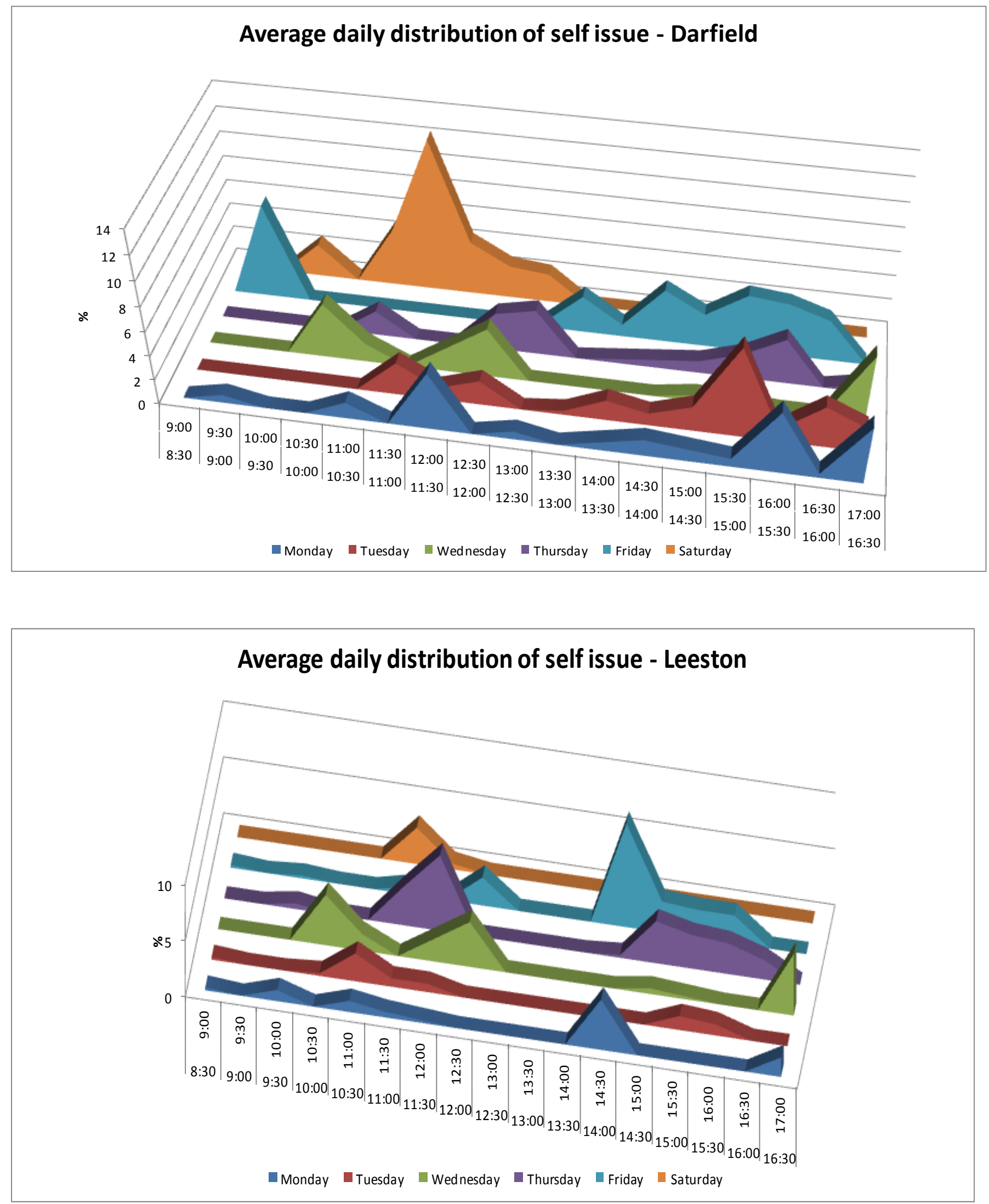

Chart 6 Average daily distribution of self-issue by time periods - Darfield and Leeston 


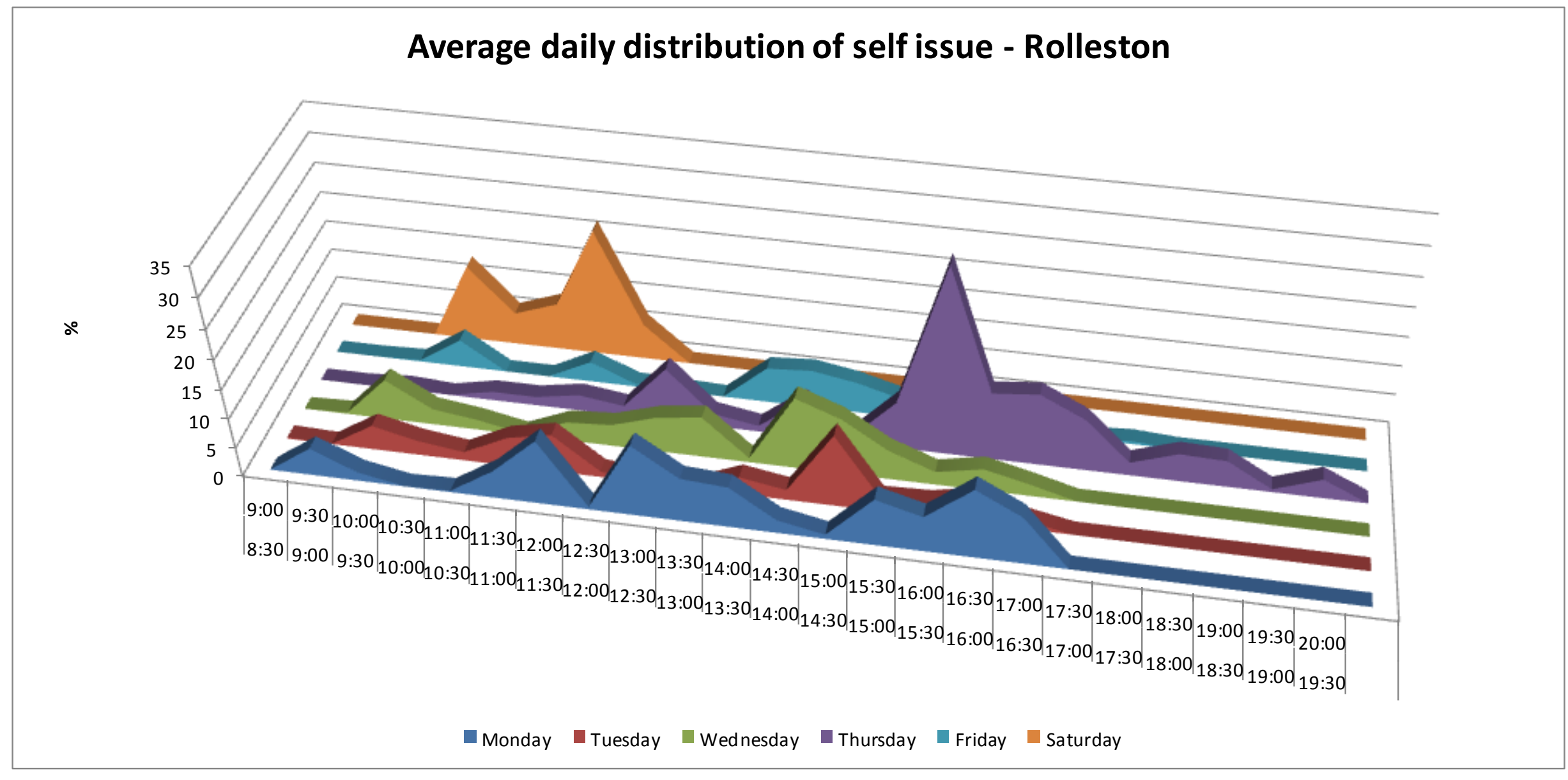

Chart 7 Average daily distribution of self-issue by time periods - Rolleston 
These graphs effectively expand the previous weekly average graph and reveal where some of the peaks and troughs have come from.

- For example the graph for Darfield showed a particularly high peak in selfissue usage on Saturday late morning, indicating a possibly popular or busy time. Likewise Friday morning showed a significant period of use, and the afternoon a consistent period of use.

- Friday afternoons in Leeston were also a relatively busy time for self-issue, though Mondays seemed pretty slow. A peak in the usage on Thursday mornings could be due to Storytime held in the library between10.30am and $11.00 \mathrm{am}$, though this did not appear to influence the other two branches whose Storytimes were Rolleston between 9.30 am and 11.00 am Tuesdays, and Darfield Mondays from 10.00 am until 10.30am.

- Rolleston's busiest period was Thursday, occurring between 3.00 and 4.00 pm; perhaps a significant factor was what classes were held at the Rolleston Community Centre before/after this time. Saturday mornings were also a period of relatively high usage. 


\subsection{Staff interviews}

The second step in answering the research questions regarding the usage of the self-issue facilities at Selwyn Library was to analyse the data from staff interviews. As previously stated, these were conducted across all levels of staff to get a rounded picture of how self-issue is perceived from all perspectives.

Answers from the questions posed during the staff interviews were coded according to the coding schedule (pages 52 and 53), and this analysis will follow that basic structure and be grouped where practicable.

\subsubsection{Job Security}

There was some discrepancy between library management and frontline staff regarding the question of whether self-issue was or could be seen as a threat to staff employment.

Contrary to the view postulated by Morris et al. that fear of job losses is inevitable (2001, p. 16), frontline staff at Selwyn Library were unanimous in their view that they did not see self-issue as a direct threat to their jobs:

- There are too many other jobs to do. People do need help all the time. I think we'll always be needed basically

- It might sort of lessen the amount of library assistants that are needed in the long run but I don't think it would be a threat wholly to the position of library assistants 
Library management views seemed to indicate that it was believed there had been some concern regarding job security from staff and even, occasionally, from customers:

- I think some people were concerned - "Oh no it's the beginning of the end, it's a way of cutting down the staff"

- I think I have noticed a few older people sort of joke and say we're doing you out of a job. ... I think there is a small section of the community who maybe do see it as taking work away from us

\subsubsection{Changes to roles}

In general frontline staff had embraced the concept of self-issue positively:

- I think it's great, I think we could have a lot more of it.

There was concurrence among all staff that self-issue could save staff time from the repetitive task of issuing, thereby freeing them up for other tasks:

- It enables you to do other things that wouldn't have normally got the time for

- I think we should be out in the library a lot more than what we are probably.

- I think other staff are probably really happy about it because it does free them up to do those other jobs and maybe more challenging activities

From a management perspective this has had the added bonus of stretching a small staff to be able to cope with increasingly busy libraries in New Zealand's fastest growing district: 
- If we have $20 \%$ in each library then that's $60 \%$ of a fulltime job, that's $\$ 30,000$ a year, that's a saving for the library. Then we can make our existing staffing go further

- Circulation has increased with more people coming to [branch] too. Logically that must have freed us up a little bit more

This may have had some bearing on the views of some of the staff who reported that the implementation of self-issue had not really changed library roles significantly:

- I don't think there has been much change to be honest.

- I don't really know that we have noticed a huge impact because I think libraries are the sort of places where you always have extra tasks to do

- It's probably a really hard thing to measure, I mean when you think that we must have $25-30 \%$ going through it must have made a difference

\subsubsection{Training}

Training for staff regarding self-issue at Selwyn Library was not undertaken in any formal manner

- I guess in some ways it did just kind of arrive but at the same time there's not really any training to be given in terms of staff

- Well, it's not a hugely different technology and we just got introduced to it and we've sort of gone with the flow really so, probably we had all the training we really sort of needed 
- ...ideally we should be pushing our staff to do better education, standing there helping people, responding really quickly if the thing goes 'dong' instead of 'ding' and showing people the right way because once they know they know forever

This appears to have resulted in some contradictory views between what is perceived by management and what is actually thought by frontline staff, especially in term of confidence when dealing with any problems that arise.

- No I think it arrived and they showed us how to turn it on, swipe the card, swipe the book, there you are. Minimum of training I think we have had

- Not really, I have to say if the thing crashes I have no idea what to do with it.

- No, it's only by chance that I kind of know that there is a password on the underside of it to reboot it up.

Oh is there, well that's news to me.

- It was just kind of put there wasn't it and then "there's the self-issue machine"

- Not particularly, if it goes down you are never really sure what to do. I sort of switch it off and switch it back on and hope for the best.

According to the literature, staff who are not confident with self-issue are less likely to train customers to use it (Whitney \& Garrett, 2008, p. 10), and this seems to be partly borne out at Selwyn Library. When asked whether the self-issue was actively promoted in their library branch, answers were mixed, but tended towards the negative:

- Yes, I would say we do actively encourage people to use it 
- Honestly no I don't think I ever think about it...it just sort of sits over there...

- No, people tend to see it and use it. If they are at the desk then they want to be at the desk.

- I wouldn't say I did.

\subsubsection{Successes}

Potential savings in any form are always attractive to public libraries due to their chronic under resourcing (Morris, Thornley, \& Snudden, 2001, p. 10) and Selwyn Library proved no different. The main success factors to emerge were improved customer service and savings:

- It helps free up our staff because we are understaffed quite chronically

- customers' have a choice and staff time is being saved so l'd say it's been successful... If we have $20 \%$ in each library then that's $60 \%$ of a fulltime job, that's $\$ 30,000$ a year, that's a saving for the library

- Gives you more time to help those customers who actually want help

Other staff comments emphasised how self-issue helped ease congestion at busy times and saved customers' time. These views were undermined somewhat by a management staff member who pointed out:

- we are a size where queues are not really an issue

- I think that to be honest self-issue isn't that much faster or easier

One of the difficulties in looking at how self-issue has worked well in the library is that too often successes are not acknowledged and it is only when things go wrong that people tend to comment, in the words of the Libraries Manager: 
- when it breaks down I start getting told "people are complaining, they really like using self issue". They never say it's good when it's working...

Some staff did acknowledge that self-issue could help to minimise the incidence of occupational related injuries:

- I am quite happy for anything that reduces the impact ...for us

\subsubsection{Inhibiting factors/Improvements}

The findings for what are considered inhibiting factors were found to often lead logically to what could be done to make things better and for this reason they were grouped together under various categories:

\section{- Awareness}

Several staff reported that they felt that many customers were not aware that there was a self-issue option at Selwyn Libraries:

- a lot of people we notice that come down from Christchurch will come up to the counter and we'll issue their books and they'll say "you should get a self-issue machine" - we say there's one just over here by the big notice....

This was backed up by the respondents in the customer questionnaire who indicated they were unaware of its existence. Other staff pointed out that the setup of the self-issue facilities were such that it was not instantly recognisable: 
- people just think it's another computer and not a self-issue. It's not obvious what it's for

- Position/location and Size/space

This was mentioned by some staff as affecting customer uptake, though lack of space in some of the branches was acknowledged as an influential factor in placement.

- I'm certainly aware that our self issues are affected by the location of the machine

- I don't think there is any other place we could really put it because we are pushed for room, but I think it could be set up a bit better maybe

Possibly more of an issue was the physical setup of the facility such as the size and height of the surface it is on. Many staff (and customer questionnaire respondents) felt there was insufficient room to accommodate a pile of books and/or a bag while issuing. The height of some facilities was acknowledged to be good for children, but too low for adult customers to use comfortably. Suggestions of different locations or trying to make it look more prominent or obvious were put forward.

- Technology and Usability/interface Many issues were mentioned that staff felt could discourage people from habitually using the self-issue facilities. These pertained to:

- Scanning issues such as scanning the ISBN rather than the library barcode 
- Pay-for items - DVDs need to be unlocked and payments need to be made at the issues counter

- Need to have library card with you

- Receipt printer issues - prints a long "wasteful" slip and when it runs out of paper

- Unable to issue if there are overdues or money owing on card

There were also some technical issues that could pose difficulties for staff such as customers removing items that have not actually been issued. Due to the lack of any security system, there is no sure way to prevent this happening, however in the context of Selwyn Library with its close customer relationships, this was not perceived as a huge problem:

- I'm pretty happy that given the nature of our community and library users in general that $99 \%$ of those books come back because people just get all their library books and bring them back

One of the most widely cited improvements from staff and customers was to have the self-issue facility touch screen. It was felt this would be more intuitive for people to use:

- touch screen... You kind of expect that, because the supermarket ones are aren't they. They are all touch, so I think people just assume, it's a big screen with a big box...

- Reliability

Touted as imperative to building customer trust ( (Brady, Kearsey, Monigatti, Sindel, \& Tsui-Po, 2009-2010, p. 9), reliability of the self-issue service 
attracted a slightly negative response from some staff as well as customers. Eliciting the only 'strongly disagree' response recorded from the entire customer questionnaire, some staff comments supported the view from Brady et al:

- people say "it hasn't given me a receipt" or whatever, so they are not sure about actually using it and maybe next time they won't go back and use it because it's kind of a waste of time if it's not working properly.

o sometimes it just doesn't work, I think mainly when people scan their card and their name doesn't come up that instant, they just keep scanning it so I think it sometimes gets overloaded so then we've got to actually restart it.

\subsubsection{Management expectation}

When asked about how well implementation of self-issue at Selwyn Library has met management expectations, the response was overwhelmingly positive, but with an admission that perhaps there was room for improvement.

- it needs a bit more care and attention to try and make it more effective and I've got a lingering sense of guilt about that ... we could have maximised it more

- $20 \%$ is a reasonable kind of percentage to get through but if we could push it up if we could get it 25, 30,40,50\% there would be a huge difference in the way our libraries worked. 
It was generally felt that having self-issue as an option was an important but not crucial part of customer service at Selwyn Library:

- I think it is really great to have in there as an option but I also kind of feel like you know we don't want that to be the only option or make it really obvious that is the preferred option

- I think it's still seen as an optional extra here. It's a bonus sort of thing.

Partly this was seen to stem from the context of Selwyn being made up of smaller, more closely knit communities:

- it's such a community friendly atmosphere, most people want to chat and say how's your family and what a nice day and that sort of thing.

- a small community and one where people seem to know each other so much, they quite value that over desk interaction...Not that the customer interaction is a bad thing, I actually think that is a really valuable part of what libraries do, particularly smaller community libraries like us; sometimes we are the only people that someone does talk to for a day

Though it was acknowledged that those customers coming to Selwyn from other library areas would be accustomed to having self-service as an option:

- customers kind of expect it, I mean they have come from other library systems and they like to be just able to come in and do their thing and get out quickly

- Lincoln and Rolleston are getting a lot of people coming out from town and they come with an expectation, they've had self-issue at New World and their 
previous libraries in Hornby or wherever so I think it's become a thing that's expected even if people don't choose it

In line with the literature regarding self-service technologies in general, the future direction for self-issue at Selwyn Library is to increase its usage while simultaneously maintaining customer service:

- I think all libraries have the same strategy with self-issue which is to push towards maximising it, you want 50\%, 90\% going through self-issue so you free the staff up for other things.

- the main thing is that people have a really good library experience when they come in

However with staffing levels being so low, the current rate of self-issue usage is not enough to result in any significant change in staff roles, it just tends to be making the job slightly easier

- we haven't come up with a plan of hey you are saving this much time you can do this and this, but because we are always trying to do twice as much as we should be, it just makes it a little bit easier to try and do that.

\subsubsection{Context}

One of the key areas for this research was how well the self-issue fitted into the small rural public library in New Zealand, so the question of context was a very important one. As already stated Selwyn was seen as being made up of small, 
closely knit communities, though it was acknowledged that there has been rapid growth in many towns particularly Rolleston. Despite this, however, the context is still regarded as a highly significant factor at Selwyn Library:

- I think the drive to talk to someone is a lot bit stronger here than in say a busy Christchurch library. We have a greater proportion of people we know by name and vice-versa and have relationships with so I think that will always be a factor at smaller libraries that people, they feel that they are rude if they don't come and talk to you today

- I think a lot of people, particularly those who live on their own, come in for somebody to talk to and it's often why they come to the desk because they get a chance to talk to someone.

- I think a lot of our customers are a bit shy about using it and we do get a lot of customers I think that do actually want to have a chat and actually say oh well if I use that I won't get a chance to have chat with you and that's actually part of the whole library experience for them

The fact that there are, and always will be, some people who just prefer the human interaction was supported by findings from both the staff interviews and the customer questionnaire. Conversely there are, and always will be, some people who naturally gravitate towards self-service. Finding the balance between maximising use without forcing people into using technologies they are uncomfortable using is seen as the key to success at Selwyn Library:

- I think we have taken the easy percent so the $20 \%$ who natively want to use it and we haven't forced anyone else on to it 
- I guess what you want to keep in mind too is that customer service is the main thing that we're focussed on and you kind of feel like you don't want to push anyone in to doing anything they are not comfortable with. 


\subsection{Customer questionnaire}

The final step in answering the research questions regarding the usage of the selfissue facilities at Selwyn Library was to analyse the data from the customer survey. As previously stated, these were placed in the self-issue enabled library branches of Selwyn Library for one month. The questions attempting to be answered were:

- Usage of self-issue

c. What factors may inhibit use of the self-issue facilities?

d. What can be done to improve usage of the self-issue facilities?

\section{- Customer perceptions of self-issue}

a. To what extent are different types of customers aware of the self-issue option?

b. What do customers think of self-issue in their library?

\subsubsection{Response rate}

In general the response rate for the customer questionnaire was disappointingly low; a total number of 59 completed questionnaire forms were collected from the participating libraries, though there was an unequal distribution from each library with the majority of questionnaires coming from two branches in particular. 


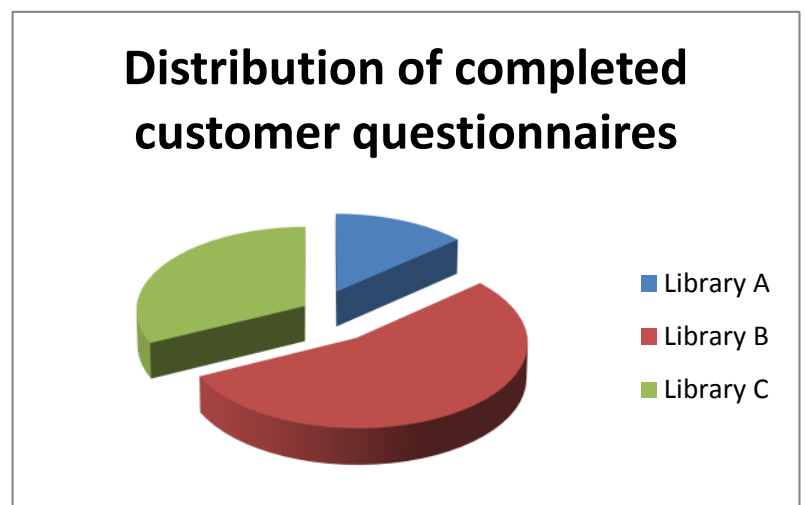

Chart 8 Distribution of completed questionnaires

It was considered that this rate of response did not constitute a large enough sample size to make radical assumptions or generalisations about the customer's use of or perceptions of self-issue at Selwyn Library, however it was decided that there was still much useful information to be gleaned from an analysis of the data.

\subsubsection{Age information}

\begin{tabular}{|l|r|}
\hline Age category & $\begin{array}{l}\text { Number of } \\
\text { responses }\end{array}$ \\
\hline Under 10 years & 3 \\
10 to 16 years & 10 \\
17 to 25 years & 0 \\
26 to 35 years & 9 \\
36 to 45 years & 13 \\
Over 46 years & 23 \\
Inconsistent & 1 \\
\hline Total & 59 \\
\hline \hline
\end{tabular}

Table 9 Number of respondents in each age category 


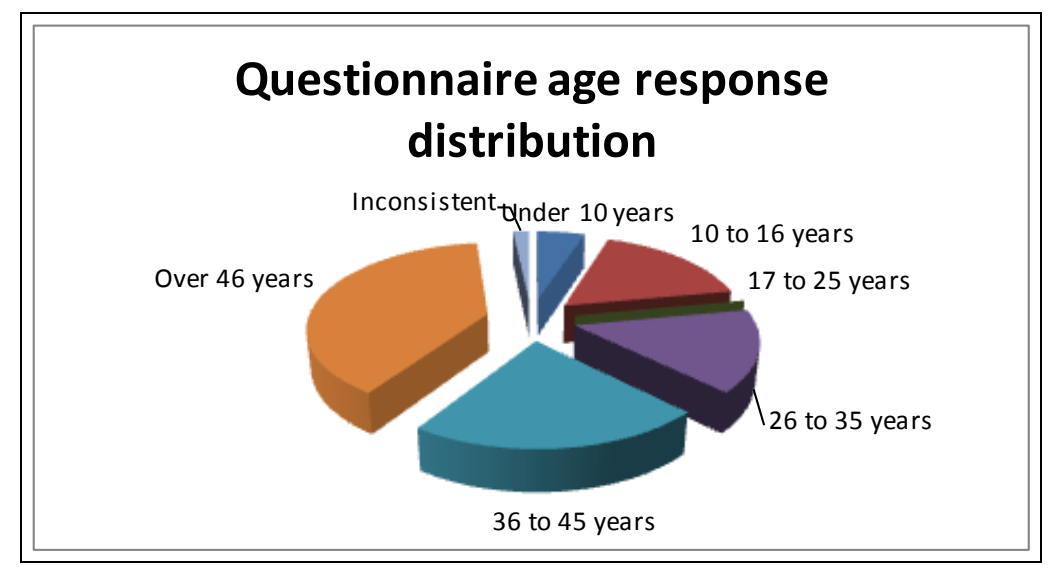

Chart 9 Questionnaire age response distribution

Analysis of the age information from the customer questionnaire showed that the majority of respondents were 36 year of age or older; in fact $61 \%$ of all those who completed the customer questionnaire fell into this category, with nearly two thirds of this number being comprised of those 'over 46 years'. It was observed by some library staff that not all of this group availed themselves of the offered incentive, indicating that their motivation for completing the questionnaire was not the free rental item. From the analysis it was also noted that the majority of optional extra comments came from these respondents.

- The other group to complete a significant number of questionnaires were the '10 to 16 years' category of respondents. It was noted that all of these completed questionnaires came from a single library branch and contained tick box or scaled answers only; there were no additional comments for this group. From follow-up checking it was found that this group were extremely enthusiastic in their wish to take advantage of the incentive being offered for completion of the questionnaire, despite not all being library members. While 
these responses are perhaps entirely legitimate, these revelations do suggest a shadow over their authenticity ( $\mathrm{J}$ Claridge; Leeston Librarian, personal communication 10 May 2013).

It was also noted that the young adult category, ' 17 to 25 years', had no respondents; this was not surprising since it is well documented/recognised that youth are often not enthusiastic users of public libraries (Mohammed \& Misilei, 2012, p. 2).

There were four questionnaires completed by children 'under 10 years': three of which appeared genuine and one that was deemed to be inconsistent. This questionnaire had stated that one of the reasons for using self-issue was 'my children like using it'. It was assumed that the respondent had mistakenly ticked the wrong age category and the rest of the data was entered into the spreadsheet, including some optional comments.

\subsubsection{Gender}

Analysis of the gender information from the customer questionnaire revealed some interesting results:

- questionnaire respondents were predominantly female

- of these nearly half were in the 'over 46 years' age category 
- there was a high percentage (19\%) of respondents who did not answer this question

\section{Questionnaire respondents - gender}

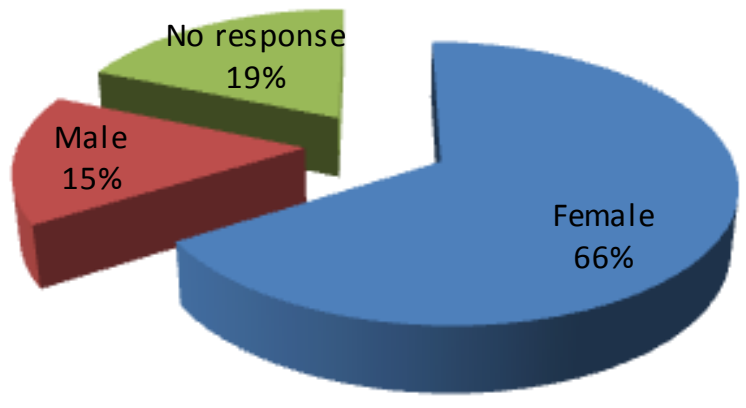

Chart 10 Questionnaire respondents gender distribution

It is perhaps unsurprising that the majority of respondents to the questionnaire were female as research has long indicated that "women use libraries more than men" (Smith, 1999., p. 310). Smith found in his 1999 study of public library use that when looking at particular aspects such as gender, education level and proportion of population (p. 310) little had changed in the previous 50 to 100 years (p. 302). While these findings present a convincing argument, there are some mitigating factors to consider here.

- Selwyn Library customer data does not include a category for gender, so statistics are unable to support the theory that more women use the library than men.

- It is possible that simply more females completed the questionnaire, and so are overrepresented in the results. 
- The high proportion of respondents who did not respond to the gender question must be taken into consideration. It is unclear whether the gender check box was overlooked by choice or because of a flaw in the questionnaire design; perhaps due to its proximity to the age information section it was merely overlooked.

\section{Questionnaire - Self-issue at Selwyn Library}

1. Please indicate your demographic information by checking one box in each of the following:

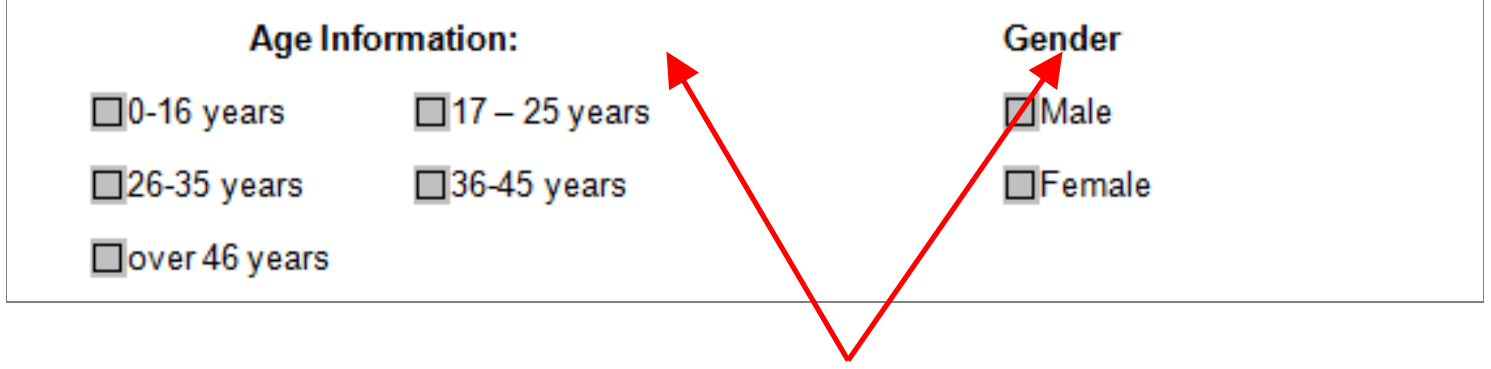

Figure 13 Showing the customer questionnaire Age Information and Gender sections proximity

Although in all likelihood library usage at Selwyn Library does reflect the findings of Smith's report and indeed the survey results indicate this is so, for these reasons the findings regarding the gender of respondents to the questionnaire must remain inconclusive.

\subsubsection{Library and self-issue usage}

Responses to the frequency of the library use section showed that the majority of respondents (around 92\%) visited their library at least monthly, and often on a 
weekly basis. These findings concur with those from the staff interviews regarding context.

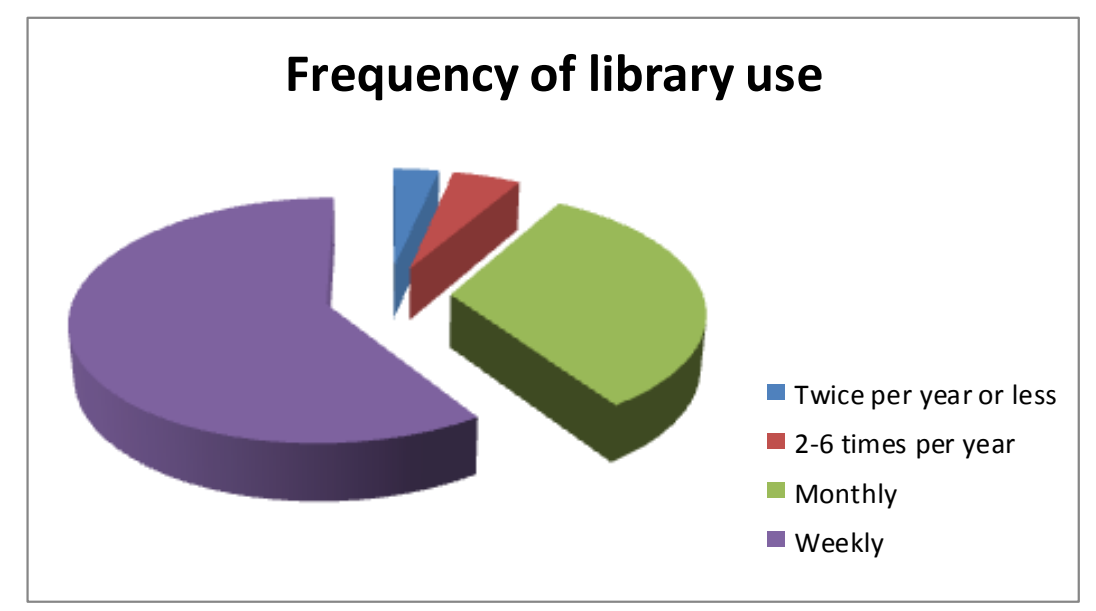

Chart 11 Frequency of library use

It was decided to further analyse this group to find out if they used the self-issue facility and, if so, to what extent.

- Twenty respondents (37\%) from this group indicated they never used the selfissue facility.

- Thirty-four respondents (63\%) signalled they used self-issue, of which fifteen said "as often as they could" (28\%).

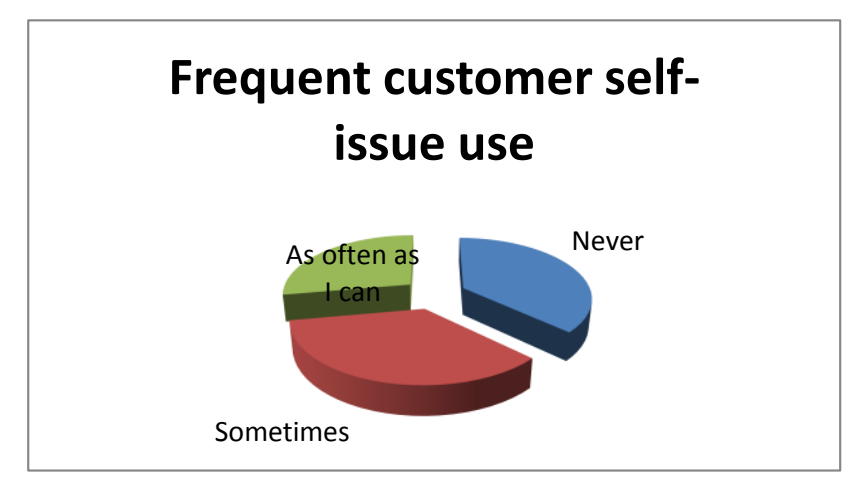


When compared with the previous circulation statistics these self-issue usage figures appear quite inflated with a bias towards self-issue use. The conclusion here must be that despite responses from some non-users of self-issue, it appears that selfissue users were more likely to complete the customer questionnaire. This is perhaps a predictable result, given that the questionnaire was often displayed at the self-issue facility and in many cases it was down to signage advertising the free rental item or direct library staff promotion to ensure questionnaires were noticed and/or completed at all.

\subsubsection{Reasons for self-issue use}

Respondents who indicated they used the self-issue facility were asked to state their reasons; they had a choice of options of which they were able to tick as many as were applicable, or they were invited to add their own reasons or comments.

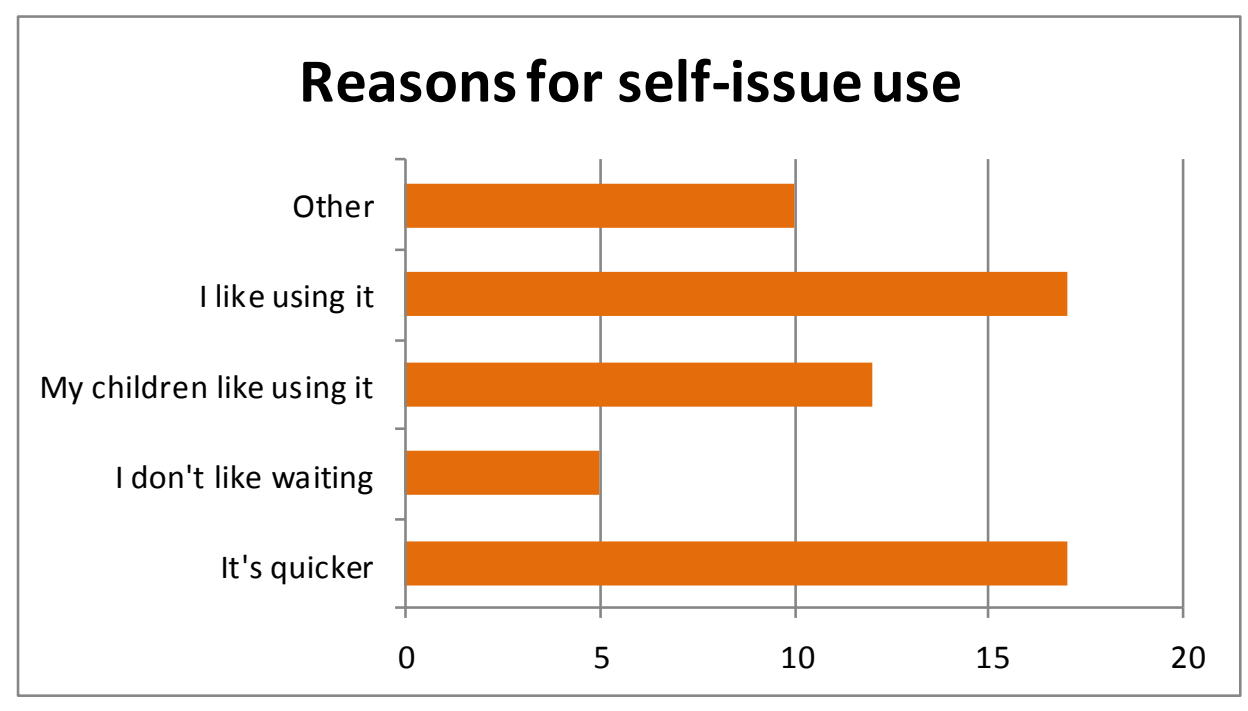

Chart 13 Reasons for self-issue use 
The results indicated that the two most influential factors for choosing to take the self-issue option were efficiency and that people liked using it. Another significant point was that customers chose to use it because their children enjoyed to do so. This finding is supported by staff who drew attention to how children could influence their caregivers to use self-issue:

- children come in with their mum and dads, they use it then and show their mums and dads how to use it. It's cool. They love making a beep happen and they are showing their mum and dads something that mum and dad don't know how to do.

Of the ten customers who offered further comments, the majority of reasons given indicated that customers were reluctant to interrupt staff they felt were busy. Comments included:

- I try not to inconvenience staff when they are busy doing other jobs away from the issues desk

- Leaves staff to get on with other jobs they are doing

- If staff are otherwise engaged

Some customers did indicate that self-issue empowered them. Comments included:

- More independent

- Because I am able to check myself how many items I have put through etc

- I like to do something for myself when library staff may be busy doing other things 
Other reasons given for using the self-issue facility were for convenience and time saving when there were queues at the issues desk, as well as simply preferring "human contact".

\subsubsection{Evaluation of self-issue experience}

Respondents who indicated they used the self-issue facility were asked to evaluate their experience of using it. Their opinions were asked regarding:

- Ease of use

- Position of the facility

- Reliability

- Availability of help

- Instructions for use

The findings for the Likert rating scale section were as follows:

\begin{tabular}{|l|r|r|r|r|r|}
\hline & $\begin{array}{r}\text { Strongly } \\
\text { agree }\end{array}$ & Agree & Neutral & Disagree & $\begin{array}{r}\text { Strongly } \\
\text { disagree }\end{array}$ \\
\hline Ease of use & 12 & 20 & 1 & 2 & 0 \\
Position of the facility & & & & & \\
$\quad$ Convenient & 13 & 17 & 4 & 0 & 0 \\
$\quad$ Enhances use & 9 & 21 & 3 & 1 & 0 \\
Reliability & 5 & 20 & 3 & 5 & 1 \\
Availability of help & 15 & 17 & 1 & 1 & 0 \\
Instructions & & & & & 0 \\
$\quad$ Useful & 12 & 17 & 4 & 1 & 0 \\
Helpful & 14 & 16 & 2 & 1 & \\
\hline
\end{tabular}




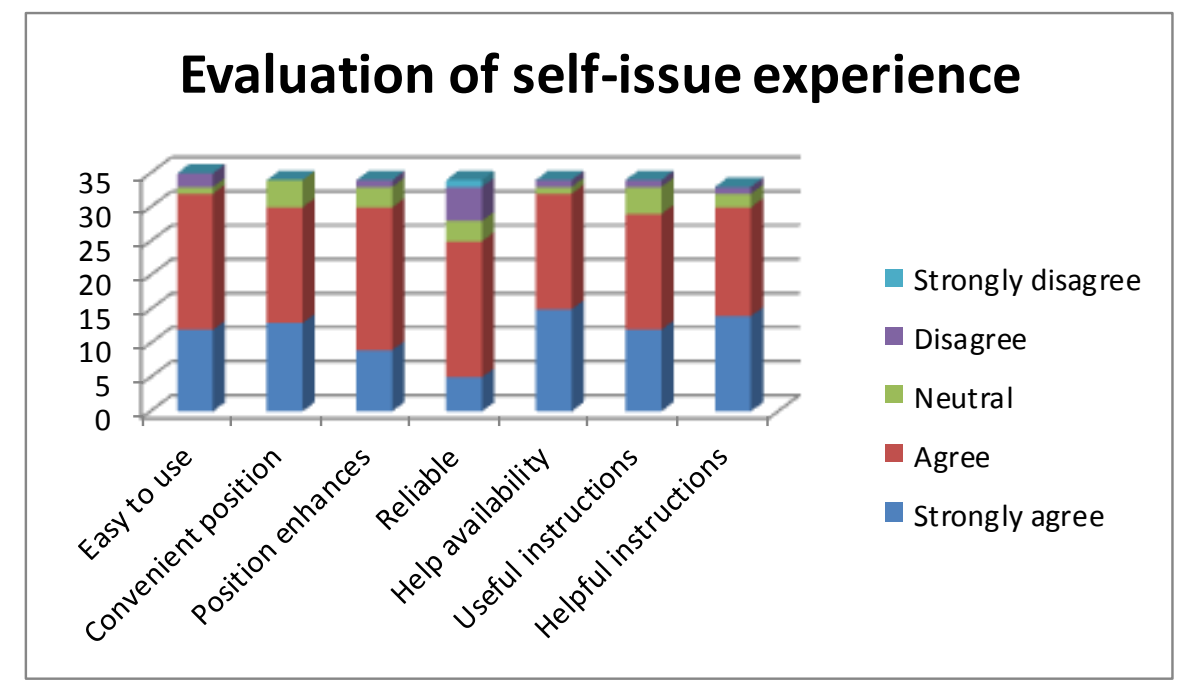

Chart 14 Evaluation of self-issue experience

The main thing that stands out with these statistics is that they are of an overwhelmingly positive nature:

\begin{tabular}{|l|r|r|}
\hline & $\begin{array}{l}\text { Positive } \\
\text { response }\end{array}$ & $\begin{array}{l}\text { Negative } \\
\text { response }\end{array}$ \\
\hline Ease of use & $91 \%$ & $6 \%$ \\
Convition of the facility & & \\
Enhances use & $88 \%$ & $0 \%$ \\
Reliability & $74 \%$ & $3 \%$ \\
Availability of help & $94 \%$ & $18 \%$ \\
Instructions & & $3 \%$ \\
Useful & $85 \%$ & $3 \%$ \\
Helpful & $91 \%$ & $3 \%$ \\
\hline
\end{tabular}

Table 11 Evaluation of self-issue experience - positive and negative responses

This is a very encouraging result for self-issue at Selwyn Library and gives an insight into how customers, who are currently using the facility, feel about it. In all the completed questionnaires there was only one 'strongly disagree' response. This was 
regarding the reliability of the self-issue facility, which got the highest negativity in the evaluation of customer experience.

Respondents were also invited to contribute further comments regarding their experiences of self-issue but, as they tended to be made in conjunction with the 'suggestion for improvement' section, combined findings of these two sections will follow.

\subsubsection{Suggestions for improvement}

Respondents were invited to offer their suggestions for any improvements that could be made to the self-issue facility in order to enhance their experience of using it. There was found to be some overlap between this section and the previous one asking for further comments regarding customer's experience of using the self-issue facilities. To avoid any data being omitted, findings for these sections have been presented together. 


\section{Combined results for comments regarding experience and suggestions for improvement}

\begin{tabular}{|c|c|c|c|}
\hline $\begin{array}{l}\text { Coded theme from } \\
\text { coding schedule }\end{array}$ & $\begin{array}{l}\text { Comments } \\
\text { regarding } \\
\text { experience of } \\
\text { using self-issue }\end{array}$ & $\begin{array}{c}\begin{array}{c}\text { Suggestions } \\
\text { for } \\
\text { improvement }\end{array} \\
\text { impor }\end{array}$ & Totals \\
\hline Availability of help & 1 & & 1 \\
\hline Success factors & & & 0 \\
\hline Staff & 1 & & 1 \\
\hline Awareness & 1 & & 1 \\
\hline \multicolumn{4}{|l|}{ Inhibiting factors } \\
\hline Size/space & 2 & 4 & 6 \\
\hline Touch screen & 2 & 2 & 4 \\
\hline Technological & 4 & 1 & 5 \\
\hline Position location & 1 & & 1 \\
\hline Usability/interface & 1 & 2 & 3 \\
\hline Reliability & 2 & 2 & 4 \\
\hline
\end{tabular}

Table 12 Response numbers for experience and improvement

The main comments and suggestions for improvement centred round having more space available around the self-issue facility; staff interview findings also emphasised this point. Customer suggestions included:

- Less clutter

- a slightly larger table

- More desk space...the scanner could be slightly higher

- I get quite a few books out at a time, there's not much space to rest my pile of books as I scan them one by one

Other comments put forward by respondents were regarding: 
Glitches with the technology: this was a potential inhibiting factor mentioned by a relatively high number of respondents:

- It is often too slow to load the first book - sometimes you're unsure its working

- "If often block users who have overdues"

- reduce the paper receipt...such a waste

- unable to print an updated list of all books currently issued

- the technology needs to be simple to use and intuitive. It looks like old/used scanners are used - they should be fixed/new ones that entice you to use it

Reliability: Several respondents were negative regarding the reliability of the selfissue facility:

- Too often not working. Slower than librarians!

- Reliable - not always

○ ...doesn't always work

Staff also reported this to be an issue, especially if there was a problem during a customer's first use of the facility which should be positive (Morris, Thornley, \& Snudden, 2001, p. 15).

Touch Screen: In line with what many staff mentioned, several respondents specifically indicated that they either expected a touch screen or felt that a touch screen would improve the self-issue facilities: 
- I keep thinking (incorrectly) the screen is a touch screen

- It would be much better if there was a "touch screen" as people are used to these and don't know they have to use the mouse

Usability/interface: A few respondents indicated problems with the usability and/or interface of the self-issue facility

- It is often slow to load the first book - sometimes you're unsure if its working

- Often have trouble scanning books

- The self-service kiosk needs correct furniture... it looks unprofessional/afterthought - increase the use and you could decrease the staff numbers?

Position/location and awareness: Two comments indicated that customers did not always know that the self-issue option was available to them at Selwyn Library branches. This was backed up by the number of non-self-issue users who stated this as the reason for their non-use; a view also supported by staff data:

- Not sure if all people notice it as it's on the way out of the library

- If self-issue was in front of the issues desk I would remember to use it more often

Success factors - availability of help

One respondent cited that staff assistance had been instrumental in helping her get to grips with self-issue 
- I was dubious of using it as I'm "old school" but with the help of your friendly staff I'm now a convert and will use it regularly

A total of eighteen customers recorded additional comments either regarding their experience of self-issue use and/or offered suggestions they felt would improve the self-issue facility; this constituted approximately $30 \%$ of respondents.

\subsubsection{Reasons for not using the self-issue facility}

Respondents who indicated they 'never' used the self-issue facility were asked to state their reasons; they had a choice of options of which they were able to tick as many as were applicable, or they were invited to add their own reasons or comments.

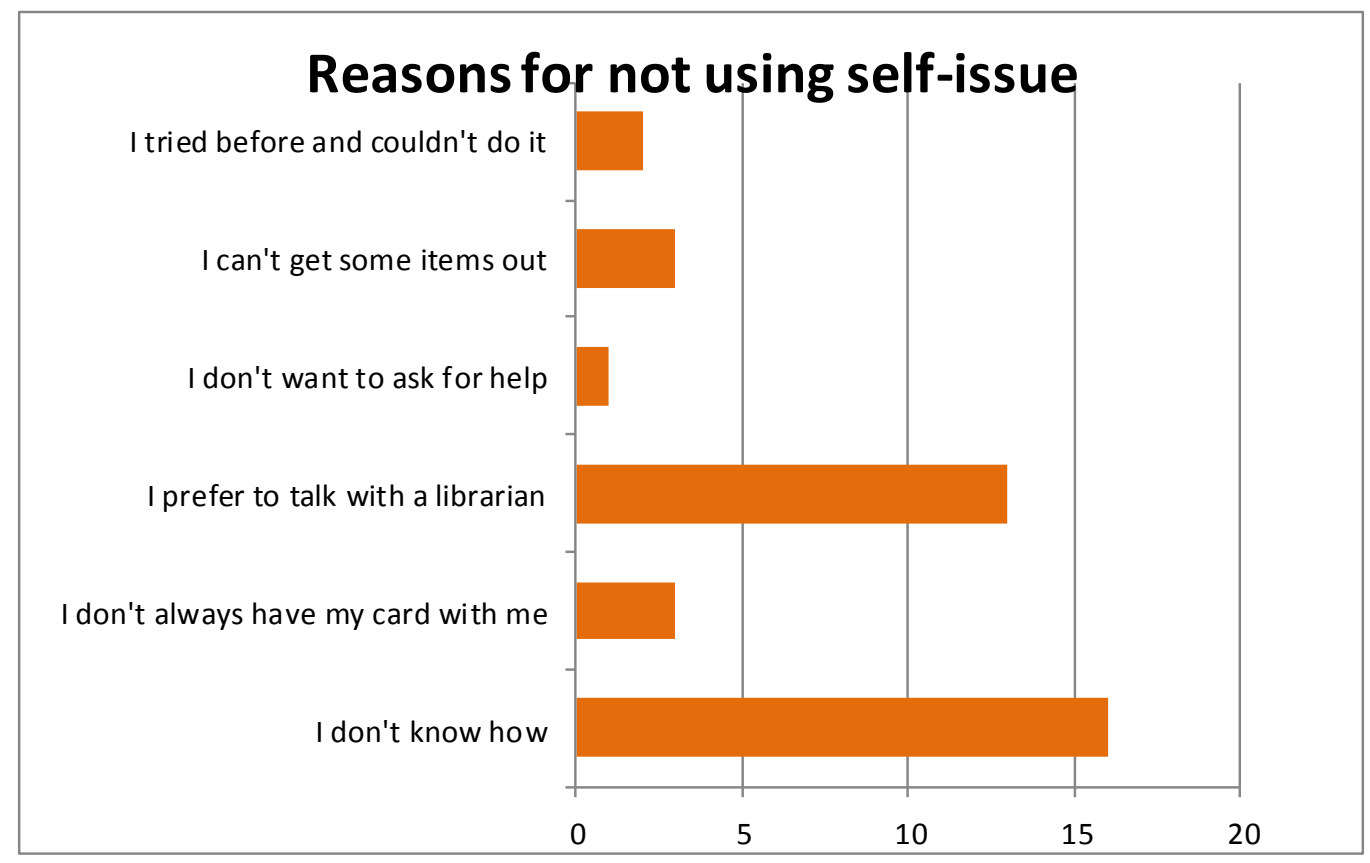

Chart 15 Reasons for not using self-issue distribution 
Several reasons received no responses:

- I don't trust it

- I don't like the position of it in the library

- I don't like computers

- It's too complicated

From the graph it is clear that there were two main reasons put forward by respondents explaining why they did not use the self-issue facility:

- They do not know how to use it

- They prefer to talk with a librarian

Many studies have found that if customers are unsure or afraid of new technology they will tend towards what they know (Holt, Larsen, \& van Vlimmeren, 2002, p. 59). This view was supported by staff comments:

- like any new technology if it is new to them, it's probably that fear of the unknown and not being able to use it properly or make a mistake or needing help half way through, so I think maybe that's a little bit of a barrier

It is significant that exactly half of the responses regarding the reasons for not using self-issue were centred around ignorance of how to use it. Additionally, a couple of respondents indicated they had tried it but had been unable to successfully complete their own issues.

Other reasons for not using the self-issue pertained to technicalities, such as not having their card with them or being unable to get "pay-for" items out. 
Respondents were also invited to contribute further explanation of why they did not use self-issue; eight customers took advantage of this opportunity. Over half of the comments indicated a complete lack of awareness that such a facility existed in the library:

- I didn't know it existed

- I have used self-issue at the Canterbury University Library - hadn't realised that [branch] had that facility

- Didn't know it was there!

These findings are supported by those of staff who indicated they felt customers may not realise that self-issue facilities existed in the library because it was not immediately obvious what they were.

Other customers cited preference to talk to a librarian, or not having their card with them as their reason for avoiding using the self-issue facility. Another respondent indicated that the position/location of the self-issue was a factor in their decision not to make use of it:

- Seems to be a high traffic area making it hard for people to get past. Close to children's area so encourages them to fiddle with it (may get broken) 


\subsubsection{Extra issues with the questionnaire}

As previously noted an apparent inconsistency appeared in relation to the gender check box whereby several customers did not complete this section. It is unclear whether customers chose not to respond to this section or simply missed it.

Two respondents answered both the reasons for using self-issue and the reasons for not using it. An assumption was made that they were referring to why they would or wouldn't use it on particular occasion, and so both sets of answers were recorded in the data.

A couple of respondents marked points between the markers on the Likert scale, in these cases the closest reading was entered in the data.

Two questionnaires contained two branches as the "library branch I would most likely visit". The branch where they completed the questionnaire was taken, but ultimately this section was deemed as not important/relevant due to the decision not to report this data in the findings. 


\section{Summary of Findings/Conclusion}

This research aimed to explore how well self-issue fits the context of the small New Zealand public library by studying the usage and perceptions of it at the branches of one such library. A mixture of methods was employed to ensure a balanced perspective; statistics were analysed, staff were interviewed and customers were surveyed to answer a series of research questions.

When considering the extent to which the self-issue facilities are used, and by whom a number of statistics were analysed. From this analysis it was found that there were distinct differences between self-issue usages at the three Selwyn library branches who offered it as an option, with Rolleston consistently showing the highest level. Though this followed the trend of general library statistics, the study compared the percentage of self-issue as part of the total issues per branch. There was also variation in who was using the self-issue facilities at each branch: At Darfield there were more Adult card holders choosing self-issue whereas the opposite was true of the Leeston branch, with Junior card types preferring self-issue. Rolleston statistics revealed a more evenly balanced distribution between the two, but with a weighting towards Junior card type.

Overall the statistical analysis showed that the times of self-issue usage did generally mirror the daily library issues, albeit as a relatively small percentage: averages ranged between nearly six percent for Leeston to nearly twenty percent for Rolleston. 
Ascertaining how staff feel about self-issue involved conducting a series of in-depth interviews with the various levels of staff, which revealed a number of points. There was some inconsistency between the views of frontline staff and management. Despite all frontline staff comments being positive towards the concept of self-issue, some of the senior staff felt there may have been some trepidation about its implementation. There also appeared to be some ambivalence towards promotion of self-issue; it was not really perceived as a management priority or definite strategy. Successful self-service implementation needs the articulation of clear objectives and outcomes (Brady, Kearsey, Monigatti, Sindel, \& Tsui-Po, 2009-2010, p. 19), but evidence of this was not found here.

The study also detected an air of uncertainty resulting from a disparity picked up between the management view of staff training, and the frontline staff's own view. Many felt there had been no formal process of training or preparation for what the expectations were for self-issue. Therefore they seemed to have little investment in it because they had a general lack of confidence in what to do if/when problems arose. This was seen to be a possible barrier to self-issue success because staff attitudes have been consistently recognised as the factor with the highest potential to influence customer uptake of self-service technology (Zeiher, 2006, p. 7); a point perhaps even more pertinent in small libraries where there are often very close relationships between staff and customers. Since reliability of the self-issue was highlighted as a contentious issue with both staff and customers, staff confidence with both using and troubleshooting problems is crucial. A clear management objective would outline where self-issue use is expected to go and how that is to be 
achieved; though staff are generally positive about self-issue, they could be more effective at promoting it if they felt more confident with the technology.

Other factors affecting the uptake of self-issue at Selwyn Library were location and space round the facility, knowing it was there and technological glitches. There were many of these that inhibited use, such as lack of room to stack books while issuing, being unable to get DVDs without going to the issues desk for lock removal, or being unable to use the facility if overdues or outstanding charges are on the customer's account. It was felt that some of these inhibiting factors could be removed by changing the location and/or equipment of the self-issue facilities; the addition of touch screens was favoured by both staff and customers.

When asked about changes to their role resulting from self-issue many staff reported they had noticed little difference. While theoretically one of the benefits for staff is a reduction in repetitive tasks and the chance to pursue other activities, the reality may be more that the addition of self-service technology has allowed the library to function more efficiently with their existing low staff numbers, especially in view of the burgeoning population in Selwyn. It is likely there will always be a disparity between staffing numbers and work flow in the library; therefore maximising selfissue usage is both a desirable and practical progression.

Customers offered a range of perceptions when surveyed about the self-issue options available to them. For some it was the first they had heard of it, while for 
others it was seen as a convenient, time saving option. However there was a significant percentage of customers who stated that they preferred to talk with a librarian rather than use the self-issue facility. This uniquely close relationship is recognised as a characteristic of small rural public libraries in New Zealand.

The research found that the small New Zealand public library context also offered some specific opportunities that may be unlikely to be available to larger institutions. Flexibility was a key factor; the size of the library ensured greater flexibility and choice. At Selwyn Library self-issue was introduced as a low key trial to gauge customer interest and uptake. This strategy of try-and-see has been able to work here in part because of the size of Selwyn Library; they have been able to bypass potentially prohibitive, expensive security technologies, and the streamlined management structure means changes are more straightforward to implement. The ability to use do-it-yourself-technologies such as the " couple of old computer screens, some ratty mice ... some new printers, and really old computers ... just cobbled together" (description of self-issue at Selwyn, G Walker, personal communication, 28 March 2013) has allowed this small public library to offer selfservice without having to find the budget for an expensive set up.

For all its benefits and challenges, the option of self-issue offers one more way that libraries can provide the best customer service they can. 


\subsection{Limitations and Delimitations}

All efforts have been made to ensure the integrity of this research; however the author acknowledges the following potential limitations:

- Sample size/selection

- Research is based on one district and the particular situation that exists there may not be applicable to all rural public libraries in New Zealand.

- Number of responses to the customer questionnaire

- Potential for bias, or reluctance to be completely open in the answers from staff

- Statistics for the last few years in Selwyn may not be completely typical, could have been influenced/skewed by the earthquakes in Canterbury during 2010 and 2011.

- Issues statistics are taken from circulation system reports and will, therefore be limited by the type and reliability of these reports

- Selwyn Library has only had self-issue in the three branches for just over one year, so data is limited to this relatively short period. 


\subsection{Future research}

Due to the overall small number of self-issues, it is difficult to recognise trends or patterns in the data because potentially one customer issuing a reasonable number of items is able to skew the results. In order to get a better understanding of what is happening with self-issue at Selwyn Library, a further study of self-issue statistics is needed over a longer period.

One option would be to implement some of the suggested improvements at all or some of the branches; for example change the position or set up of the facility.

Another possibility would be a sustained period of promotion both in the library and on the library website, teamed up with having a staff member assigned to help people with self-issue.

Monitoring the results of either or both of these changes at different branches would allow usage statistics to be analysed to see what changes had the greatest impact on self-issue usage. 


\section{Appendix I - Participant Information Sheet - Staff}

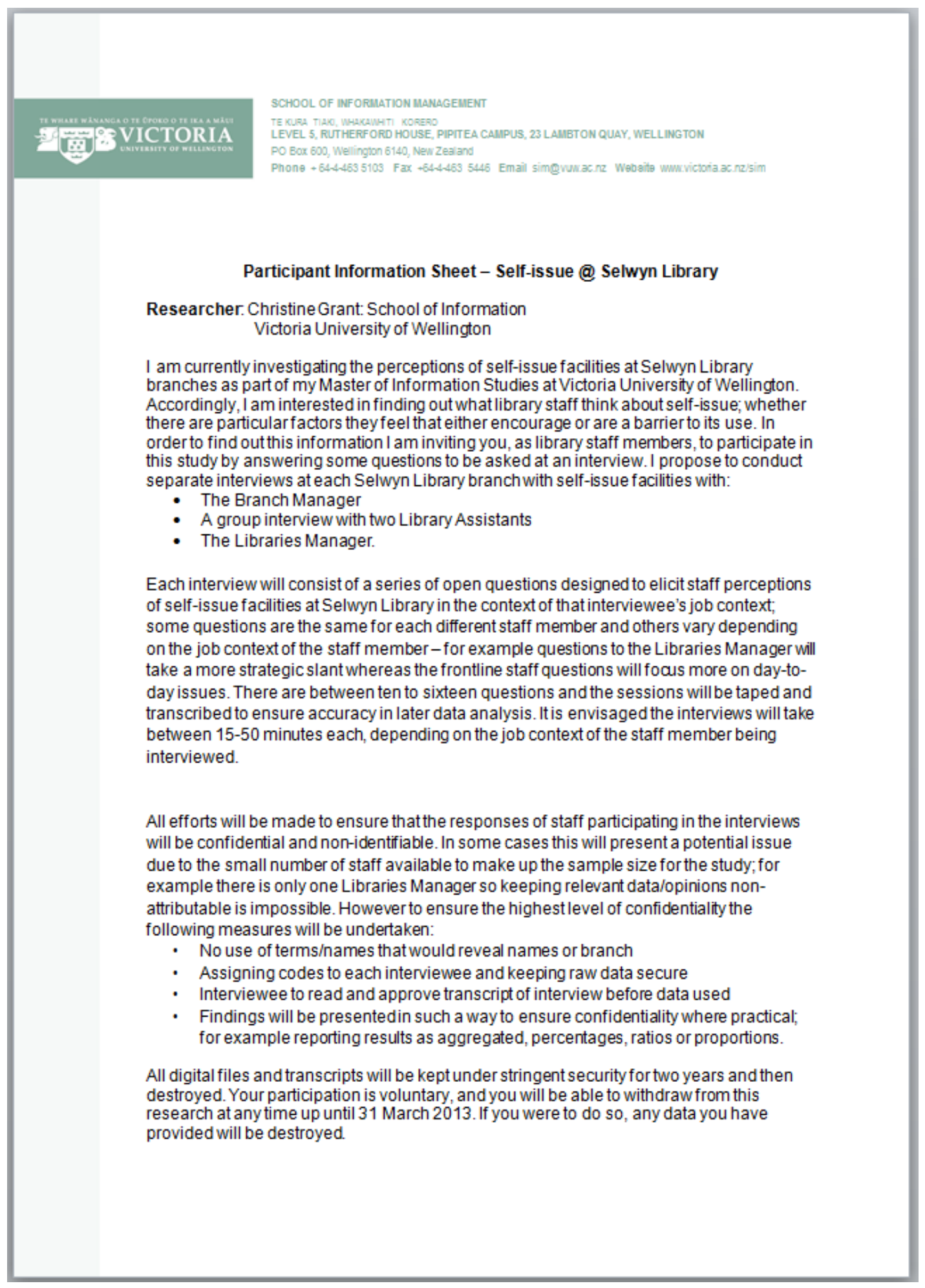


Your responses will form part of the findings for my research projed and will be collated in a written report which will ultimately be depositedin the Victoria University institutional repository. For those who are interested, findings from the research will be made available in library branches for one month after the study has been completed.

This data is being collected for research purposes and to improve library services to customers. Consent for use of your answers in this research will be obtained from the attached consent form. The University requires that ethics approval be obtained for research involving human participants.

If you wish to know more about this research please feelfree to contact me:

Christine Grant on grantchri@myvuw.ac.nz

Or my supervisor:

Dr Brenda Chawner on brenda. chawner@vuw.ac.nz

School of Information Management at Victoria University 


\section{Appendix II -Consent Sheet - General Staff}

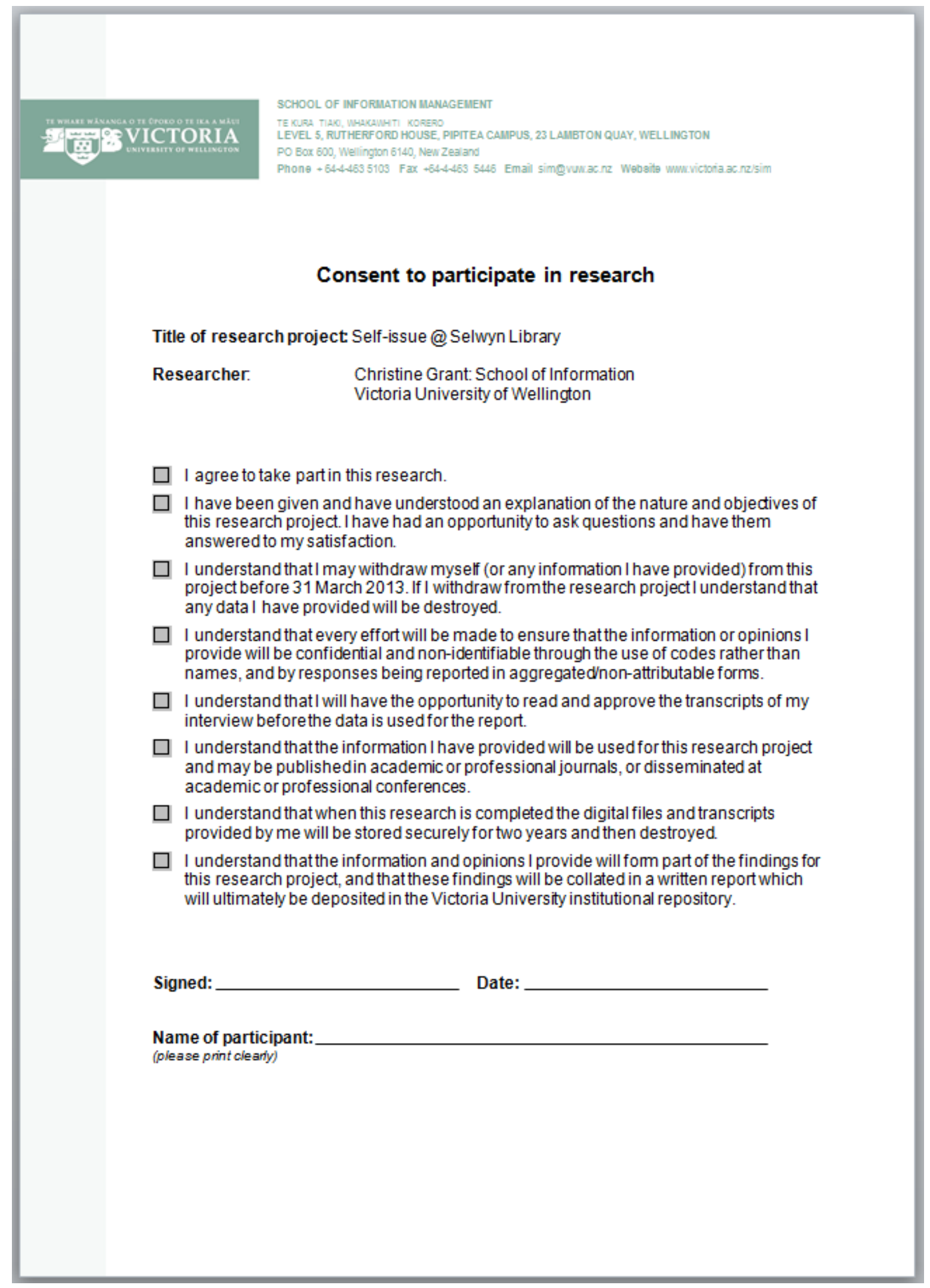




\section{Appendix III - Consent Sheet - Libraries Manager}

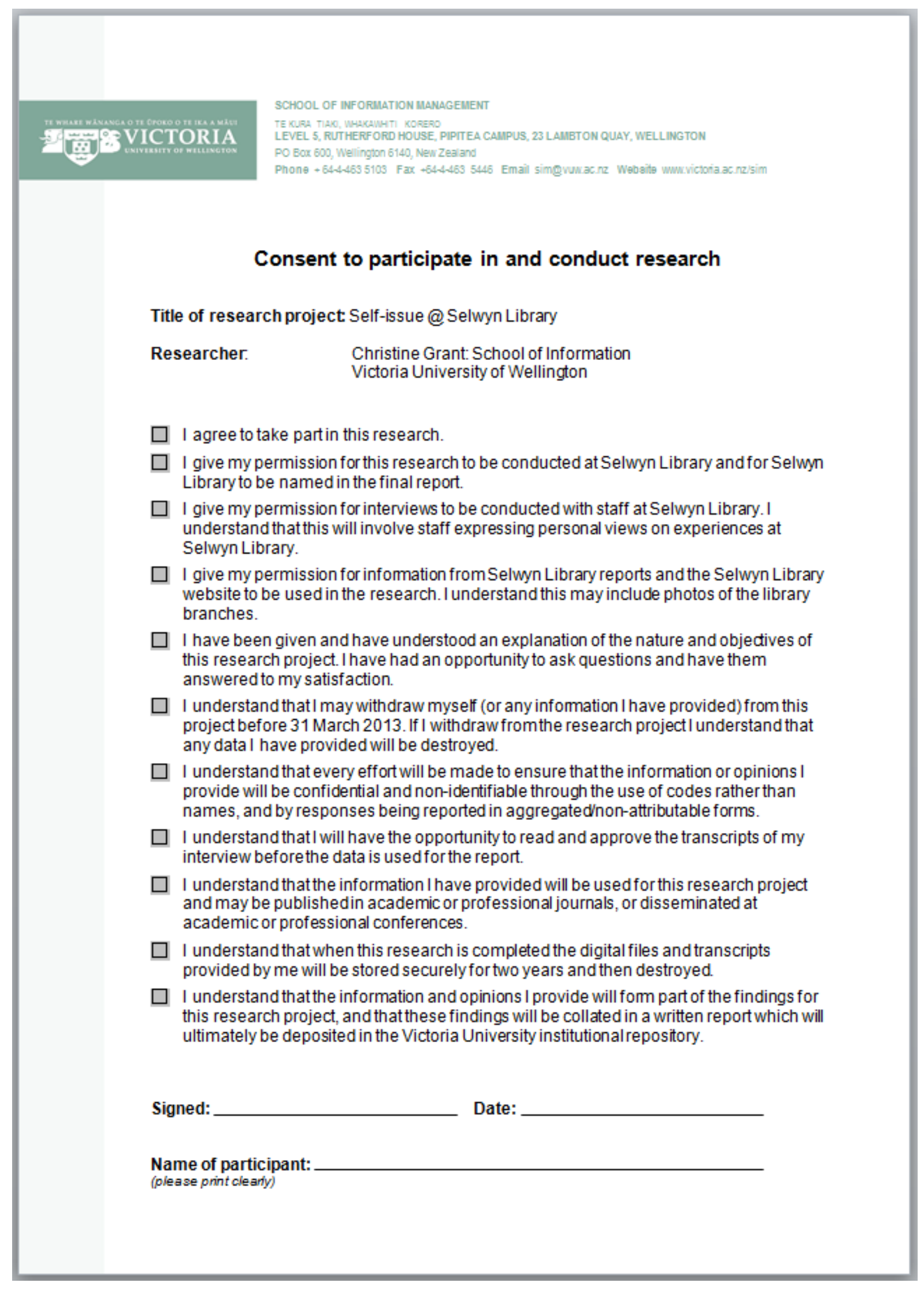




\section{Appendix IV - Participant Information Sheet - Customers}

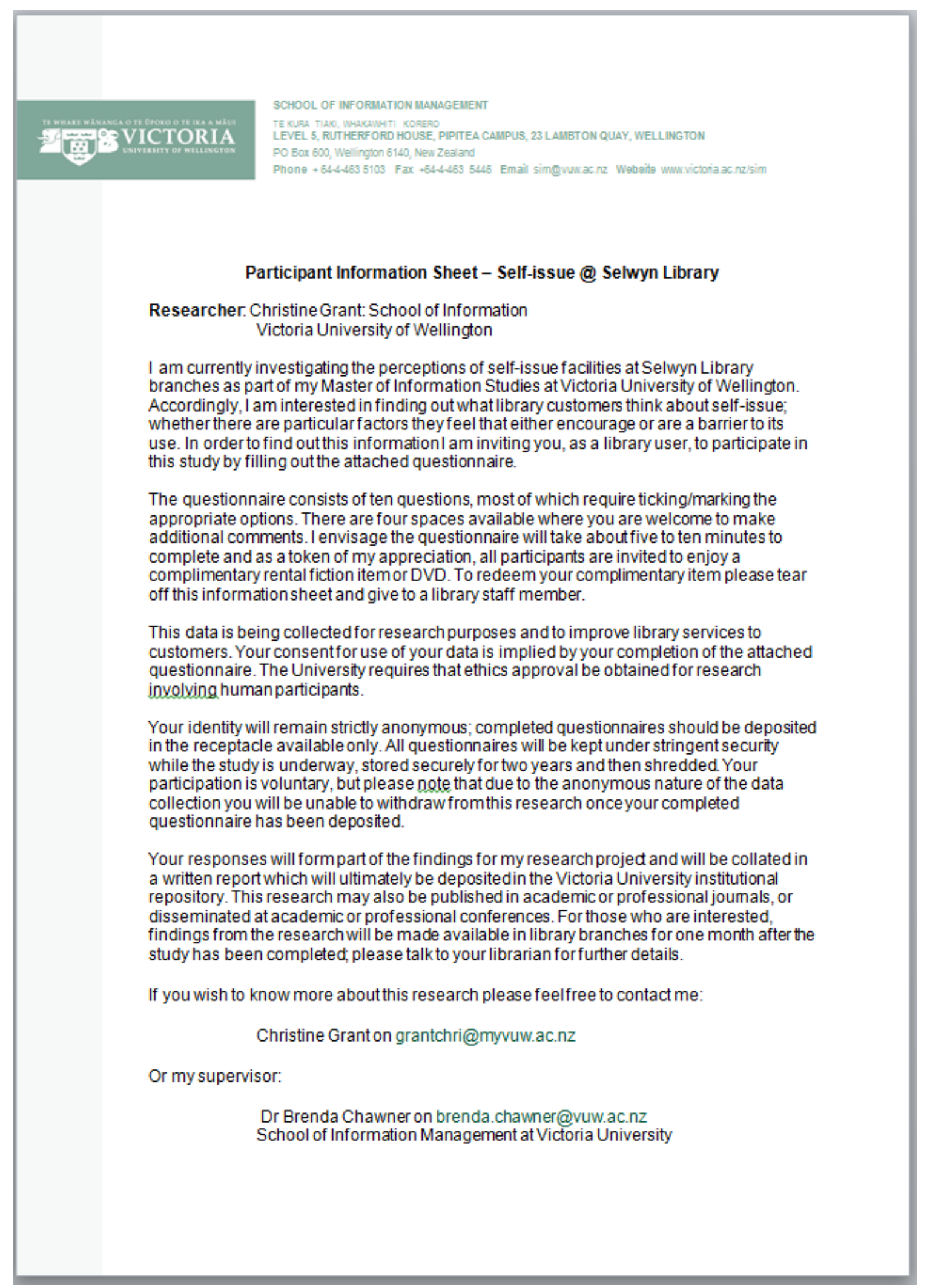




\section{Appendix V - Interview Questions - Libraries Manager}

1. Can you briefly outline the self-issue facilities available at Selwyn Library branches?

2. Why did you choose to implement self-issue at Selwyn Library branches?

3. How did you prepare for implementation?

4. What benefits were you expecting from self-issue implementation and have they been realised?

5. What were the challenges you faced in introducing self-issue?

6. Were there any unexpected consequences resulting from the introduction of self-issue?

7. What things are working well with self-issue?

8. What improvements could be made to self-issue?

9. What about long term strategy - what does self-issue hold for the future at Selwyn Library?

10. How has self-issue affected current Selwyn Library policy? Will this necessitate change in the future and, if so, please explain?

11. As the manager of Selwyn Library, how well do you think self-service technologies fit within the context of the small rural public library? 
12. In your opinion, are there any particular factors unique to small rural public libraries that influence/affect use of self-issue?

13. Much of the current literature about self-service technologies in libraries considers the issue of customer resistance, one article claims:

People only accepted self-service if it was clearly advantageous and if they practically had no choice. Although no one was going to force patrons to check out their own materials, the plan was to make it obvious that self-check was faster and easier to use.

What is your opinion on this viewpoint?

14. Much of the research also discusses various outcomes resulting from the successful implementation of self-service technologies in libraries, particularly the changing roles of staff due to less routine, repetitive tasks that allow for the addition of community tailored value-added services - what is your opinion on this view in the context of Selwyn Library? 


\section{Appendix VI - Interview Questions - Branch managers}

1. What things are working well with self-issue?

2. What improvements could be made to self-issue - are there any particular issues arising regarding self-issue?

3. How do you think customers feel about the self-issue facilities at your branch?

4. How well do you think self-service technologies are accepted by a rural population

5. What discourages customers from using the self-issue option at your branch?

6. What would encourage customers use the self-issue option at your branch?

7. How do you think your staff feel about self-issue in the library?

8. Do you think self-issue is seen as a threat by staff?

9. Some of the current literature about self-service technologies links them to the reduction of occupational related injuries; what is your opinion of this view?

10. Do you think self-issue is seen as a threat by customers?

11. Is self-issue actively encouraged by staff in the library?

12. What have been the implications in terms of task management or allocation since the introduction of self-issue? 
13. Do you feel adequate training and support has been given regarding selfissue?

14. How do customers react if the self-issue facility at your branch is unavailable?

15. Is a register kept of any problem $\mathrm{s}$ or issues that arise with self-issue facility For example when it is out of service, for how long, why,

16. Is there a troubleshooting procedure in place - what happens if there is a problem with the self-issue equipment? 


\section{Appendix VII - Interview Questions - Frontline staff}

1. How do you feel about the self-issue facility in the library?

2. What have been the implications in terms of changes to your role due to the introduction of self-issue?

3. Do you see self-issue as a threat to your position?

4. Do you actively encourage the use of the self-issue facility in the library?

5. Do you feel adequate training and support has been given regarding selfissue?

6. In your opinion what things are working well with self-issue?

7. In your opinion what improvements could be made to self-issue?

8. How do you think customers feel about the self-issue facility?

9. What do you think discourages customers from using self-issue?

10. In your opinion what would encourage customers to use self-issue?

11. How do customers react if the self-issue facility is unavailable? 


\section{Appendix VIII - Customer Survey Questionnaire}

\section{Questionnaire - Self-issue at Selwyn Library}

1. Please indicate your demographic information by checking one box in each of the following:

Age Information:

$\square 0-16$ years

$\square 17-25$ years

$\square 26-35$ years

$\square 36-45$ years

$\square$ oxer 46 years

Please check the box that most closely indicates your answer for each of the following:

2. I use the library:

$\square$ Hardly ever

$\square$ couple of times a year $\square$ monthly

$\square$ weekly

3. The library branch I would most likely visit is:
$\square$ Rolleston
$\square$ Darfield
$\square$ Leeston
$\square$ Lincoln

4. I use the self-issue facility:
$\square$ Never
$\square$ Sometimes
$\square$ All the time

If you answered Never for question 4 please skip the next 3 questions and go to question 8 .

5. The reasons I use the self-issue facility are: (please tick as many as applicable)

$\square$ It's quicker $\quad \square$ I don't like waiting $\square$ My children like using it $\square$ l like using it

Other (please add any reasons that have not been mentioned in the list): 
6. Please evaluate your experience of using the self-issue facility by marking your opinion on the scale for the following:

The self-issue facility is easy to use

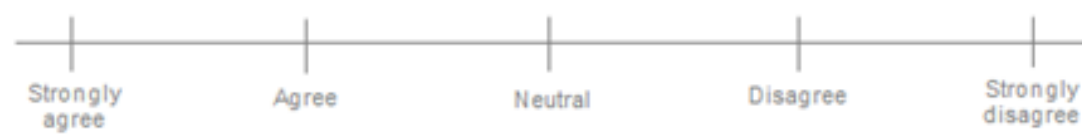

The position of the self-issue facility is convenient

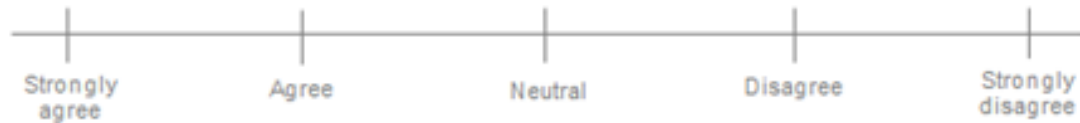

The position of the self-issue facility enhances its use

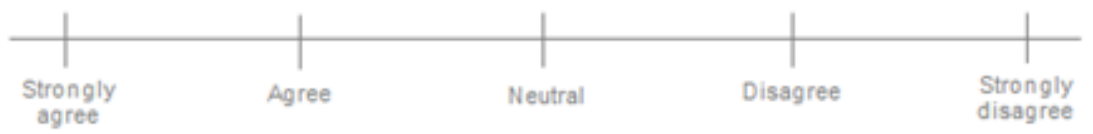

The self-issue facility is reliable

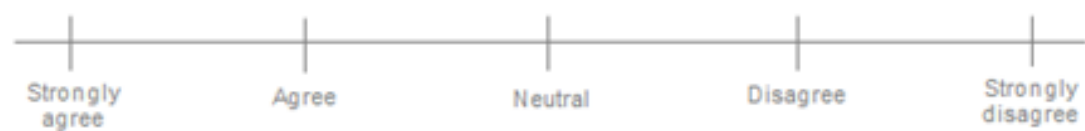

There is always help available for the self-issue facility

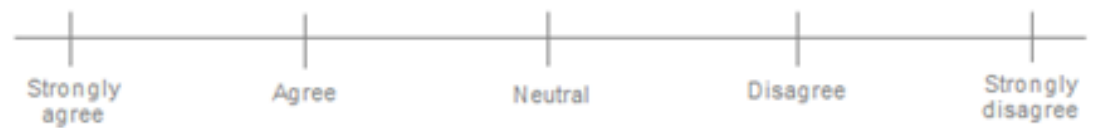

The instructions for using the self-issue facility are useful

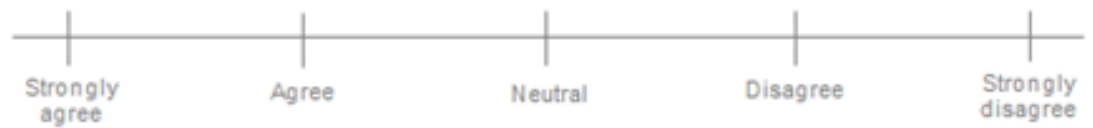

The instructions for using the self-issue facility are helpful

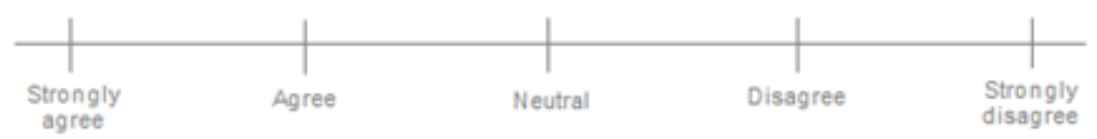

Other (please add any other comments you feel would be useful): 
7. Suggestions for improvement - please add anything you feel may enhance your experience of using the self-issue facility

If you answered Never to question 4, please answer the following:

8. The reasons I do not use the self-issue facility are: (please tick as many as applicable)
$\square$ lt's too complicated
$\square$ I don't trust it
$\square$ I don't know how
$\square$ I don't like the position of it in the library
I don't always have my card with me
I don't like computers
$\square$ I prefer to talk with a librarian
I can't get some items out, like DVD's
$\square$ I don't want to ask for help
I tried before and couldn't do it

Other (please add any reasons that have not been mentioned in the list):

Once again, thank you very much for taking part in this survey, your time is really appreciated.

Please ensure you have ticked the consent box at the top of the form.

Enjoy your complimentary DVD or rental fiction item. 


\section{Appendix IX - Self-issue by time period data}
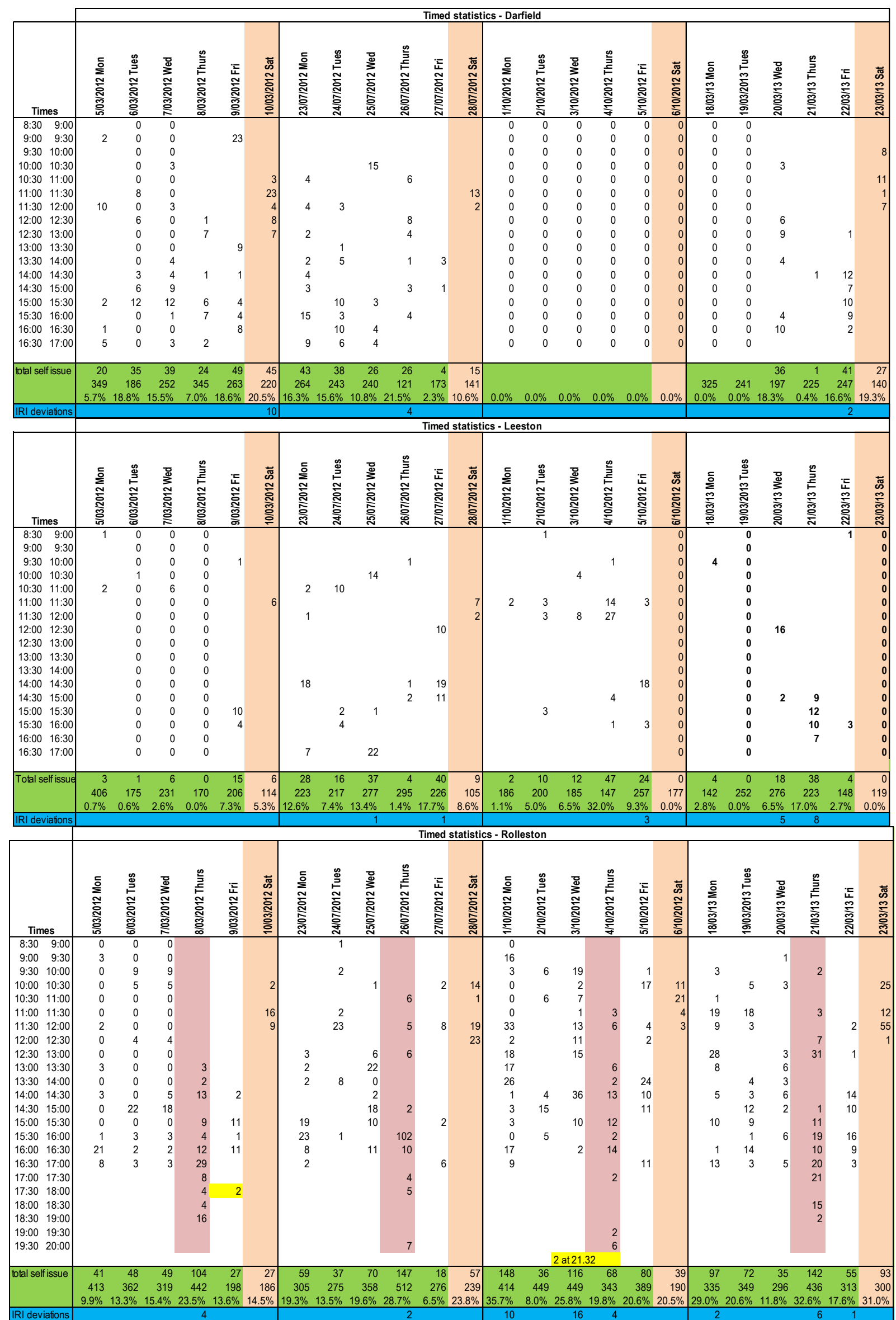


\section{Appendix X - Customer Survey Questionnaire Data}

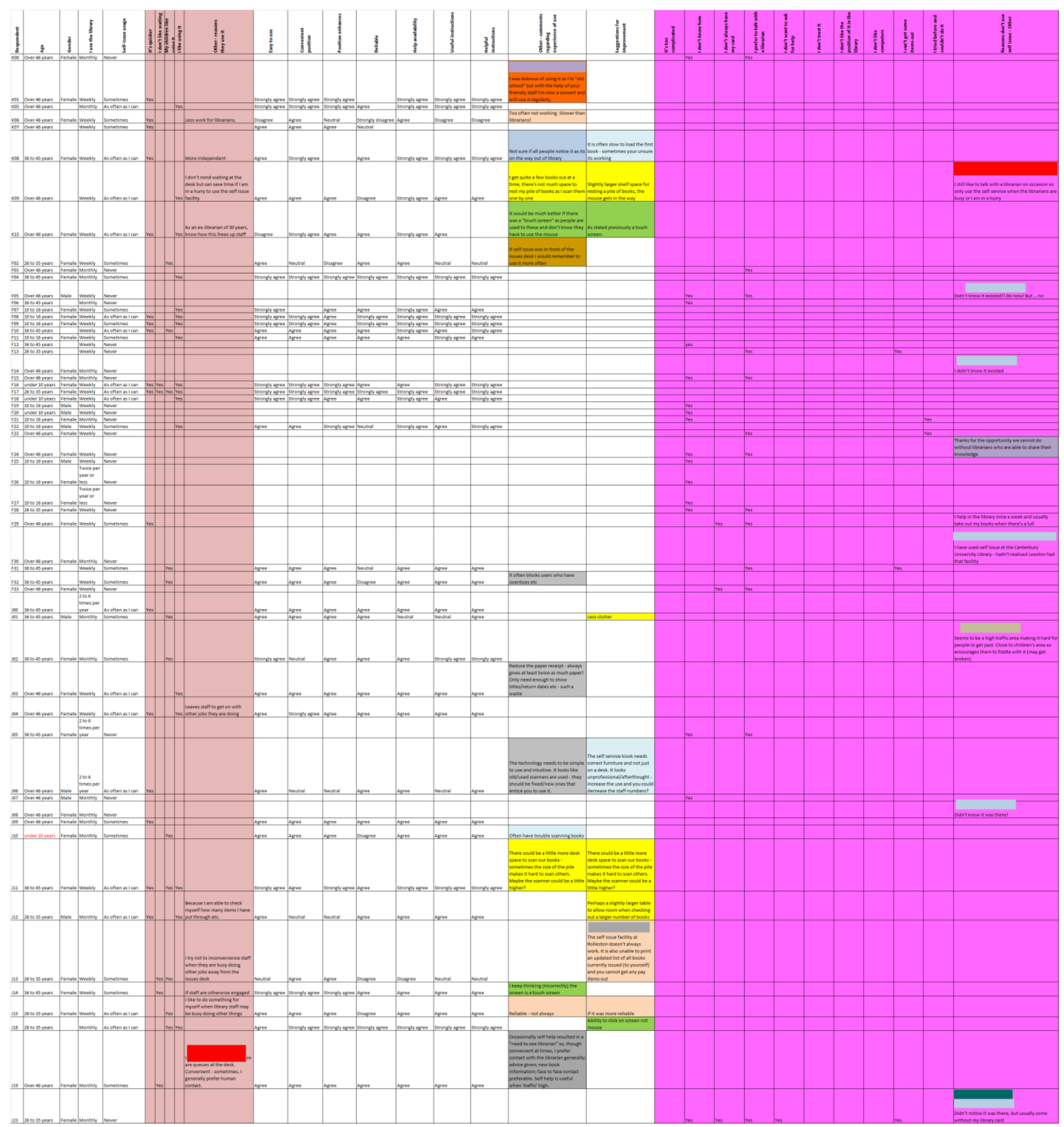




\section{Works Cited}

Association of Public Library Managers Inc. (2012). Public Libraries of New Zealand: A Strategic Framework 2012-2017. Retrieved from http://www.publiclibrariesofnewzealand.org.nz/strategicframework on 15 September 2012.

Berry, J. N. (2004). Dehumanizing the Library. Library Journal (1976), 13:10. pp. 10. Retrieved from Library Literature \& Information Science Full Text on 15 August 2012.

Brady, S., Kearsey, K., Monigatti, M., Sindel, T., \& Tsui-Po, N. (2009-2010). Customer Service excellence in the self-service public library. Retrieved from https://www.google.co.nz/\#hl=en\&output=search\&sclient=psyab\&q=customer+service+excellence+in+the+self+service+library\&oq=customer+ servic\&gs I=hp.1.0.35i39j0l3.608.5834.0.8174.17.15.1.0.0.0.578.4401.3$7 \mathrm{j} 2 \mathrm{j} 2.11 .0 \ldots 0.0 \ldots 1 \mathrm{c} . \mathrm{ahs} \mathrm{VpAFN} 1 \mathrm{TI} \& \mathrm{pbx}=$.

Childs, P. (2006). Sssh! The quiet revolution. New Library World, 107:3. pp. 149-156. Retrieved from Emerald database 10 October 2012.

Creswell, J. (2003). Research Design: Qualitative, Quantitative, and mixed methods approaches. Second edition. Sage Publications. Retrieved from http://files.myopera.com/caohockinhtek21/blog/Qualitative,\%20Quantitative,\%20a nd\%20mixed\%20methods.pdf on 2 August 2012.

Cunningham, M. (2010). A case study into the implementation of RFID at the Pilkington Library, Loughborough University. (Unpublished master's dissertation, Loughborough University, 2010.) Retrieved from https://dspace.lboro.ac.uk/dspace-jspui/handle/2134/8820 on 10 August 2012.

Dempsey, B. (2010.). Do-lt-Yourself Libraries. Library Journal (1976), 135:12. pp. 24-28. Retrieved from Library Literature \& Information Science Full Text on 15 August 2010.

Department for Work and Pensions. (2009). What is Work Related Upper Limb Disorder. Retrieved from http://www.dwp.gov.uk/publications/specialist-guides/medicalconditions/a-z-of-medical-conditions/wruld/ on 15 October 2012.

Fitzsimmons, J. (2003). Is self-service the future of services? Managing Service Quality, 13:6. pp.443-444. Retrieved from Emerald Database 15 August 2012.

Holt, G., Larsen, J., \& van Vlimmeren, T. (2002). Customer self service in the hybrid library. Retrieved from http://www.public-libraries.net/page7/page8/page8.html on 15 August 2012. 
Hurunui District Council. (2013). Library Locations and Hours. Retrieved from http://www.hurunui.govt.nz/library-home-2/about-us/library-locations-and-hours/ on 10 January 2013

Johannsen, C. (2012). Staffless libraries - recent Danish public library experiences. New Library World, 113:7/8. pp. 333-342. Abstract retrieved from Emerald database 10 October 2012.

Kantor-Horning, S. (2009). Self-service to the people. Library Journal, pp. 16-19. Retrieved from http://www.libraryjournal.com/article/CA6674915.html on 1 September 2012.

Leedy, P., \& Ormrod, J. (2012). Practical Research: Planning and Design Tenth Edition. Pearson Education.

Local Government Online (a). (2010). Hurunui District Council. Retrieved from http://www.localgovt.co.nz/site/Local_Government/find_a_council/by_region/Cant erbury/Hurunui/default.aspx on 10 January 2013.

Local Government Online (b). (2010). Selwyn District Council. Retrieved from http://www.localgovt.co.nz/site/Local_Government/find_a_council/by_region/Cant erbury/Selwyn/default.aspx on 10 January 2013.

Mackenzie, C., \& van Vimmeren, T. (2004). Implementing Customer Self Service. Retrieved from http://www.public-libraries.net/page7/page8/page8.html on 15 August 2012.

Mohammed, T., \& Misilei, R. (2012). South Auckland Libraries - Connecting with Southside Youth. LIANZA Conference 2012, (pp. 1-10). Palmerston North, New Zealand.

Morris, A., \& Dyer, H. (n.d.). (as cited in Morris, Thornley \& Snudden, (2001). Self-issue and return systems: experiences in the UK). The Electronic Library, 19:1. pp. 718. Retrieved from Emerald Database on 15 September 2012.

Morris, A., Thornley, L., \& Snudden, K. (2001). Self-issue and return systems: experiences in the UK. The Electronic Library, 19:1. pp. 7-18. Retreived from Emerald database on 15 September 2012.

selfserviceworld.com. (2013, January). 3 Vital Trends of 2013. Retrieved from http://www.selfserviceworld.com/article/206029/Report-3-Vital-Trends-of-2013 on 10 January 2013.

Selwyn District Council (a). (n.d.). Map of Selwyn District. Retrieved from http://www.selwyn.govt.nz/contact-us/map-of-selwyn-district2 on 10 January 2013.

Selwyn District Council (b). (n.d.). Selwyn Growth Projections. Retrieved from http://www.selwyn.govt.nz/_data/assets/pdf_file/0018/55305/2011-SELWYNGROWTH-PROJECTIONS.pdf on 10 January 2013. 
Selwyn Library (a). (2013). Holdings Report. Accessed 18 January 2013.

Selwyn Library (b). (n.d.). About Us. Retrieved from http://www.selwynlibrary.co.nz/about-us on 10 January 2013.

Sheffer, C. (2008). Self-Service at Your Library (And Now at PLA). Public Libraries, 47:5. pp. 7-8. Retrieved from Library Literature \& Information Science Full Text database on 10 October 2012.

Smith, I. M. (1999.). What do we know about public library use? Aslib Proceedings, 51:9. pp. 302-314. Retrieved from Emerald Database on 1 May 2013.

Southern Cross Healthcare Group. (n.d.). Occupational Overuse Syndrome (OOS). Retrieved on 15 October 2012, from http://www.southerncross.co.nz/AboutTheGroup/HealthResources/MedicalLibrary /tabid/178/vw/1//temID/133/Occupational-Overuse-Syndrome-OOS.aspx

Stafford, J. (1997). The self-service project at Information Services, University of Sunderland. New Library World, 98:2. pp. 44-52. Retrieved from Emerald database on 15 September 2012.

Statistics New Zealand (a). (2006). QuickStats About Selwyn District. Retrieved from http://www.stats.govt.nz/Census/2006CensusHomePage/QuickStats/AboutAPlac e/SnapShot.aspx?type=ta\&Parent $I D=1000013 \&$ tab=PopulationDwellings $\& i d=200$ 0062 on 10 January 2013.

Statistics New Zealand (b). (2011). Subnational population estimates tables. Retrieved from

http://www.stats.govt.nz/browse_for_stats/population/estimates_and_projections/ subnational-pop-estimates-tables.aspx on 10 January 2012.

Statistics New Zealand (c). (2006). QuickStats. Retrieved from http://www.stats.govt.nz/Census/2006CensusHomePage/QuickStats.aspx on 10 January 2013.

Statistics New Zealand (d). (2006). QuickStats About Selwyn District. Retrieved from http://www.stats.govt.nz/Census/2006CensusHomePage/QuickStats/AboutAPlac e/SnapShot.aspx?type=ta\&Parent $\mid \mathrm{D}=1000013 \&$ tab $=$ Agesex $\& \mathrm{id}=2000062$ on 10 January 2013.

Statistics New Zealand (e). (2006). QuickStats About Hurunui District. Retrieved from http://www.stats.govt.nz/Census/2006CensusHomePage/QuickStats/AboutAPlac e/SnapShot.aspx?id=2000058\&amp;type=ta\&amp;ParentID=1000013 on 10 January 2013.

Statistics New Zealand (f). (2013). The official website of the New Zealand 2013 Census. Retrieved from Retrieved from http://www.census.govt.nz/ on the 1 May 2013.

Werne, K. (2007). Self-Service Works! Public Libraries, 46:3. p. 19-20. Retrieved from Library \& Information Science Full Text on 15 August 2012. 
Whitney, A., \& Garrett, A. (2008). Our Journey Down the Self-Check Road. Computers in Libraries, 28:2. pp. 6-47. Retrieved from Library \& Information Science Full Text on 15 August 2012.

Wikipedia. (2012). Selwyn District. Retrieved from http://en.wikipedia.org/wiki/File:Selwyn_Territorial_Authority.png on 10 January 2013.

www.school.nz. (2009-2013). Schools in Selwyn District. Retrieved from http://www.school.nz/area/selwyn-district on 10 January 2013.

Zeiher, L. (2006). Self-Check Success. Library Journal (1976) Buyer's Guide, pp. 6-9. Retrieved from Library Literature \& Information Science Full Text on 15 August 2012.

Zhong, H. (2007). Research on reader self-service in a public library. Library Management, 28:1. pp. 101-106. Retrieved from Emerald database on 14 September 2012.

Word count: 17,025 (excludes Appendices, Abstract, Acknowledgement, Definitions) 